\title{
The Identity Formation Experiences of Second Wave Argentinian Immigrants to Canada
}

\author{
by \\ Pamela Evangelina Groh
}

A thesis submitted to the Faculty of Graduate and Postdoctoral Affairs in partial fulfillment of the requirements for the degree of

Master of Arts

in

Sociology

Carleton University

Ottawa, Ontario

(C) 2013, Pamela Evangelina Groh 


\begin{abstract}
The thesis explores the processes of identity formation among high-skilled Argentinian immigrants to Canada's National Capital Region on the basis of a mixed method qualitative research consisting of 14 interviews with Argentinian professionals who migrated to Canada since 1999, participant observation and the analysis of Internet blogs. The thesis examines the identity formation experiences of these immigrants as the "meeting point" of social conditions of migration and personal practices of reacting, reflecting and feeling. Approaching identity as fluid, relational, strategic, positional, and always developing, I argue that the 'new' identities that Argentinian immigrants have developed are linked to two main relational processes, namely identification and differentiation. By critically examining the 'location' of these immigrants in Canadian society, I suggest the group's experiences of integration and marginalization are interconnected to these relational processes influencing their notions of who they are in Canada.
\end{abstract}




\section{Acknowledgements}

I want to express my sincere and profound gratitude to the thesis Director, Dr. Xiaobei Chen, for an incredibly dedicated work of supervision. I am indebted to Xiaobei for sharing with me her expertise and knowledge and also for treating me with kindness, fairness, respect, and for always providing a space for me to explore my ideas and express myself with freedom. I am grateful for her confidence and trust in me and for her continued encouragement along this journey.

I also deeply thank Committee Members Dr. Janet Siltanen and Dr. Laura Macdonald for their close guidance, for sharing with me the wealth of their experience, and for encouraging me to explore beyond my comfort zone. I have learned immensely from you and I thank Janet for awakening in me a true passion for research methodology.

I am grateful to the Department of Sociology and Anthropology, especially to Dr. Aaron Doyle and Ms. Paula Whissell for their continued support and for making my stay at Carleton University a truly positive experience.

I am indebted to research participants for sharing with me their views, opinions and insights and it is my sincere hope that I have honoured their contributions by writing about 'our' identity with the respect it deserves. I also thank mentors who, one way or another, have taught and guided me in the past. I especially thank Dr. Fatemeh Givechian for sharing with me wonderful life (and ethnographic) lessons.

I thank my parents, Olga and Jorge, for their support, trust and unconditional love. I am grateful to them for giving me everything they have, for teaching me perseverance and for inspiring me with their own lives. I thank my sisters, Jésica and Analís, for their continued presence, words of encouragement, wisdom and love. I especially thank my baby niece, Bianca, for her beautiful smiles, which can truly lighten up the writing process.

I thank Mariana and Gabriel, 'mis amigos del alma', for their love, patience, contention and company in the past eleven years. I thank you both for being there and for showing me the real meaning of friendship.

I thank and dedicate this thesis to Ivo.

For always encouraging me to improve myself yet for loving me exactly as I am.

Y con profundo agradecimiento a Dios.

Por su constante compañía y por haber encontrado mi camino con el de estas personas. 


\section{Table of Contents}

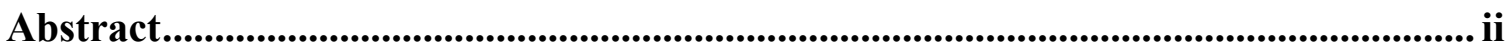

Acknowledgements ......................................................................................................... iii

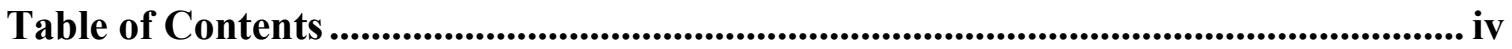

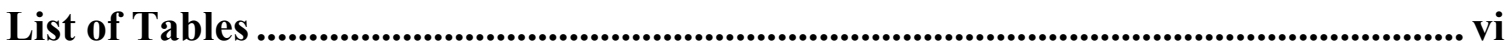

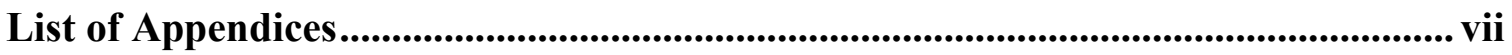

\section{Chapter 1: Argentinian Immigrants to Canada: Introduction and Theoretical}

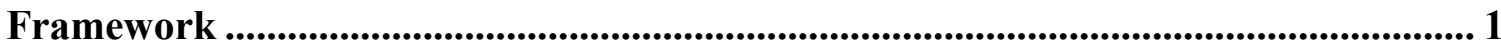

1.1 The Five Waves of Latin American Immigration to Canada ....................................... 5

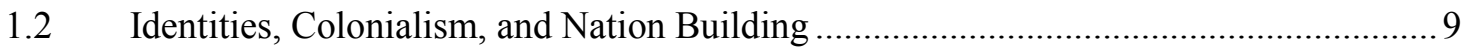

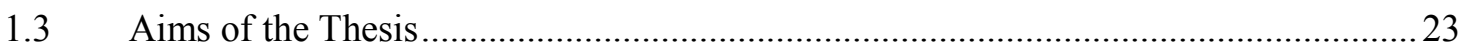

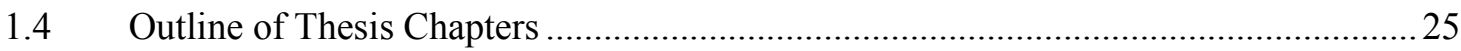

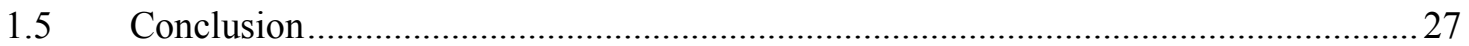

Chapter 2: Talking, Seeing, and Reading Identity: The Research Methodology ..... 28

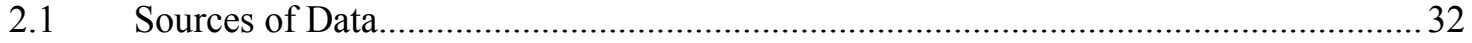

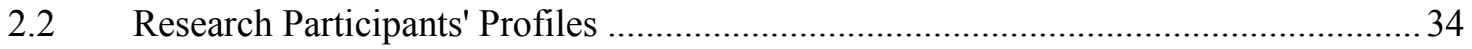

2.3 Accessing Participants and Other Opportunities to Conduct Research......................39

2.4 My Role as a Researcher: On the Degree of Involvement as an 'Insider' ...................41

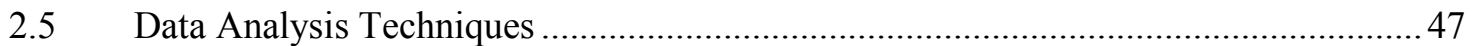

2.6 Stories of "Argentinian-ness": Main Narratives and Methodological Adjustments..... 50

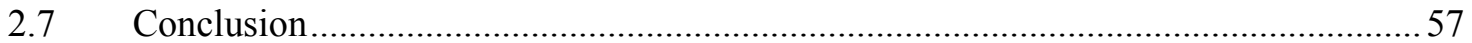

\section{Chapter 3: "I Say From Argentina, but Being a Canadian Citizen Gives Me Great} Satisfaction": Identifications and Differentiations ...................................................... 58

3.1 Argentinian Identity Formation Experiences in the Context of Migration to Canada.. 62

3.2 On the Fluidity of Identity and the Emotional Connection ...................................... 81 


\section{Chapter 4: On the Verge of Belonging: the Partial Inclusion of 'Others' into}

Canadian Society ......................................................................................................8 89

4.1 The Location of Argentinian Immigrants in Canadian Society: on Being Included, but

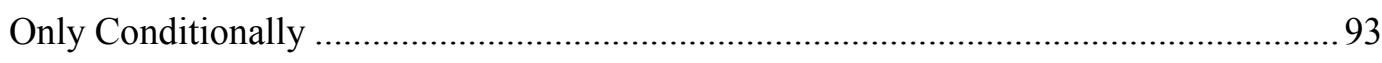

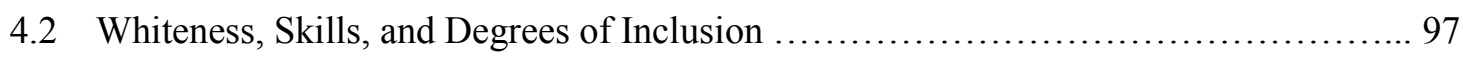

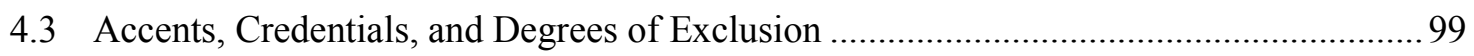

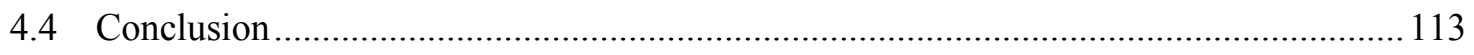

\section{Chapter 5 "I am Interested in Understanding the Place Where I Live... and From}

There, I Can Feel I Belong": Conclusions ............................................................... 115

5.1 The Formation of 'New' Identities and the Location of Argentinian Immigrants in

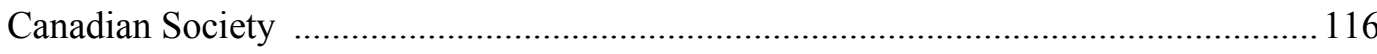

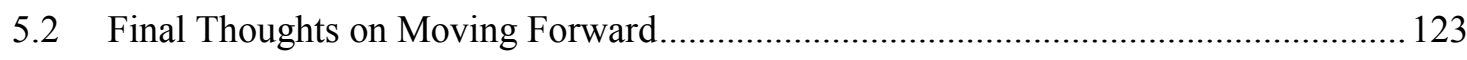

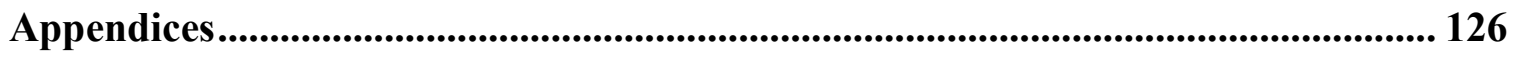

Appendix A General Interview Questionnaire For Research Participants ............................ 126

A.1 Interview Questionnaire for Research Participants. English Version .................... 126

A.2 Interview Questionnaire for Research Participants. Spanish Version.................... 128

Appendix B Interview Questionnaire for Blogger.......................................................... 131

B.1 Interview Questionnaire for Blogger. English Version ...................................... 131

B.2 Interview Questionnaire for Blogger. Spanish Version ....................................... 134

Bibliography .................................................................................................................. 143 


\section{List of Tables}

Table 1 Latin Americans in Canada's major cities as of 2001 .............................................. 137

Table 2 Latin Americans in Canada's major cities as of 2006 ............................................ 138

Table 3 First Wave of Argentinian Immigration to Canada 1970s.......................................... 139

Table 4 Central and South American Immigration to Canada: 1968 to 1995 ......................... 140

Table 5 Second Wave of Argentinian Immigration to Canada 2000s .................................... 141

Table 6 Latin American Immigration to Canada in 2007 by Main Countries of Origin .......... 142 


\section{List of Appendices}

Appendix A General Interview Questionnaire for Research Participants ............................. 126

A.1 Interview Questionnaire for Research Participants. English Version .................... 126

A.2 Interview Questionnaire for Research Participants. Spanish Version..................... 128

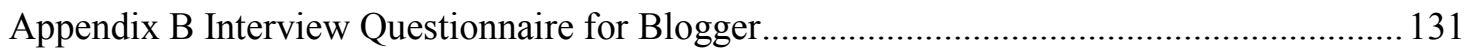

B.1 Interview Questionnaire for Blogger. English Version ........................................ 131

B.2 Interview Questionnaire for Blogger. Spanish Version ...................................... 134 


\section{Chapter 1}

\section{Argentinian Immigrants to Canada:}

\section{Introduction and Theoretical Framework}

In January 2009 I was standing in line waiting to register for a French Language and Civilization Course at the Université La Sorbonne in Paris. I had left Canada for France without knowing if this would be a temporary or a permanent stay. All I knew at that point was that I needed some time to figure out my next life move. While I had been living in Canada for nearly a decade after leaving Argentina, my homeland, I still never seemed to feel as if it was my home or my place in the world. However, as I considered what to do next, going back to my homeland did not seem an option anymore. The combination of factors that drove me to make the decision of leaving Canada were complex and deeply rooted in personal and social circumstances that made me question the purpose of remaining in a place where I was constantly feeling a stranger and an outsider. The notion that I had lost myself somewhere between my homeland, Argentina, and my adoptive country, Canada, persisted but what was even more discouraging was the self-awareness that I did not belong to either. I wondered, where do I belong? So as the urgency of finding an answer to this question grew stronger, I decided that if I needed to go yet somewhere else, I would do that in the hopes that somewhere along my journey I would find my place of belonging.

As I stood in that line, waiting for my turn for registration, with excitement and confusion, I started talking to my neighbor. She was a lovely Korean girl. In our broken French we started talking about who we were and what we were doing there. She was 
from South Korea, a fashion design student who was in Paris for four months to learn about fashion in the city of haute couture and glamour. She asked me where I was from to which I replied 'I am from Canada'. I did not go on to explain that I was actually born and raised in Argentina, and that Canada was the country where I had been living for the past decade. Reflecting later on why I did not do this, I realized that there was no need to as far as the girl was concerned. To her, I looked and sounded like a Canadian. She did not detect a South American accent in my French nor did my physical appearance raise any suspicions (I have noticed that people tend to assume that 'all Canadians' are white, tall, fair-skinned and I happen to more or less fit that stereotype). I had decided to 'play along' and enjoyed not having to explain myself, as I had been doing for the past decade. It felt good to get a break.

Clearly the experience marked me, however, this was only the continuation of a series of self-inquiries and reflections that began many years ago. My own immigration experience made me start thinking almost constantly of my own identity, my sense of belonging, my geographical location and my ancestry. If I were to trace the origins of this thesis, I would probably identify this encounter in Paris, as it crystalizes countless moments since my departure from Argentina, which involved decisions about how to identify who I was and where I belonged. The thesis is concerned with understanding how the processes of identity formation of immigrants like myself are connected to the migration experience.

To this day, I am still puzzled by my response in that line up. I still try to understand why I self-identified as Canadian when the very reason for leaving Canada for France was the profound sense of alienation and the sadness and pain that came along 
with having to speak of the absence of a home. Fortunately, time is a healer, traveling was a good teacher, and the journey became my answer.

This thesis is the story of Argentinian immigrants living in Canada for the past five to fifteen years who, in D. Soyini Madison's words, 'departed home in order to arrive home' $(2008,244)$. The study of the second wave of Argentinian immigrants around the turn of the $21^{\text {st }}$ century to Canada, more precisely to the National Capital Region, deserves much attention. The first wave of Argentinian immigrants was composed of two general groups: professionals seeking opportunities to practice their professions abroad, and those who emigrated escaping the political crisis and imposition of military dictatorship in 1976. In comparison, much more complex reasons drive the new wave of immigration, giving rise to narratives that are different from those of previous Argentinian immigrants.

The thesis is concerned with these more recent immigrants' narratives of migration experiences to Canada since the year 1999 and with how the experience of migration, taking place within a constellation of conditions, is linked to processes of identity formation in the new social context. I am concerned with gaining a better understanding of how both the left-behind social setting and the new one encountered are constitutive of the identity formation experiences of Argentinian immigrants to Canada. Within this framework of inquiry, the research question that guides the present investigation is: how do Argentinian immigrants to Canada experience identity formation at the "meeting point" of social conditions of migration in Argentina and Canada and individual practices? 
There are various sub-questions explored in the thesis, which elaborate the main research question. These include: How do Argentinian immigrants self-identify in the new social context and how have these processes of identification developed throughout time? How have Argentinian immigrants claimed their rights for inclusion and equality in Canadian society and has it occurred through the assertion of group identities and rights? How have emotional processes been part of the identity formation experiences of these immigrants? And more generally, how have personal and social elements been mutually constitutive of the identity formation experiences of recent Argentinian immigrants to Canada's National Capital Region?

Based on the notion that the formation of identities is both continual and relational through interactions between the individual and the social world, the central argument of the thesis is that for Argentinian immigrants to Canada the process of identification and negotiation of identity is shaped by two sets of postcolonial identity categories: 1) the Argentinian/European ${ }^{1}$ versus the rest $^{2}$ division, which originated from Argentina and persists among Argentinian immigrants in Canada; and 2) in Canada, the English (even British) versus the rest division, which challenges Argentinian immigrants' notion of "who count as Europeans" (Gunew, 2004). This process is closely related to the need to be strategic in placing oneself in the social world, the need to belong, the desire to integrate, and the emotional responses towards the homeland and the new society. The 'new' identities that Argentinian immigrants have formed in Canada are characterized by a strong sense of identification with the Canadian body politic, even though selective

\footnotetext{
${ }^{1}$ In other words the Argentinian category that is defined as equivalent to the European.

2 "The rest" refers not only to others in Argentina such as the indigenous, the hybrid populations, and the more recent immigrants who are considered as lesser Argentinians, but also to the Latin Americans that Argentinians do not identify with.
} 
identification with the Argentinian identity is preserved. This strong sense of identification with the white majority is in part accomplished through 'splits' from three key referential 'Others', namely some other Argentinian immigrants, Latin American immigrants, and immigrants and minority groups in general. By looking at the location of Argentinian immigrants in Canadian society, I propose that these processes of identification and differentiation are not coincidental but rather connected to the group's experiences of incorporation and marginalization. I argue that the partial 'blending in' of these immigrants is linked to notions of 'whiteness' and their conditions of entry to Canada. Both these elements are connected to the unmarked white centre of multiculturalism in Canada where these immigrants are incorporated as conditional allies of the nation.

In the following sections, I contextualize the present investigation within the existing literature of Latin American immigration to Canada. I then discuss some of the main concepts for the present investigation as well as three sets of historical contexts relevant to the discussion of identity formation processes of the Argentinian diaspora, namely discourses of homogeneity, whiteness and European-ness in the Argentinian context, notions of Argentinian identity in the context of Latin American identity, and the unmarked white centre of multiculturalism in the Canadian context. Lastly, I discuss the aims of the thesis and provide an outline of chapters.

\subsection{The Five Waves of Latin American Immigration to Canada}

Latin American immigration to Canada is a phenomenon that begun in the second half of the $20^{\text {th }}$ century. The literature on Latin American immigration to Canada is at a 
relatively 'young' stage, however, it is slowly expanding due to the increasing number of Latin American immigrants and the expectation that this growth will continue. Furthermore, interest in the issue has expanded due to rapid changes occurring in the social, political and economic landscapes of the Americas.

The literature notes that population flows from Latin America to Canada have occurred in the form of noncumulative migratory waves (Mata 1985; Goldring 2006; Landolt et al. 2011) and that "[e]ach wave of Latin American migration has been fairly short-lived and linked to a specific political event or economic situation in the country of origin" (Landolt et al. 2011, 1243). Scholars refer to five waves of Latin American immigration to Canada (Le Golf 2004; Veronis 2006, 2007; Gininiewicz 2010; Landolt et al. 2011). The first four waves of immigration were identified in 1985 by Fernando Mata, a Canadian sociologist of Peruvian origin who classified them as: the "Lead" wave including Latin Americans of European origin migrating to Canada between the mid1950s to mid-1960s shortly after they migrated to Latin America; the Andean wave composed of immigrants mainly from Ecuador, Colombia and Peru who migrated mostly due to economic reasons in the late 1960s and early 1970s; the Coup wave, formed by political refugees from Chile, Uruguay and Argentina fleeing the political crises of 19731976, and the Central American wave of refugees from Guatemala and El Salvador escaping military, political and social unrest in Central America in the 1980s (Veronis 2006; Landolt et al. 2011). A fifth wave of Latin American immigration beginning in the 1990s has been identified as being comprised of "mostly professionals from throughout 
Latin America coming under Canada's 'skill worker' and to a lesser extent 'business' classes of immigration" (Veronis 2006, 18-19) ${ }^{3}$.

Durand and Massey, who analyze trends of Latin American immigration throughout the world, stress that in Canada Latinos represent less than 3 percent of all foreigners and for this reason they are "a small minority with little influence on any dimension" (2011, 32). However, Veronis explains that the number of Latin Americans coming to Canada "has been increasing rapidly and is expected to continue to do so in the future considering the situations of unrest in countries such as Colombia, Ecuador, Argentina and Venezuela" $(2006,19)$. Furthermore, considering Canada's labour market demands and rising levels of education in Latin America, it is expected that larger numbers of students and skilled workers will be arriving in Canada in the coming years. In addition, Veronis (2006) stresses that due to its heterogeneity, the growth of this group raises new questions with regards to notions of community, identity, and the politics of difference that need to be further investigated.

Currently, most of the research conducted on the various waves of Latin American immigration to Canada has focused on the case of Latin American immigrants living in Toronto. This research analyzes diverse aspects of claims to urban spaces and equal rights (Veronis 2006, 2007), and immigrant politics such as political participation, representation, and agenda setting (Gininiewicz 2008, 2010; Landolt et al. 2011). Veronis (2007), who argues that new immigrant groups (re)construct their collective identities

\footnotetext{
${ }^{3}$ It is important to note that the waves are noncumulative due to various reasons; for instance in the case of immigrants arriving during the coup years, many of them returned to their countries after democratization. For more see Landolt et al. $(2011,1243)$.
} 
spatially, stresses the need to continue examining this highly diverse group of immigrants and factors such as immigration class, time, and circumstances of arrival. She argues that these factors "enhance differences and even create new inequalities within heterogeneous groups such as Latin American migrants" (Veronis 2006, 20). In addition, this literature points to the need to continue researching how "each wave adds to the diversity of Latin Americans who constantly need to re-imagine, re-invent, and re-create their identity and community" (Veronis 2006, 21).

The thesis builds on these growing discussions in the literature of Latin American diaspora studies in Canada, paying special attention to contributions seeking to gain a better understanding of the dynamics of recognition, integration and inclusion. I aim to contribute to discussions about the construction of immigrants' identities by looking at the case of Argentinian professional immigrants as a group that enjoys a somewhat 'privileged' position and higher degree of inclusion. This, in my view, is linked to the conditions of entry of this group and their location as a white ethnic group that is actively incorporated as an ally of the nation, albeit conditionally. Where the present thesis differs from previous works is in its emphasis on the need to gain a better understanding of how social conditions in interaction with personal practices contribute toward the development of diasporic identities and the power dynamics that render certain minority groups more included or excluded than others. The thesis critically examines notions of 'inclusion' in order to better understand its limits and conditions. While larger groups of Latin 
American immigrants are located in cities such as Toronto and Montreal ${ }^{4}$, the number of Latin American immigrants arriving to the National Capital Region is on the rise. As these demographic changes occur, previous analysis of the positionality of Latin Americans in Toronto may not align with the social conditions that these immigrants encounter in other geographical locations or their lived experiences in these settings. In this regard, the present thesis contributes to much needed research and analysis of the Latin American diaspora in Canada.

\subsection{Identities, Colonialism, and Nation Building}

The thesis is informed by concepts from several bodies of literature: diaspora studies, identity formation, and whiteness in the context of postcolonial liberal multiculturalism. In this section, I bring together discussions of the main concepts that have shaped my research, and the broader contexts in Argentina and Canada within which Argentinian identity formation processes are situated.

Discussions of diaspora and migrant identities have been taking place across different disciplines over the past few decades. Here, I approach the notion of diaspora and migrant identities as discussed by Braziel and Mannur who explain that the term diaspora "has historically referred to displaced communities of people who have been dislocated from their native homeland through the movements of migration, immigration,

\footnotetext{
${ }^{4}$ In cities such as Toronto and Montreal, the population of Latin American origin accounted for $2 \%$ in 2001 and for 1\% in cities such as Vancouver, Calgary, Edmonton and Ottawa. From Statistics Canada http://www.statcan.gc.ca/pub/89-621-x/89-621-x2007008-eng.htm\#2.

For more see: Table 1: Latin Americans in Canada's major cities as of 2001 on page 137 and Table 2: Latin Americans in Canada's major cities as of 2006 on page 138.
} 
or exile" $(2003,1)$. This definition makes specific references to notions of geography, national identity and belonging. Post WW II mass migration, global displacement, and globalization have changed our understanding of nation-states and have impacted how we see diasporas (Braziel and Mannur 2003). While 'diaspora' remains a contested term, I employ the notion of diasporic identities as fluid, hybrid, heterogeneous, and emergent of negotiation (Hall [1993] 2003; Braziel and Mannur 2003; Gilroy 2003). In the thesis I aim to explore how the Argentinian diaspora in the National Capital Region has developed a sense of 'multiple belonging' and experiences the double (or plural) identifications that constitute hybrid identities (Braziel and Mannur 2003).

The literature on identity theory includes a vast amount of works dating back to the second half of the $20^{\text {th }}$ century. I draw as my theoretical framework Stuart Hall's understanding of identity as a "meeting point" between the historical discourses and practices where subjectivities are produced ([1996] 2000). In the thesis, I approach identity as fluid, relational in the sense of co-constitutive, positional, strategic, and always in development, following postcolonial theorists' work such as Fanon ([1952] 1967), Said (1978), Bhabha ([1994] 2000), Hall ([1991] 1997, [1993] 2003, [1996] 2000). This 'constructivist' notion of identity stands as a "critique of the self-sustaining subject" (Hall [1996] 2000), which sees identities as integral, originary and unified. In addition, the thesis also differs from the psychological approach to identity formation, which focuses exclusively on the maturation and cognitive developmental processes that individuals undergo (Rummens, 2003).

In his essay "Old and New Identities" ([1991] 1997), Hall explains that identity is always in formation, being constructed both through self-reflection as well as in 
relationship to others from whom we either 'differentiate' and split from, or identify with. It is important to distinguish between the notion of identity, and that of identification. While 'identity' is understood as something pertaining to the individual, 'identification' refers to the processes where various individuals come into relation and interaction with each other and form bonds of affinity and proximity (Fanon [1952] 1967; Bhabha [1994] 2000; Hall [1991] 1997, [1996] 2000; Rummens 2003; Ahmed 2004). Identification suggests that while every individual has a unique identity that belongs to him or her, we need to understand identities as further developed in relation to others. Through these relational processes with various others, individuals either differentiate themselves from or identify with others (Fanon [1952] 1967; Bhabha [1994] 2000; Hall [1996] 2000). These notions also apply to processes of formation of various forms of group identities (e.g. ethnic, cultural, etc.)

In his analysis of Fanon's work, Bhabha ([1994] 2000) explains there are three conditions that underlie an understanding of the process of identification. The first one is that we exist when we are in relation to others. In this sense, existence is considered relational. The second is that the place of identification is also a space of splitting where 'difference' is what gives us an identity. It is at this moment of identification and difference that splitting distances the 'Self' from the 'Other'. Finally, Fanon explains that the process of identification does not imply an affirmation of the pre-given identity but it is rather a production of an image of identity and the transformation of the subject in assuming that image ([1994] 2000, 99-101). In thinking of the experiences of Argentinian immigrants, we can appreciate how these processes unfold through identification with the 
'host society' and differentiation from points of similarity and familiarity, that is, a departure from Argentinian-ness, Latin-American-ness and other immigrants.

In order to better understand the development of diasporic identities it is important to also consider the role of emotions and affects. Different disciplines (e.g. sociology, psychology) have different understandings of the place of emotions and memory in the formation of identities. While the psychological approach to emotion, memory and nostalgia sees these as 'psychic' processes (e.g. Espin 1987), I approach the concepts of emotion, affect, memory and nostalgia as practices that are personal but also social and material (Ahmed 2004; Silva 2009; Svašek 2010; Davidson 2011). In the thesis I emphasize that emotions are developed in relation, and by proximity, to others, and on the notion that "emotions do things" (Ahmed 2004, 120). Furthermore, Maruška Svašek stresses that "emotional processes shape human mobility and vice versa" (2010, 865). I agree with this theoretical positioning, which emphasizes "affects and emotions are central aspects of international migration" (Svašek 2010, 867). In this sense, emotions are understood as dynamic processes where the self is not closed and/or static but rather an entity that is relational and multiple (Svašek 2010, 868). In parts of the thesis I pay attention to how emotional practices "meet" with social conditions, in other words, how emotions interact to shape the identity formation experiences of Argentinian immigrants to Canada.

To summarize how the notion of identity is used in the thesis, two key elements should be stressed. First, identity is not to be understood as simplistic, singular, unique, and/or static but rather pluralistic and encompassing a multiplicity of elements and manifestations that vary and change as the individual develops throughout life, and as 
s/he comes into relation with others. Second, it is important to note the need to understand the notion of identity within historical contexts including the discourses, practices and processes embedded in society. These elements are not only meaningful but rather central to the development of these identities, as illustrated by the following discussion of processes of identity formation in Argentina.

\section{Argentina's Nation Building Strategies: Official Discourses of Homogeneity,}

\section{Whiteness and European-ness}

A critical examination of the identity formation experiences of Argentinian immigrants to Canada suggests that, based on Hall's emphasis on how identities are constructed through self-reflection and self-examination within particular historical and discursive contexts ([1996] 2000), Argentina's colonial discourse constructing a 'homogeneous, white (Euro) Argentinian identity' (Garguin 2007) is linked to these immigrants' experiences in the Canadian context.

The question of Argentinian identity points to the need to look deeper into the historical roots and the first attempts to build an Argentinian nation. By doing this, I seek to unveil the role of the State in the construction of an Argentinian identity through official discourses of homogeneity, whiteness and European-ness. While such discourses have been challenged in recent years, giving rise to extensive debate on whether new configurations of an Argentinian identity are emerging ${ }^{5}$. This discussion is central to our understanding of identity formation processes of second wave Argentinian immigrants to

\footnotetext{
${ }^{5}$ For more on this, see Alejandro Grimson and Gabriel Kessler (2005) and Dalia Kandiyoti
} (2008). 
Canada. It is also important to look at the notion of Argentinian-ness in the context of 'Latin American identity' in an effort to understand the historical dis-identification of Argentinians with Latin Americans.

In contrast with the experience of most of Latin American countries, Argentina's population consists primarily of descendants of European settlers. This is due to a combination of factors such as: Argentina's colonial history, the various efforts to eradicate the Indigenous populations, the decline of the African population ${ }^{6}$, and mass European migration to Argentina.

Europeans first arrived in the territory at the beginning of the $16^{\text {th }}$ century and the first Spanish settlement was established by Pedro de Mendoza in 1536. Although there were two British invasions (in 1806 and 1807), Argentina acquired independence from Spain in 1816 (Grimson and Kessler 2005). Linked to its colonial past, the modern country of Argentina has been one of immigration (Diameti 2001). There have been three main immigration waves to Argentina (Grimson 2005). The first wave occurred at the end of the $19^{\text {th }}$ century, the second one at the beginning of the $20^{\text {th }}$ century, and the third

\footnotetext{
${ }^{6}$ Several scholars refer to the historical tendency to minimize the presence of African slaves in Argentina. This is partly due to an overall lack of recognition of the presence and mix of Indigenous and African populations in Argentina (Picotti 1998; Grimson [2004] 2005; Guzman 2006; Garguin 2007; Armony 2011). Garguin for instance refers to the "erasure of Indigenous and African ascendancy" (2007, 172). In the particular case of African slaves in Argentina, it should be noted that although Argentina received smaller numbers of African slaves when compared to Brazil, the Caribbean and Peru, a failure to acknowledge their presence is linked to the overall lack of knowledge and research conducted on the presence of Africans in Argentina as well as a "long history of distortion" (Picotti 1998, 17). It is only recently that more is known about the African population in Argentina. Scholars who study the presence of Africans in Argentina (notably Picotti 1998 and Guzman 2006) emphasize that the tendency to diminish the numerical and cultural presence of the group is connected to the decline of this population in the $19^{\text {th }}$ century. Picotti (1998) notes 'various reasons' for this decline (e.g. high infant mortality rates, cholera epidemics at the end of the $19^{\text {th }}$ century, yellow fever and wars). Furthermore, Guzman (2006) emphasizes that as this population transitioned from slavery to freedom, they became increasingly invisible when mixing with the indigenous population. More information on this is provided on footnote 8 .
} 
immigration wave started in the 1990s. While the first two waves were comprised of mostly Europeans, the third immigration wave is comprised of those coming from neighboring countries, especially Paraguay and Bolivia (Grimson 2005). Various authors (Grimson [2004] 2005, 2005; Kandiyoti 2008) have argued that Argentina's processes of both immigration and emigration call for a re-examination of Argentinian identity where new transnational challenges are accounted for.

Looking at the historical construction of an Argentinian identity through official discourses, three main processes can be identified. In the $19^{\text {th }}$ century one can highlight the prevailing 'myth' of the 'white European-descent nation'. In the first half of the $20^{\text {th }}$ century (between 1920 and 1960) the emergence of the racial articulation of the middle class was noted by some scholars. Finally, since the 1990s and as a result of the third wave of immigration paired with a shift in Argentina's political focus (which is much more centered in strengthening regional alliances), an emphasis in addressing changing notions of identity have given rise to the emergence of new ideologies (Grimson [2004] 2005, 2005; Garguin 2007; Kandiyoti 2008; Armony 2011).

Grimson (2005) explains that according to the myth, Argentina is described as a melting pot. This melting pot has been more precisely referred to as a "crucible of race (crisol de razas) in which immigrants (mostly from Italy, Spain and several eastern European countries) and Spanish Americans (criollos, descendants of the original colonists) purposely merged to create a new man" (Armony 2011, 165). Whereas in the case of neighboring countries (such as Brazil), the notion of the melting pot includes whites, Indians and descendants of Africa-born blacks, in Argentina, the notion has been paired with European diversity since "according to the official version, because 
Argentines descended from ships, they have no Indian blood" (Grimson 2005, 119). While it is correct that Argentina has received mass immigration from Europe ${ }^{7}$ and that these Europeans have remained in Argentina eventually becoming Argentinians themselves, it would be wrong to say that Argentinians are 'a pure European race' given that these Europeans arriving by ships mixed with the existing indigenous population ${ }^{8}$ of Argentina.

In spite of the efforts to eradicate Indigenous populations in Argentina, which were carried out through the 'Conquest of the Dessert' at the end of the 19th century", history testifies to the origins of Argentines as a mixed race where three races converged: the European or Caucasian, the indigenous and the Ethiopian (Garguin 2007, 166).

Grimson explains that there is a consensus among Argentinian anthropologists on the notion that "the point of departure for cultural homogenization in Argentina is the period between 1880 and 1930, when the modern nation state was constructed" (2005, 120). The process of de-ethnicizing towards a homogeneously white nation was purposely carried out through education in schools and efforts such as the wearing of a white dustcoat over regular clothes in public schools, the prohibition of using indigenous languages, among other practices (Grimson 2005, 120). In this regard, Argentinian national identity can be considered as historically built on the basis of European cultural

7 In 1869 Argentina's population was of 1,800,000. Between 1880 and 1905 Argentina received 2,827,800 immigrants from Europe. During the WWI, 30\% of Argentina's population were immigrants. For more see Irse by Diego Melamed (2002).

${ }^{8}$ Furthermore, it should be noted that when transitioning from slavery to freedom, the African population greatly mixed with the existing Indigenous population. However, in this 'passing' there was an erasure of the 'mulato' component of the mix as the children ('afromestizos') were regarded as 'indians' or 'mestizos' only (Guzman 2006).

9 For more information see Alejandro Grimson and Gabriel Kessler "Territory. Nation and Mercosur" in On Argentina and the Southern Cone: Neoliberalism and National Imaginations (2005). 
proximity while ignoring Argentina's geographical location as a Latin American country. Furthermore, the emphasis on suppressing indigenous identities and ignoring the mixed racial composition of its inhabitants was carried through official discourses taught in schools from the early $20^{\text {th }}$ century until less than twenty years ago emphasizing that there were no Indians left in the country (Armony 2011). However, Garguin stresses that while "the nation was constructed as homogeneously white European (by contrast to the mestizo representation of other Latin American Nations)" $(2007,162)$ "the making of this national identity was never a smooth, linear process" (Garguin 2007, 163).

The racial articulation of the middle class in Argentina between 1920-1960 emerges out of a complex process linked to the empowerment of the Peronist working class movement in the 1940s and 1950s (Garguin 2007). Prior to this period, a 'middle class identity' "was not clearly articulated [...] due in part to "common sense" understandings of the nation as homogeneously white, European" (Garguin 2007, 162). During this period, the ruling party (at the time the UCR - Radical Civic Union ${ }^{10}$ ) would refer to the middle class in general terms as 'the people', as this was a way to distinguish them from the oligarchy/elite, which consisted of the "white, educated and "civilized position"” (Garguin 2007, 164). However, Garguin (2007) emphasizes that this notion changed when the Peronist party came into power, and in an effort to link with both the middle class (comprised of 'hard working European immigrants') and the working classe (formed by 'workers from the provinces moving to the city') started referring to both groups jointly as 'the people'. The middle class sectors, who considered themselves not only as 'the people' but also the 'heirs of Europe and immigration' wanted to still

\footnotetext{
${ }^{10}$ In Argentina, the Peronist party emerged as the main oposition to the UCR.
} 
differentiate themselves from both the oligarchy (elite groups/landed bougoisie) and also from the 'the new Peronist Other' (the working masses mostly comprised of 'rural' migrants coming to the city). In this effort to differentiate themselves, they begun referring to the working class as "'cabecitas negra' (little black head) which became tantamount to Peronist worker" (Garguin 2007, 164).

Garguin (2007) argues that in the first half of the $20^{\text {th }}$ century there was a bipartite image of Argentinian society consisting of the oligarchy/people divide. However, with the rise and empowerment of the Peronist movement we see the emergence of a 'new tripartite' image of society consisting of oligarchy/middle class/people divide competing with the old bipartite one $(2007,163)$. The tripartite image of Argentinian society Garguin refers to was racialized as follows: the elite group (landed bougoisie/oligarchy) as the 'white, educated, intellectual and civilized class'; the middle class (both immigrants and (Euro) Argentinians) as the 'white' European/Argentinians who in its majority established themselves in cities; and the working class (the 'rural man') as the 'cabecita negra'. As pointed by Garguin, this can be understood as "the racialization of the social and political 'Other' performed by anti-Peronist forces" (2007, 162). Furthermore, he emphasizes that "such a racist reaction suggests that a deep sense of whiteness may have played an important role in the process of middle class formation" $(2007,164)$.

The third wave of immigration to Argentina, mostly non-European immigrants of Latin American origin particularly from neighboring countries, which started in the 1990s, has led to the emergence of new discourses and xenophobic analysis, giving rise to new articulations of Argentinian identity (Grimson 2005). In this regard, two important 
aspects about the present ideology of the nation are of relevance here. The first one has to do with still prevalent $19^{\text {th }}$ century notions of the (Euro) Argentinians, which stresses the predominance of the 'white European race' over 'black and Indian bloods' (Argentinian/European versus the rest divide). The second one is that despite pressure exerted by minority groups calling for a 'redefinition' of the notion of the 'white European Argentinian nation', much work still needs to be accomplished in order to challenge this definition, which erases the existence of indigenous and immigrant minorities.

\section{'Argentinian Identity' in the Context of 'Latin American Identity'}

Victor Armony explains that because Latin America is a region of huge contrasts and extreme diversity, speaking of a 'Latin American identity' is controversial (2011, 164). Furthermore, in an attempt to understand present relationships between Latin American countries, Armony points to history and explains that "[w]ithout exception, albeit with varying degrees, Latin American societies exhibit both deep inner ethnic and social fractures and compelling narratives about their national cohesion" $(2011,164)$. While Latin American countries share a history of colonization, "nation building processes in Latin America predate successful anticolonial movements" (Armony 2011, 164). This notion is important, for it helps us understand the possibility of an Argentinian nation being conceived as white and distant to Latin American culture and geography. Consistent with this, my research shows that these historical narratives are still embedded in notions of 'who Argentinians are'. They result in a failure to recognize the similarities 
between the social positions of Argentinian immigrants and Latin American immigrants in Canada and continue the projection of a sense of a proximity to Europe.

The 'fantasy' of Argentina being closer to Europe (that is in cultural rather than geographical terms) than to Latin America, finds its origins in official discourses that constructed the nation as homogeneously white and European in contrast to the mestizo representation of most other Latin American nations (Garguin 2007, 162). Furthermore, this construction has been continuously strengthened by "the myth of the European origins of the Argentine population linked to the $19^{\text {th }}$ century elite efforts to think of Argentina as different from the rest of Latin America, which according to the ideological tropes of the time, did not fit within the category of 'civilized societies"' (Garguin 2007, 165). These notions have, on the one hand, promoted a self-perception that does not coincide with that of Europeans, and on the other hand, been the source of tensions between Argentinians and Latin Americans.

Dalia Kandiyoti (2008) offers some arguments to support this observation. She looks at how Argentinians, when in exile in Europe, have been confronted with the reality that their identification with European-ness is not recognized by Europeans. Regardless of Argentinians' self-perception, in the eyes of Europeans, Argentinians are no different from Mexicans or Bolivians "hence the potency of the fantasy of racial and cultural proximity, the over-investment in geography as the chief explanatory factor of difference and the 'shock' and melancholy at Europeans' narrow definition of European-ness that excludes Argentines" (Kandiyoti 2008, 626). This aspect, along with a historical 'denial' of belonging to Latin America has contributed, according to Kandiyoti, to the preoccupation and uncertainty Argentinians have about their own identity $(2008,625)$. 
Furthermore she emphasizes that Argentina's legendary 'dis-identification' with its own terrain is already found in the foundational writings of Domingo Sarmiento and Juan Bautista Alberdi and strengthened through national discourses (Kandiyoti 2008, 624).

It is important to reflect on this legacy of the "homogeneously-white-European Argentina' (Garguin 2007) and its consequences, which have materialized in ever-present tensions between Argentinians and other Latin Americans. While Argentinians feel a lack of belonging to the collective 'Latin American identity', at the same time the Latin American community has reciprocated by strengthening its boundaries to subtly exclude Argentinians.

\section{The Unmarked White Centre of Multiculturalism in Canada}

In Canada, the dynamics of the official multiculturalism discourse shape, among others, the identity formation experiences of Argentinian immigrants, and so in this section, I briefly review some of the literature produced by critical multicultural theorists. Scholars such as Ghassan Hage (1998), Yasmeen Abu-Laban and Christina Gabriel (2002), Sneja Gunew (2004), Sunera Thobani (2007), Rita Dhamoon (2009), Caroline Dick (2011), Suzanna Reiss (2011), and Xiaobei Chen (2013) argue that despite a politics of tolerance that multiculturalism purports to promote, Canada remains fundamentally a white, Christian and Euro-centric nation. This presents profound limitations to the complete integration and acquisition of equality and full rights by all groups in Canadian society.

In Canada, multiculturalism was first implemented as a state policy 'within a bilingual framework' in 1971. In 1988 the Canadian Multiculturalism Act came into 
effect "giving Canada's multiculturalism policy the force of law, and for a while, departmental status in the federal government' (Adsett 2011, 47). The implementation of multiculturalism in Canada can be traced to the 1960s, which was a decade of intense involvement from various groups seeking to redefine Canada's national identity (Reiss 2011). In 1965 the Royal Commission on Bilingualism and Biculturalism declared in a report that Canada was passing through the greatest identity crisis in its history (Reiss $2011,68)$. At the time this report was released, minority groups started exerting pressure on the government, asking for further recognition and inclusion.

In tracing the origins of 'Canada's identity crisis' as announced by the Commission, Reiss points to a combination of two main factors. On the one hand, there was the increasing need to address internal tensions between Canada's two 'founding cultures', the English and the French, while on the other hand, there was Canada's intention to "self-consciously transform itself from a British Commonwealth country to a Canadian nation in a hemisphere dominated by the growing global power and influence of the United States" $(2011,68)$. This attempt to 'distance' Canada from Britain occurred in the context of British imperial decline and the rise of nationalist anti-colonialist movements in the late 1960s (Reiss 2011, 68).

The emergence of the policy can then be summarized as finding its origins in rising Quebec nationalism, the above-mentioned identity crisis, and increasing demands from minority groups for recognition. In light of the increasing deterioration of the relationship between the government and some minority groups (such as immigrants of Caribbean origin, see Reiss 2011, 79), the Royal Commission recommended to then Prime Minister Pierre Trudeau the implementation of multiculturalism. While the notion 
of multiculturalism promotes the celebration and preservation of cultural and ethnic diversity, critics note that the use of the term 'multicultural' creates a false notion of inter-ethnic social trust (Reiss 2011). Furthermore, it has also been argued that the policy is more about setting the proper limits to the tolerance of diversity and preserving the fundamentally 'white, Christian, Euro-centric nation'. Mackay, for instance, argues that “specific forms of Canadian pluralism bolster 'unmarked whiteness' and help to affirm a dominant white Anglophone 'Canadian-Canadian' culture and nationalist program” (2002, 142), much similar to the unmarked white "owner" of the nation in Australia (Hage 1998). Similarly, Gunew (2004) argues that in Australia, the notion of 'European' has been narrowed to denote Anglo Europeans while excluding other Europeans (e.g. Eastern Europeans). These observations are important for they help us understand how ethnic identities and their associated categories, hierarchies and formation processes have varied in postcolonial conditions. As I show in later chapters, the case of Argentinian immigrants supports and illustrates this notion of how certain groups, while located at one level among the white centre in Canadian society, still remain at its margins.

\subsection{Aims of the Thesis}

This thesis follows the conceptual and theoretical insights of diaspora studies, whiteness studies, the constructivist notion of identity (particularly Hall's emphasis on identity as a "meeting point"), and the sociological approach to emotions, affects, memory and nostalgia. It examines the identity formation experiences of Argentinian immigrants in Canada's National Capital Region informed by the three contexts outlined above. 
This thesis aims to contribute to the field of Latin American diaspora studies in Canada by seeking insights that will broaden our knowledge of this group and of its internal differences and contestations. Argentinians, as well as other Latin Americans, are usually amalgamated within the larger category of "Latino", however such a generalization fails to recognize the heterogeneity of this group and how 'different identities' are claimed by groups in negotiating their rights in Canadian society. Linked to historical and discursive processes in Argentina, the narratives of these immigrants speak to very different experiences and strategies of integration than those of other members of the 'Latino' group. In part, this is because when referring to the second wave of Argentinian immigration to Canada we are most likely to find a group of professionals. It is important to highlight this distinction as most literature portrays Latin Americans as poor and oppressed. While the experience of Argentinian immigrants, as a group that is relatively privileged, is different from that of other members of the 'Latino' group, they still face many challenges. Furthermore, their experience is different from that of other racialized 'white' minority groups such as Southern and Eastern Europeans. By exploring the narratives of a minority group within another minority group, this research seeks to investigate the intersection of race and power central to the management of diversity in Canada.

In addition, this research aims to contribute to the field of critical white studies (Nayak 2007) by exploring the case of Argentinian immigrants as an example of a 'white' minority group living in a dominantly white society yet at its 'margin'. As clearly

\footnotetext{
${ }^{11}$ It should also be noted that the term 'Latino' not only fails to acknowledge the heterogeneity in terms of nationalities but also in terms of class, gender, age, and ethnicity among others. For more see Veronis 2006, 19.
} 
stated by Nayak, it is important to re-examine our understanding of whiteness and recognize "that white people also have an ethnicity" $(2007,738)$. Furthermore, we ought to "demonstrate that sociologists can no longer afford to ignore whiteness but should see it as a mutually constitutive aspect of their investigations into race" (Nayak 2007, 738). I aim to gain a better understanding of how and why different 'kinds of white' occupy different places in society and what this tells us about potential limits to full inclusion and equality.

Finally, the present investigation aims to make a contribution to the broader field of identity studies by expanding our understanding of identity formation processes. As the social, historical, political and economic conditions continue changing we also need to further explore how these various dynamics intersect, creating new spaces of contestations.

\subsection{Outline of Thesis Chapters}

The thesis is organized in five chapters. Following this introductory chapter, chapter two is concerned with the research methodology, placing emphasis on the reflective process and my own positioning as a researcher. In this chapter I outline the methods used for data gathering, data analysis, and discuss my sample of Argentinian immigrants in Canada. In the final section of the chapter I also discuss some of the limitations and challenges encountered during the research process.

The third chapter examines how the formation of immigrants' 'new' identities is linked to processes of identification and splitting vis-à-vis various 'Others', and to immigrants' emotional reactions as they interact with various social structures and relate 
to those they either identify with or differentiate from. In this chapter I argue that the identity formation experiences of Argentinian immigrants to Canada is linked to two main relational processes of identification and differentiation. While Argentinian immigrants refer to a strong sense of identification with Canada's values and lifestyle, they also referred to processes of differentiation from elements of similarity and familiarity. Participants' narratives suggest that, as Argentinian immigrants seek integration into Canadian society, they tend to split from minority groups such as other Argentinian immigrants (notably those with whom they do not share points of similarity, such as educational and 'cultural' level) Latin Americans, and other immigrants. I argue that the roots of these processes of identification and differentiation are strategic, historical, habitual and emotional.

The fourth chapter looks closely into participants' narratives in order to better understand the positioning of Argentinian immigrants in Canadian society. Here I seek to better understand how the conditions of entry of this group as well as their 'whiteness' favour their 'partial inclusion' into Canadian society while certain 'markers of difference' such as accents and language barriers give rise to subtle forms of discrimination towards the group. I emphasize that the group's experiences of integration and also marginalization influence these immigrants' patterns of identification and differentiation as well as their notions of who they are in Canada. It is important to stress that the sample for the thesis consists of a sub-set of Argentinian professionals as this has implications in these immigrants' experiences. I argue that while Argentinian immigrants may enjoy certain 'benefits' when compared to other minority groups, this should not be interpreted as evidence of full acceptance into Canadian society, but rather as evidence of existing 
racial and cultural hierarchies that prevent all groups from attaining full equality in Canadian society.

In the fifth, concluding chapter, in addition to summarizing the contents of the thesis, I return to my research questions and offer final arguments emergent from this investigation. I also provide thoughts on implications for future research.

\subsection{Conclusion}

This chapter was concerned with introducing the topic of investigation and the theoretical framework for the thesis. I started by presenting the research question and preliminary main arguments and then discussed the context of the present investigation and its location within the existing literature of Latin American immigration to Canada. Second, I discussed various concepts, which draw from different bodies of literature as well as three sets of historical contexts relevant to the discussion of identity formation processes of the Argentinian diaspora. In the final sections of this chapter I discussed the implications of the present investigation and provided an outline of the thesis chapters. The next chapter is concerned with presenting and discussing the methodology for the present investigation. 


\section{Chapter 2}

\section{Talking, Seeing, and Reading Identity: The Research Methodology}

"desde mi punto de vista es un proceso de crecimiento constante, o sea, no te quedás demasiado estancado[...] en mi caso es un proceso de re-inventarme continuamente [...] no sé, la palabra para mi es 'de-costruction', es algo que te desarma completamente, tenés todas las piezas arriba de la mesa, y empezás a ponerlas juntas y a veces hay algunas que las dejás afuera y... las reemplazas con otras, y en mi caso por ejemplo, no me molesta dejar agujeros, o sea, cosas que alguna vez estuvieron ocupadas por una pieza hoy por hoy quedó un agujero que no sé con qué lo voy a llenar en algún momento. ",12

\section{Lautaro}

"from my point of view, it is a process of continuous growth, I mean, you don't stay stuck [...] in my case, it is a process of continuously re-inventing myself [...] the word for me is deconstruction, there's something that shakes you up completely, you have all the pieces on top of the table, and you start putting them together again, and sometimes, you leave some pieces out... you replace them with others, and in my case, for example, it doesn't bother me to leave gaps. I mean, places that at some point where occupied by a certain piece may have a hole now, which I don't know how I'm going to fill up but I know I will at a certain point."

\section{Lautaro}

Embarking on the project of conducting research and writing a thesis on the processes of identity formation of the Argentinian diaspora in Canada proved to be a fascinating yet highly challenging task. Doing research presents a number of practical difficulties that need to be addressed and overcome. In addition, in my own case, it was also somewhat difficult due to my positionality within the subject of study, that is, as an insider researcher. Being an Argentinian immigrant to Canada myself required a moral commitment to searching with honesty while constantly setting boundaries to my own imaginary as there is always the 'fear' and 'risk' that as researchers, our emotional investment will prevent us from conforming to standards of intellectual rigor (Brannick and Coghlan 2007, 60). Addressing this concern required that I 'developed' some tools to

\footnotetext{
${ }^{12}$ All interviews were conducted in Spanish. I translated all participants' quotations from Spanish to English.
} 
aid myself along the research process. One of these is reflexivity, which implies turning a critical gaze towards oneself, and which has had a long history in qualitative research and refers to "the project of examining how the researcher and inter-subjective elements impact on, and transform research" (Findlay 2003, 3-4). From the beginning of this research, I was committed to remaining reflexive not only in the initial stages of my research, but also, throughout the entire process (Mauther and Doucet 2003). This meant being reflective during my initial decisions, during the 'navigating through', as I analyzed and interpreted the data, and finally, as I wrote my research. Both Mauther and Doucet (2003) and Siltanen et al. (2008) refer to the 'reflexive turn' in the social sciences and to "shifts [in] our understanding of reflexivity away from seeing it as a form of metaanalysis about the researcher's relation to the research process, and towards regarding it as a continuous and fundamental feature of research practice" (Siltanen et al. 2008, 47).

In the months preceding my decision to write about this topic, I wrestled with myself. I tried to find excuses and convince myself that the topic was too emotionally close and hence too risky to be investigated. However, during the summer of 2012, I came to realize these were excuses and that I could not pass by the opportunity in front of me. I realized that I needed to learn more about myself and challenge my own assumptions and narratives of the past twelve years. In retrospect, I realize that the increasing self-awareness and acceptance of the fact that my values and location, while having to be acknowledged and addressed in the research, did not represent an impediment, gave me the freedom to explore a subject so personal and so emotionally close. As suggested by Mauther and Doucet "the more researchers can be self-conscious about, and articulate their role in research processes and products, the more readers can 
engage in symbolic dialogues with the author (s) and the more their confidence in the work will increase" $(2003,424)$. Indeed, as the research progressed, I also grew out of my fears and concerns and was further convinced that insider researchers are capable of conducting 'rigorous' and sound research.

In addition to these fears, I had a number of practical concerns in mind. To begin with, I knew that I wanted to conduct interviews because I was interested in learning about other people' stories and understanding to what extent we shared similar views on our identity formation experiences as linked to the process of migration and integration into a new society. However, I was concerned about whether or not I would be able to access a large enough group of Argentinians who would fit the selection criteria I had developed for my research. That is, I wished to focus on professional Argentinians belonging to the second wave of Argentinian immigration to Canada, which is mostly comprised of adults arriving under the Federal or Quebec skilled worker programs, as well as members of the family category accompanying main applicants.

One of my initial findings was realizing that participants had very different views than my own about the social context we all live in. This first impression was further strengthened when visiting blogs written by Argentinian immigrants to Canada where discussions on various topics took place. Some of these blog entries talked about integration and interactions between Argentinian immigrants and Canadian society, discussions on culture, language, and to some extent, identity. These 'first impressions' made me realize that I needed to listen very carefully to what Argentinian immigrants were saying and writing. The narratives encountered were rather different from what I came into my research expecting to find. Again, I turned to reflexivity and the emphasis 
it places on understanding and "recognizing the social location of the researcher as well as the ways in which our emotional responses to respondents can shape our interpretations of their accounts" (Mauther and Doucet 2003, 418) in an effort to remain faithful to their accounts in my own construction of meanings and knowledge.

As the research progressed, my sense of responsibility towards the participants became increasingly strong. I knew that I had to be attentive, dedicated and meticulous in listening; and when writing, careful, honest, and rigorous in my selection, analysis and reporting. The notion that the researchers' values and personal history influence our choices is pointed in the literature (Denzin and Lincoln [1994] 2000; Flyvbjerg 2001; Mauthner and Doucet 2003; Siltanen et al. 2008). This is why particular emphasis needs to be placed in the reflexive process, for it allows a researcher to remain attentive, especially when making choices about which transcripts are presented as evidence and how these should be interpreted (Mauthner and Doucet 2003, 417).

In what follows, I reflect on the various methodological decisions I made in order to understand my research question and to overcome the various challenges and limitations faced along the way. In the first section, I describe the research methodology and the various techniques employed in order to gather data for the thesis. Second, I discuss my sample of research participants and look at patterns of Argentinian immigration to Canada. Third, I address some of the challenges faced in order to access participants and other opportunities to conduct research and discuss how research relations were developed. Fourth, I reflect upon my own positioning and involvement within the research process by focusing on a discussion of the 'insider' researcher role. Fifth, I discuss data analysis techniques and some of the ethical dilemmas that arrise out 
of the analysis and interpretation phases. Sixth, I begin to introduce participants' narratives and reflect on some of the methodological adjustments made in light of early findings and finally summarize the chapter's discussion.

\subsection{Sources of Data}

Guided by an interest in learning more about the processes of identity formation of Argentinian immigrants to Canada, and more particularly, with an emphasis on understanding the social conditions of migration and personal practices that contribute to the development of these experiences and processes, I chose a qualitative approach that would allow me to access the narratives and constructions of meanings of these experiences. My main interest was to hear from participants themselves, to understand their own 'assessment' of the situation, keeping in mind that some of the issues I wanted to address were rather personal and sensitive in nature.

With this in mind, between November 2012 and January 2013, I conducted a total of 14 interviews in the Ottawa-Gatineau area. These were face-to-face, semi-structured interviews that lasted one to two hours in length, with the exception of a few interviews, which lasted longer than that. All interviews were conducted in Spanish and recorded for the purposes of accuracy, transcription and translation. Participants were ensured anonymity and confidentiality through the use of pseudonyms, with the exception of one of the research participant, blogger Guillermo Ziegler ${ }^{13}$. All research participants signed consent forms that included all details of the research project.

\footnotetext{
${ }^{13}$ Guillermo Ziegler agreed to be presented as a public research participant consistent with the nature of his activity as a blogger (the blog is public and open to anyone to visit).
} 
The interview questionnaire ${ }^{14}$ consisted of approximately twenty-one questions, which were meant to address various research questions. The questionnaire is composed of five main sections. The first section included between three and four general, open ended, non-sensitive questions that aimed to build rapport. The following three sections consisted of open-ended questions meant to address different elements of the thesis research question, namely self-identification and identity; group organization, affiliation and notions of inclusion/exclusion; and lastly, memories and connection to the homeland. The fifth and final section of the interview questionnaire consisted of three open ended closing questions inviting participants to offer final thoughts. While I had a list of tentative questions that I wanted to address with each participant, the questionnaire also allowed some flexibility and I included follow-up or clarifying questions, as necessary. In addition, I included 'reminders' throughout the questionnaire so that I could learn more about participants themselves (e.g. their age, profession, occupation, etc.). In the case of Guillermo's interview, for the most part, I followed the same interview schedule but I added a few more questions addressing specific aspects of blog entries. Asking these questions helped me clarify my own interpretations of the $\operatorname{blog}^{15}$.

In addition, I conducted participant observation as a way to complement the data gathered through the interviews. I envisioned that jointly, the techniques could provide me with different types of data and different angles for analysis. I conducted nonobtrusive participant observation on five occasions where I had the opportunity to

\footnotetext{
${ }^{14}$ Research questionnaire is included as Appendix A on page 126 and 128.

${ }^{15}$ Research questionnaire is available as Appendix B on pages 131 and 134.
} 
observe Argentinian immigrants within various contexts such as formal and informal social gatherings and Embassy sponsored events.

I also decided to work with blogs where some Argentinian immigrants to Canada engage on a range of discussions. In addition to finding the discussions on the blogs quite fascinating, doing content analysis of blogs is a non-intrusive technique that allows a researcher to gather interesting data that might aid him/her to make sense of previously encountered data. I regularly visited three blogs: two Facebook pages entitled "Argentinos en Canada"; and "Festival Latino Ottawa-Gatineau" and the blog "Los Ziegler en Canadá". Out of the three, the content of the blog "Los Ziegler en Canadá" proved to be closest to my area of research. The blogger, an Argentinian-born, Canadian citizen and Ottawa resident, Guillermo Ziegler, conducts self-guided research and reports findings along with comments and 'reflections' shared with regular visitors of the blog. Blog entries include a variety of topics going from immigration/work advice for newcomers and those planning to immigrate to Canada, to discussions about life in Canada, culture, and 'immigrants' stories'. In the next section I will discuss research participant's profiles based on patterns of Argentinian immigration to Canada.

\subsection{Research Participants' Profiles}

Because my main interest was to understand how both the social context as well as personal practices of reflecting, feeling and reacting shape the immigration experience and the identities of these immigrants, I wanted to interview participants who had been living in Canada long enough to be able to speak about their interactions with Canadian society and about their 'strategies' for integration. Due to the various political and 
economic crises that Argentina has faced in the recent past, I needed to make some decisions about which group of Argentinian immigrants I wanted to interview. The literature informs us that Canada has received two main waves of Argentinian immigrants. The first immigration wave dates back to the 1970s and 80s and it consists of mostly, although with some exceptions, professionals fleeing the political crisis of $1976^{16}$. The second larger wave of immigrants began in the 1990s and increased after Argentina entered the economic crisis of 2001 (Veronis 2006, Veronis and McAlone 2010). While in the year 2000 Argentinian immigration to Canada accounted for a total of 401 (including all provinces), in the year 2002 the number doubled to 815 . In 2003 the total Argentinian immigration reached its highest for the period 1981-2007 at 1,669. In 2004 it accounted for 1,548; in 2005 was 1,086; in 2006 was 759, and finally in 2007 was 565 (Statistics Canada, Report on the Demographic Situation in Canada 2005 and 2006) ${ }^{17}$. Although Argentinian immigration to Canada has been ongoing, the 'political' wave of the $70 \mathrm{~s}$ and the 'economic' wave of the $2000 \mathrm{~s}$ are the two largest. Compared to other groups of Latin American recent migrants to Canada (especially Mexicans, Colombians and Peruvians), Argentinian immigration is significantly smaller. However, the social composition of these immigrants needs to be considered as there are significant differences among these groups (e.g. groups arriving as refugees, migrant temporary workers, etc. $)^{18}$

\footnotetext{
${ }^{16}$ For further information on this see: Table 3: First Wave of Argentinian Immigration to Canada 1970s on page 139 and Table 4: Central and South American Immigration to Canada: 1968 to 1995 on page 140.

${ }^{17}$ See Table 5: Second Wave of Argentinian Immigration to Canada 2000s on page 141.

${ }^{18}$ For instance, Mexican landed immigrants to Canada in 2007 totaled 3,226, Colombia's 5,382 and Peru's 1,502. For more details see Table A-4.1 Landed immigrants in Canada by country of birth, 1981 to 2007 on p. 60 the Report on the Demographic Situation in Canada 2005 and 2006
} 
Cognizant that the two groups of Argentinians would share some similarities but that the narratives of the two groups were likely to be very different, I decided to focus on 'recent immigrants' arriving to Canada between 1999 and 2007 as I considered this timeframe would allow me to capture the narrative of participants who, due to having lived in Canada long enough, would be able to reflect on their immigration experience and changes emerging from this process. My decision to focus on professionals was initially based on a feasibility study I carried out during 2011 as well as informed by the literature available on Latin American immigration to Canada, which stresses that the majority of immigrants from this origin, arriving after 1990 did so under the skill worker program (this is further described below). Aware of the social, economic, political, and cultural differences between Quebec and the rest of Canada, I decided to focus on participants who share a connection to the National Capital Region, that is, that either had immigrated to this region or that, while maintaining permanent residence somewhere else, work or study in the region. My decision to interview participants who had a connection to the National Capital Region was based on the limitations of time and resources. An interesting finding was that, while about half of the participants in this research currently reside in the Gatineau area, all participants who are currently employed work in Ottawa. Half of the participants initially arrived in the province of Quebec (four to Montreal and three to Gatineau/Hull/Aylmer), six participants arrived in the province of Ontario and one arrived in the province of Alberta.

available http://www.statcan.gc.ca/pub/91-209-x/91-209-x2004000-eng.pdf . See Table 6: Latin American Immigration to Canada in 2007 by main countries of origin on page 142. 
There are, however some characteristics that apply, broadly speaking, to Argentinian immigrants to Canada. The 'recent' immigration wave can be generally described as a group of professionals coming under the Federal Skilled Worker (FSW) program or its Quebec equivalent, the Quebec-selected Skilled Worker program, and their family members arriving as 'dependents'. Under these programs (without reflecting changes to the immigration program and requirements for these categories of immigration recently released in January 2013) immigrants need to have certain qualifications in order to be eligible for residency. The main requirements for entry and residency include: 1) a high education level. The minimum level of education accepted is a Bachelors degree and higher points are given to applicants holding a Masters degree and/or a $\mathrm{PhD} ; 2$ ) in the case of applicants coming through the Quebec program, the university degree has to be completed in one of the professions included in a list of 'professions in high demand'; and 3) language requirements. Applicants must be able to speak at least one of the official languages, preferably both. In the case of applicants coming through the Quebec program, applicants must show proof of proficiency in French. In addition, a candidate will also preferably have arranged employment and be considered a person with a "high degree of adaptability", which according to Canada Citizenship and Immigration website consists of having previous work experience and/or education in Canada. There are also some financial considerations that need to be kept in mind when applying (CIC website, dates retrieved July 2012 and December 12, 2012).

Participants in this research were immigrants who arrived in Canada under either of these two programs, or those who arrived under the family program, that is, joining a 
main applicant under the above-mentioned categories ${ }^{19}$. Partially, these selection criteria were developed in order to discover whether arriving in Canada as the main applicant or whether arriving in Canada as a family member of a main applicant would result in some discrepancies in the identity formation experiences.

Of the 14 interviewees, 10 arrived under the skilled worker program and 4 arrived as family members. All the family members who arrived under the family class were at least of high-school age at the time of immigration. Seven participants arrived under the Federal program and seven under the Quebec program. A large number of research participants came under the Quebec program because of the strong recruiting campaign for professionals that the Government of Quebec carried out in Argentina shortly after the economic crisis of 2001.

The remaining selection criteria for research participation consisted of having a fairly equal gender representation as well as having participants who would represent the diversity of the country of origin. Seven of the interviewees were female and seven were male. Participants were originally from the provinces of Cordoba, Mendoza, La Pampa, and Buenos Aires (both 'porteños' and bonaerenses ${ }^{20}$ ). Broadly speaking, participants were members of the middle class in terms of income levels, occupations and education level. However, speaking of an Argentinian middle class is not without problems, especially in light of the impact of neoliberal practices in the 1990s and its legacy of

${ }^{19}$ With the exception of one research participant who arrived under the family category but to join his Canadian partner.

${ }^{20}$ Both the terms porteño and bonaerense denote being an inhabitant of the province of Buenos Aires. However, 'porteño' means 'that one who is from a city with a port' and in the particular case of Argentina, the term denotes those who are from the capital city. 'Bonaerense', however, makes reference to the people from the province of Buenos Aires but not from its capital city. 
increased polarization between the rich and the poor and a middle class on the verge of extinction in the early 2000 s.

\subsection{Accessing Participants and Other Opportunities to Conduct Research}

In choosing a methodology for my research, I knew that I would have some difficulties accessing research participants as well as finding opportunities to conduct observations. I knew there were 'lots of Argentinians' in Ottawa who would fit my selection criteria and who could potentially be excellent research participants but I was not sure how I would actually get them to participate. Initially, my concerns were around my 'shyness' and my reservations to ask people to speak about 'identity'. In retrospect, I realize my main concern was people would think I was trying to intrude in their personal lives by asking sensitive questions about topics that could be difficult to talk about.

My recruitment strategy consisted of a combination of accessing my personal network as well as a snowball sampling technique. I started by contacting people I knew. As the research progressed and as I started contacting people, I encountered a number of difficulties in actually accessing them. Several people initially agreed to be interviewed but due to a number of reasons were unable to participate on the research. Arranging and conducting the interviews was a tiring and, at times, overwhelming process. The fact that I didn't know approximately half of the participants required the investment of time and persistence to meet informally with people, carry out phone conversations and long email exchanges. Some interviews took over a month to be arranged only to be cancelled at the last minute without rescheduling. Overall, conducting the 14 interviews involved persistence, discipline, hard work, and forcing myself out of my comfort zone. The entire 
process of attending meetings, and conducting both interviews and observations, although challenging, draining, exhausting and at times intimidating was also highly rewarding.

I assumed that conducting participant observations was going to be less difficult, however, as the research progressed, I found myself with few opportunities to conduct observations. I have knowledge that several cultural public events are carried out throughout the year. Based on previous participation to these events, I assumed that these would provide some opportunities to observe how Argentinians interact with members of the Latin American community. I figured that attending a few events hosted by the Embassy of Argentina as well as some other informal gatherings would provide a good mix of settings. As time progressed, I started noticing how little Argentinian representation there was at the Latin American events (such as the Latin American Heritage day, the Latin American Parade, community celebrations such as National days and Christmas parties). Later, in Chapter 3, I return to this discussion and comment on how these findings became a resource for interpreting some of the characteristics of Argentinians as a group within the Latin American community.

In contacting research participants, I struggled with how much information about the research I needed to share up front. I knew from the beginning that the only way to talk openly about identity was by being honest and open about the purpose of my research. I wanted to talk about identity, I was interested in learning more about the immigration experience of participants, and I was particularly interested in learning more about the emotional connection to the whole experience.

Contacting interviewees to invite them to participate in the research raised a number of concerns. At times, the e-mail or phone call was welcomed with curiosity and 
predisposition to participate. Other times the reply was silence, which left me doubting whether my approach was too open (was I over sharing information and scaring them? was my research sounding too serious? too deep?) Yet other times, participants seemed interested and would agree but for various reasons decided later on to withdraw their participation. I adjusted as I went, trying to find a balance between how much information needed to be shared at this stage. I also asked for feedback when I felt it was appropriate to do so. My first three interviews were pilot interviews where I was able to ask for participants' feedback on the recruitment materials, my interviewing style and whether or not I was creating a space comfortable for them to talk openly about the topic. The feedback was extremely helpful and it helped me to adjust to participants' needs.

\subsection{My Role as a Researcher: On the Degree of Involvement as an 'Insider'}

In his research about white identity constructions, Charles Gallagher explains that he "came to [his] research project with the understanding that [his] racial background would be an asset" $(2000,67)$, which he critically reflected upon later. Similarly, I also came to my research assuming that being Argentinian would grant me access to and equip me to do research about 'my people'. I agree with various authors who defend the role of the insider researcher (Brannick and Coghlan 2007; Corbin Dwyer and Buckle 2009) and argue that "as researchers through a process of reflexive awareness, we are able to articulate tacit knowledge $[\ldots]$ and that because we are close to something or know it well, that we can research it" (Brannick and Coghlan 2007, 60). In addition, I also assumed that as 'a group' we would share somewhat similar immigration experiences and somewhat similar views on the social context that we all live in. 
There are, without question, a number of benefits that come with being an insider researcher, as Corbin Dwyer and Buckle explain, "insider role status allows researchers more rapid and complete acceptance by their participants. Therefore, participants are typically more open with researchers so that there may be a greater depth to the data gathered" $(2009,58)$. A clear example of how my insider status worked to my benefit was being able to fluently speak the language in which participants preferred to be interviewed. While interviewees had the option to speak Spanish or English, all the interviews were conducted in Spanish ${ }^{21}$, and I am aware that being a native Spanish speaker and an Argentinian immigrant myself allowed me to better interpret both the conversations and also the political, cultural and social context of the interviews and the participants. In addition, being a member of the group allows one to better understand, and hence better interpret, the particularly active body language of participants in this study. Furthermore, there were two other 'insider' traits that allowed me connect with some participants. The first one is that approximately half of these interviews were conducted in a comfortable and casual environment where participants and I conversed over 'mate'. 'El mate' is a traditional hot drink that is typically drunk in Brazil, Uruguay and Argentina. It is similar to tea but the practice of drinking mate can be regarded as a 'ritual of friendship' and, contrary to tea, the drink is shared and drunk over a period of approximately an hour. Being a mate drinker allowed me to share a special bond with some of the research participants that would exclusively be reserved to an insider. This also supports the argument that one of the benefits of being a group member one is studying is acceptance and trust (Corbin Dwyer and Buckle 2009, 58).

\footnotetext{
${ }^{21}$ The researcher has translated all participant quotations.
} 
The other insider characteristic that is important to mention is the fact that I was born in the province of La Pampa but lived for an extended period of time in Buenos Aires. Buenos Aires is the capital province of Argentina and, while I will not enter an extensive discussion about tensions between the capital city/province it is important to mention that having a 'dual' status as a 'pampeana' (that of someone from the province of La Pampa) but having lived half of my life in the province of Buenos Aires allowed me to better grasp some of the nuances of the diversity of my research participants. As pointed out by Brannick and Coghlan,“[i]nsider researchers are native to the setting and so have insights from the lived experience" $(2007,60)$. An example that speaks to this can be gathered from my field notes:

Welcomes: As soon as I entered the room, I introduced myself to a couple who were sitting by the living room door. I figured I should speak English to them. After that, I said hi to some fellow whose shirt caught my attention (he was wearing an Argentina rugby shirt with a big "Argentina" logo on the front) however what caught my attention was the Argentinian emblem on the shirt and so I immediately switched to Spanish. He asked where I was from and I replied "I'm from Argentina". He rephrased so that I would understand his question: "where in Argentina was I from". I was puzzled for a moment (I didn't realized he already knew I was Argentinian, after all we had never met before and I was always assumed to be Canadian) and replied "from La Pampa, but I've lived in Buenos Aires most of my life". From that moment on the night took on a completely different course, I was part of the group... (Field notes, September 2012)

Being an insider gave me many 'privileges' and as the research progressed, I became increasingly aware of this. But it also reminded me of my responsibility towards participants. To begin with, the challenges encountered in accessing research participants made me more appreciative of peoples' time, generosity and commitment towards the research. I am grateful and indebted to my research participants for their contributions. As the research progressed, I felt one of the best ways to repay people's contribution was to be open and engaged. 
Initially, I assumed that in order to remain objective I had to find the 'perfect' balance between being an insider due to my Argentinian-ness but "being an outsider by technique" (Gallagher 2000) by reminding myself that my purpose here was to conduct research and to ensure that I was being faithful to the information provided by participants and not being 'too leading' in the direction I wanted my research to go. My concerns over being 'rigorous' enough were informed by the ever present legacy of the positivist critique of qualitative research (Brannick and Coghlan 2007), however aware of the advantages of subjective aspects of the research process (Corbin Dwyer and Buckle 2009, 58). Flyvbjerg (2001) and others (Mauthner and Doucet 2003; Brannick and Coghlan 2007; Siltanen et al. 2008; Corbin Dwyer and Buckle 2009) emphasize the aspect that social research is not value free or neutral. In fact, "data analysis methods are not just neutral techniques [but rather] [t]hey reflect and are imbedded with theoretical, epistemological and ontological assumptions, including conceptions of subjects and subjectivities, and understandings of how knowledge is constructed and produced" (Mauthner and Doucet 2003, 413). Furthermore, it is important to understand the researcher's context (gender, class, ethnicity, etc.) as part of narrative interpretation (Corbin Dwyer and Buckle 2009). Aware of my own positioning as an insider researcher I knew that I needed to remain careful of my emotional closeness to the topic of investigation. However, I carefully created the proper conditions for participants to feel comfortable enough to talk about their experiences and their identity. This awareness allowed me to adopt a 'dialogical approach' to the interviews much in the style of Ruth Frankenberg (1993). Frankenberg explains critically that in a detached style "the researcher is $[\ldots]$ expected to avoid sharing with the interviewees her research goals and 
her analysis of the issue at hand" $(1993,31)$, so like her, I also "broke the silence of the blank-faced interviewer" $(1993,35)$ with the purpose of accessing the interviewee's emotions and opinions.

Inquiring about one's identity can position people in a fragile, vulnerable place where one opens up, trusts the other, and shares sensitive and personal information in the hope that this information will be treated fairly and with respect. Such trust and openness deserve, in my view, commitment and engagement rather than detachment. An example of my approach can be gathered from the interview with Daniel, whom I didn't know prior to this research. Daniel told me at one at one point "now I would like to hear about you, tell me your story". I felt it was only fair to give him as much information about my own immigration experience and about my own reflections on identity as he was interested in hearing.

Coming into my research, one of my concerns was to come across certain traits that are often assumed as typical of Argentinians, and which I find conflicting with my own views. In the chapters to follow, I discuss at length how this group's heterogeneity takes on the form of 'disunity'. Furthermore, I will reflect on how certain 'traits of Argentinian-ness' feed the stereotype of Argentinian as 'considering themselves superior to others' and being 'arrogant'. Clearly these features have fostered tensions and divisions between Argentinians and other Latin Americans. While there are many groups that exhibit these kinds of traits, for me, this is a particularly and personally sensitive point, as I believe these notions need to be challenged and changed.

During my research, I aimed to learn more about the relationship between Argentinians and Latin Americans. Given that I had personally always sought these 
interactions, I assumed that other Argentinians would too. While the responses were mixed, the majority spoke of no relationship and no feelings of belonging to the Latin American group. As anticipated, indeed I faced the challenge of sitting and hearing opinions 'confirming' the stereotype of Argentinians thinking rather highly of themselves. For instance, during the course of an interview when I was seeking information about the relationship between Argentinians and other Latin Americans in order to better understand the lack of sense of belonging to the Latin American group, an interviewee replied that Argentinians are clearly different than Latin Americans because 'we' have "so much more". My participant was not only referring to the wealth of the country in terms of natural resources but was also implying that there is something in the culture and personality of Argentinians that is somewhat 'far ahead' to nationals of other Latin American countries. Clearly those moments when the interviewer disagrees with the opinion of the interviewee pose internal conflict. Corbin Dwyer and Buckle remind us that it is due to the insider status that "it is possible that the participant will make assumptions of similarity" $(2009,58)$ and assume agreement with their opinions. I will never know whether a participant would mention such things to a researcher that they do not consider an insider but I know that they probably would not mention this, for instance, to a Latin American researcher of other origin than Argentinian. What became clear to me was the importance of my commitment to remaining respectful and 'unchallenging of the participant's view' whether I agreed or not with their views. Clearly interviewing those who shared similar views to mine was pleasant and inviting while interviewing those who didn't was extremely difficult and drove me to remain silent, and at times, to blush. 


\subsection{Data Analysis Techniques}

My approach to the analysis of data involved working with the data as I conducted the research based on the understanding that the processes of collection of data and analysis are not strictly distinct phases (Glaser and Strauss 1967; Strauss and Corbin 1990). This meant that as I was conducting interviews, observations and collecting blogs, I interpreted, analyzed data and continued my engagement with the literature. For the most part, I followed a three step coding process based on what Strauss and Corbin refer to as open coding, axial coding, and selective coding $(1990,58)^{22}$. For interviews, I first listened the transcripts and took general notes to begin identifying main themes in each interview. A second step consisted of cross-examining interviews and identifying recurrent themes. During this second coding step, I created a coding sheet that consisted of five main categories (identification, social inclusion/exclusion, views on multiculturalism, immigration experience, and outcomes of immigration experience) with between 3 and 5 sub-categories each. These categories and sub-categories reflected different themes that participants raised during the interviews. A final coding step (selective coding) consisted of identifying links between these five larger categories in order to narrow down the findings into the two main categories to be presented as the 'stories' in this thesis. During the last step of interview analysis I conducted a second listen of all interview transcripts in order to transcribe and translate fragments and quotations to be presented as supporting data. In addition, I produced an interview synthesis table' which summarized the findings of each of these five larger categories and

\footnotetext{
${ }^{22}$ For more on coding procedures see Strauss and Corbin $(1990,57-74)$.
} 
established links among them. This allowed me to identify patterns (in terms of age, gender, conditions of immigration, etc.) in participants' responses.

For the observations and content analysis of blogs, I followed a similar system. In the case of observations, I first conducted the observations and immediately wrote down all notes including date, time, location, and other details. Secondly, I classified these notes into main themes and created between five and fifteen labels for each occasion. In a final step, I produced a synthesis table where I identified main themes observed on more than one occasion. This allowed me narrow to down main categories (e.g. 'cultural' expressions of Argentinian-ness; accounts of Argentinian-ness, identification, etc.) and establish patterns of interaction.

For the content analysis of the main blog I followed Strauss and Corbin's (1990) three steps but adjusted it in light of Altheide's (1996) ethnographic content analysis (ECA) approach. "ECA follows a recursive and reflexive movement between concepts development-sampling-data, collection-data, coding data and analysis-interpretation" (Altheide 1996,16) and although in this system the researcher allows initial categories to guide him/her through the study, it is expected that new ones will emerge through constant discovery and comparison (Altheide 1996) ${ }^{23}$. I started by glancing through the entire blog. After about four months, I started identifying the main topics, issues and categories as organized and presented on the blog. Based on the categories identified in the blog itself, I developed a coding chart, which comprised a total of seven categories, each with three sub-themes (language, culture and identification). I developed a selective coding chart where I would classify blog entries according to their main category (1

\footnotetext{
${ }^{23}$ For more on Ethnographic Content Analysis see David Altheide (1996, 13-22).
} 
through 7) and their theme (a to c). During this step I backed up content within each category and started selecting data for the thesis. This back up consisted of twenty-five key entries and five additional entries. Similar to the interview analysis, the final coding stage consisted of producing a synthesis chart where I summarized the content analysis and categorization of key articles. Out of this process, I selected three out of the seven main categories and themes: 'stories of immigration' (focus on life in Canada, language, culture and self-identification); 'language, culture and home'; and 'notions of Argentinian-ness' (focus on self-identification and identity). This final step allowed me to establish patterns in blog entries and discussions.

During the data analysis and interpretation phases, I faced some ethical dilemmas. Most of my concerns prior to, during and after I concluded the research had to do with honouring and respecting participants' contributions and treating them fairly, knowing that at times participants were purposely leaving information out of an interview or asking me to withdraw information from an interview. Ruth Frankenberg explains that "there is a general power imbalance between a researcher and the subjects of research in the sense that the researcher sets the agenda and edits the material, analyzes it, publishes it, and thereby takes both credit and blame of the overall result" $(1993,29)$. This is a widely held concern within the feminist research perspectives. While I was extremely clear on the notion that I would respect participants' requests to abstain from answering a question or withdraw information that might give their identities away, as a researcher one cannot avoid feeling a sense of loss over those pieces of information that could potentially be key to the overall understanding of a research question. Sitting in preliminary meetings, some participants would share crucial information that they later 
either did not repeat during the interview or asked to be withdrawn from the research. Another time there was information provided off the record that would add to the understanding the question of identity. Although this did not happen in the majority of the cases,${ }^{24}$ having had the participants' consent to share that information would have added to some of the findings that will be discussed in following chapters.

\subsection{Stories of "Argentinian-ness": Main Narratives and Methodological}

\section{Adjustments}

I have referred extensively to how having insider status within the group also comes with a number of expectations. While I was mindful that going into the field I would encounter different narratives and opinions than my own, I found myself 'guilty' of, to an extent, assuming that the narrative would be much more homogeneous. Despite knowing that groups are highly heterogeneous, I somewhat envisioned that research participants would, if not hold similar views to mine on certain issues, at least have the same 'concerns' or awareness over certain aspects of Argentinian identity as I had.

When I started designing and building my research, I made methodological decisions that would take me in the direction of addressing my research question. In other words, I made decisions guided by my theoretical, epistemological and ontological positions. For instance, I wanted to know about how Argentinian identity is impacted by the social context, by encounters with other members of society, and with institutions. I

\footnotetext{
${ }^{24}$ On one occasion the participant e-mailed several times after the interview asking to withdraw pieces of information. Another participant shared further personal information that according to her was the reason why the she felt she had 'lost her identity' and finally in two instances participants shared extensive information during preliminarily meetings; however, they did not go into that much detail during the interviews.
} 
wanted to learn more about how the experience of being an Argentinian immigrant unfolded for others, whether they had met the resistance of the host society to their integration and participation through different forms of exclusion, and if so, whether this was racialized, subtle, overt, covert, etc. In addition to finding 'the facts' I was interested in learning how these experiences interacted with Argentinian immigrants' identities, emotions and memories of the homeland.

Coming into my research I expected to find stories of exclusion, discrimination, and nostalgia among, obviously, the successful stories of integration. Because my own experience had been complex, I assumed a similar degree of complexity (or struggle if one will) in other immigrants' stories. However, as I started interviewing people, doing content analysis of blogs and conducting participant observations, it became increasingly clear that there were 'other stories' out there. In the initial stages of my research I came across two main narratives, of which one was dominant in terms of number of participants sharing these views. The first main narrative is a 'positive immigration experience' where participants have made a conscious decision to leave the homeland behind to embrace the new country. For instance, Martin speaks to this narrative:

Martin: I came here with the idea of living here and forming my own Canadian identity which, of course, is never going to be, I think, as if I was born here... but... on the other hand, there are immigrants who, I think I am an example of this, feel adopted by this place and for this reason you end up loving it, or maybe appreciating the things this country has to offer even more than a Canadian.

These participants identified strongly as Argentinians but also with Canada. They were, overall, well integrated and had little to say about feeling excluded. The second main narrative I encountered was much more critical of the new social context and rather nostalgic about the homeland, however, these participants were 'caught' somewhere between feeling outsiders in their adopted country yet strangers in their homeland. There 
is no clear-cut division between the two groups but in general terms these were the two main narratives. To my surprise, participants felt little or no identification with the larger group of Latin Americans nor a strong point of reference when self- identifying.

What became increasingly curious to me was that, while participants with a positive story of integration seemed content and non-critical of the social context, they provided a number of examples during the interviews that somewhat contradicted their own story of successful integration. Another curious finding came from participants' responses when I asked them where they felt they fit in the most in terms of the main groups in Canadian society, to my surprise, except for two participants who spoke of "an obvious dominant class" and of a "racial hierarchy", the remaining 12 participants struggled to even understand that the question aimed to learn whether participants identified themselves with majority or minority groups, or in racialized terms.

While the questions asked throughout the interviews were more or less consistent, there were a few modifications required in order for participants to better grasp the questions. Noticing that some participants had, for instance, difficulties in talking about certain experiences (e.g. about forms of exclusion and discrimination) also encouraged my dialogical style where I provided examples and at times, even my own reflections and partial analysis on certain aspects of the investigation. As I increasingly noticed that, contrary to my expectations, Argentinian immigrants struggle to form an organized community and that they don't actively participate (as a community) within the larger Latin American community, I strongly relied on participants' views and opinions in order to understand this group dynamic, as shown in the following example:

Pamela: Have you even been involved with the Argentinian community? 
Guillermo: no, never, the only time... you mean the Argentinian community as an organization? Because I have plenty of Argentinian friends that I hang out with...

Pamela: no, I mean, with an organized community

Guillermo: the only time was in the summer of 2005, with a local organization of Argentinians... [laughs] and... I didn't feel like coming back... I don't know what is going on with us Argentinians... it seems that far from wanting to do things to unite ourselves and help each other we do things to repel us...

[further thoughts]

Pamela: why do you think it is that it is so difficult for us to build some sort of community? Because... I see other groups, right? Colombians, Mexicans, I imagine they also have their differences and internal conflicts but I see their solidarity, I see they have their activities, their parties...

Guillermo: yes! The Brazilians, or at least this is what you see from the outside, that as a community they have a much more interesting organization than what you see for the Argentinians, that is true...

Pamela: I think this is curious... what's your opinion?

Guillermo: no... I... I don't know if this is curious, I think that actually, ehm... even though we are no longer there, we still bring with us much of our DNA, and here we continue being... we continue acting... with the same harmful habits or with the same characteristics that we had there and if over there we belonged to a disunited country, here... here we continue as disunited Argentinians.

As the example shows, often times I found myself having a conversation with participants about the potential reasons why Argentinians don't seem to have a unified diasporic identity but rather a divisive one. The adoption of this dialogical style did, however, present the ethical dilemma related to finding the balance between being an active interviewer so that participants would feel comfortable enough talking to me while not being leading. As the interviews progressed I found more balance but I still remember when after my first interview I asked the participant to give me some feedback and she said something along the lines that perhaps I could be a bit more engaging because my silence was making her feel as if she was saying things that made no sense or that were wrong. At other times, when dealing with an extremely emotional interview, when a 
participant faced some sad and disappointing episodes of exclusion and discrimination, it was extremely difficult to carry on the interview when the topic was clearly upsetting the interviewee in spite of her desire to proceed.

When I was doing preliminary research for this thesis, I came across Guillermo's blog entitled Los Ziegler in Canada. My first impression of the blog was that it would be an excellent tool to help me access opinions and comments about the various topics on which Guillermo reflects upon. Guillermo's style is thorough and somewhat provocative. However, as I progressed with my analysis of the blog, my impressions of it changed slightly to understand that both the blogger and his followers were part of what I had classified as 'the positive' narrative. While my initial response was one of accepting the information as it was presented without questioning whether this narrative would also reflect elements of other narratives, or potentially some internal contradictions, I decided that interviewing Guillermo would provide further clarifications and possibilities to shed light on my own interpretations of some of the blog content. In doing so, my understanding of the blog narrative was enriched.

When I decided to conduct participant observations, I envisioned that attending events of the Latin American community would, not only provide several occasions for me to observe 'expressions of Argentinian-ness' and their interactions with other Latin Americans, but also, somewhat connect me with the Argentinian community itself. While I was able to attend a few gatherings where I met and spoke with other Argentinians, it became increasingly noticeable to me that, in attending events and gatherings of the Latin American community, there was rather an absence of an 'Argentinian community'. This finding was intriguing to me for I knew, from previous years, that there was in fact some 
sort of organized community, furthermore, I was able to track the online presence of such an association. My first reaction to the lack of opportunities to conduct participant observations was to think that perhaps this technique had to be removed from my methodology; however, as the research progressed and I conducted interviews, the absence of an organized Argentinian community and its lack of participation within the larger Latin American community became increasingly meaningful in itself.

As I tried to figure out all the pieces of the puzzle, I decided to approach several people who I thought might be able to help me make sense of this absence. I first contacted a woman who I had been told was the President of the above mentioned Argentinian organized community, however, I never heard back from the person. Second, I approached the Embassy of Argentina to see if they could facilitate contact and offer their general comments on the Argentinian community in the National Capital Region. I met with an Embassy Official who was able to provide general information about the composition of Argentinian immigration to Canada as well as comment on the activities of the Argentinian community. This information helped strengthen some of my interpretations as well as validate some of my methodological choices (especially in designing the criteria for selection of participants). Finally, I contacted one of the leaders in the Latin American community in Ottawa. While initially this person agreed to comment on the participation of Argentinian immigrants (individually or collectively) on the Latin American community (and interactions in general), however, in the end I was not able to secure a meeting with this person.

Partially the decision to approach these persons was based on what I was able to observe at a social gathering hosted by the Embassy of Argentina during the month of 
December 2012. The event was an art and cultural exhibition featuring works of ten Canada-based Argentinian artists, typical dances (folklore and tango), music, food, and wine. There were about 200 people present at the event and about half were Argentinians. What I thought was curious was that none of the people I had interviewed was present that evening. However, that was not too surprising given that most participants had said for diverse reasons they do not relate to other Argentinians (especially not in communitytype events) and/or other Latin Americans.

At this point, it was clear to me that I needed to seek clarification in finding more about the composition of the Argentinian diaspora and potentially contacting these people, while at the same time I had to face myself in a moment of honesty. I wondered whether my snowballing technique might have excluded relevant voices from the narrative. While I knew that this strategy was chosen in order to address a specific population, I wondered whether I had fallen into a trap of the very thing that I was trying to avoid. That is, of privileging some voices over others. My own questions made me further reflect and decide to pursue whatever opportunities were available in order to include as many other stories as I was able to find. This meant that I would seek more opportunities to meet, observe and conduct interviews. It was with this objective in mind that I reached out to the Embassy official and the community leaders, as well as conducted two additional observations, and four additional interviews.

As a researcher, ultimately one tries to work around the strengths and weaknesses of the chosen methodology keeping in mind that the decisions taken are well informed and founded in preliminary research and in the literature. One of the biggest lessons learned throughout this process is that as a researcher, one is to take the research design 
as a point of departure but not necessarily as a point of arrival; and that it is somewhere in the middle where rich, constructive, and fascinating research happens.

\subsection{Conclusion}

In this chapter I began by presenting the research methodology and the various techniques employed in order to gather data for the thesis. Second, I focused on patterns of Argentinian immigration to Canada and discussed my sample of research participants. Third, I referred to some of the challenges faced along the research process in order to access participants and opportunities to conduct research. Fourth I reflected upon my own positioning as an insider researcher and discussed some of the strengths and weaknesses of this role. Then, I discussed my data analysis techniques. In the final section, I introduced some of participants' narratives and discussed how in light of initial findings

certain methodological adjustments were made. In the next chapter, I discuss processes of identity formation of the Argentinian diaspora in the National Capital Region. 


\section{Chapter 3}

\section{"I Say From Argentina, but Being a Canadian Citizen Gives Me Great Satisfaction": Identifications and Differentiations}

P: "Cuando la gente te pregunta de donde sos, que les decís?

J: oh [risas] 'oh boy'... cuando estoy acá, eso es interesante... cuando estoy acá en Canadá digo que soy argentina pero que hace mucho tiempo que vivo acá, pero cuando estoy afuera y la gente me pregunta de donde soy, tiendo a decir que soy de Canadá ... y de Argentina ... porque cuando estoy en otros lugares me pasa que me identifico más con esto, con donde estoy que con Argentina, entonces por ejemplo ... 'nací en Argentina pero vivo en Canadá, y es ahí donde tengo mi vida'."

Juliana

$P$ : "When people ask you where are you from, what do you tell them?

J: oh [laughs] oh boy... when I'm here, that's interesting... when I am here in Canada, I tell them that I'm from Argentina but that I've been living here for a long time, but when I'm somewhere else and people ask me where I'm from I usually say I'm from Canada ... and from Argentina...

because when I am in other places what happens to me is that I identify more with this, with where I am now than with Argentina, so for example... 'I was born in Argentina but I live in Canada, and it's here where I have my life.'”

Juliana

As Stuart Hall ([1996] 2000) reminds us, identity is always part of a narrative: it is positional and strategic, attached to context and time. He reminds us that identity is always in the process of becoming, and that this happens as we interact with others, within our location at a given historical time. Juliana, as many other Argentinian immigrants living here in Canada, speaks to Hall's notion of identity as positional and contextual. In this chapter, I concentrate on how the identities of Argentinian immigrants to Canada are, as Hall stresses, in a continuous process of becoming as we interact with various 'Others' in a given context. 
Who am I? Where am I from? These are simple yet universal questions. For the immigrant, the 'who' becomes intrinsically linked to the 'where' in a quest to redefine the 'self' in the new social world.

Conducting research for this thesis, I came across many immigrants who started re-considering their 'who' as they re-established their lives in Canada. They spoke of how the immigration experience changed, and continues changing them; of how at times the experience of migration calls for a 're-invention' of the self. Therefore, in order to better understand the identity formation experiences of Argentinian immigrants to Canada, we need to understand processes of becoming as well as the role of Othering within these processes.

This chapter is concerned with gaining a better understanding of the experience of identity formation of the Argentinian diaspora as one that comes into being through the processes of identification and splitting. Hall argues that as we get to understand who we are through understanding our many points of similarity with a given culture, we ought to also unveil those "critical points of deep and significant difference which constitute "'what we really are'; or rather - since history has intervened - 'what we have become"" ([1993] 2003, 236). Hall reminds us "cultural identities come from somewhere, have histories. But like everything which is historical, they undergo constant transformation" (Hall [1993] 2003, 236). In trying to understand the identity formation experiences of Argentinian immigrants, Hall's notions of identification and differentiation are particularly significant.

The overall argument of this thesis is that the case of recent Argentinian immigrants to the National Capital Region exhibits the fluidity of diasporic identities. I 
argue that the 'new' identities Argentinian immigrants have formed in the new social context are characterized by a strong identification with the newly encountered social world, while at the same time, selective elements of their previous identity are preserved. In addition, as the process of identification occurs, 'new' identities are further developed on the basis of differentiation, where Argentinian immigrants 'split' from three key referential 'Others', namely other Argentinian immigrants, Latin American immigrants and, other 'Others' such as immigrants and minority groups at large.

During the course of my research, I heard Argentinian immigrants speak of a sense of identification with Canadian values and lifestyle while at the same time they spoke of an increasing sense of differentiation from 'Others', even those who are arguably quite similar to them. This process of differentiation appeared to grow stronger with time as their sense of identification with the Canadian context strengthened. The integration and 'blending in' of this group, I argue, is a process that for most of the participants involve the making of a decision as illustrated by this quotation:

Veronica: We came mentally prepared, we came very happy; we came with a concrete plan, which was to find a job, not to question the fact that we were immigrants, what for?

However, the 'positive' integration the majority of the participants speaks of, is also conditioned by their racialized, classed and perhaps even gendered positioning in Canadian society. For many, integration requires a departure from the 'former' Argentinian identity and from nostalgic longings in order to embrace the new identity.

The context of the conversation with Veronica suggests that the link between finding a job and not questioning the fact that they are immigrants meant a willingness to work at whatever is available even if this meant doing jobs that require a lower skill level to that required to immigrate to Canada. Like many other research participants, Veronica 
is aware that in a new country one is going to have to make some 'sacrifices' or even have to start all over again. However her 'decision' was to make a commitment 'not to question her positioning in the new country'.

If I were to base the conclusions of my research exclusively on what the majority of research participants say, I would tell the story of a group of immigrants who have 'successfully' adapted to Canadian society, who consider themselves well integrated and who are happy to contribute to a country that has welcome them. However, there would be two major problems with this story. The first is that it would say little about how participants' narratives are fraught with internal contradictions revealing the depth and complexity of the identity formation experiences. The second is that I would be purposely singling out the narrative of the majority while silencing the experience of the minority. In carefully considering the emotional responses shared during the interviews, I was able to grasp a deeper understanding of the integration experience, and its link to the development of their identities for both the majority and the minority.

This chapter has two main sections that aim to present participants' narratives of their identity formation experiences. The first section focuses on the Argentinian experience in the context of immigration to Canada by looking at how this group has either identified or differentiated from other groups, namely 'Canadians', fellow Argentinians, Latin Americans, and other racialized immigrants. The second section explores the emotional aspects of the immigration experience by arguing that emotions (positive, negative, ambivalent) are social and material (Ahmed 2004) as well as constitutive of diasporic identities. 


\subsection{Argentinian Identity Formation Experiences in the Context of Migration to}

\section{Canada}

With only one exception, all interviewees self-identified as Argentinians while making also references to their provinces of origin (especially those who come from other provinces than Buenos Aires). While many participants made references to their European ancestry (especially those who have a European last name), this does not mean that they self-identify as European-descent Argentinians, rather they do so as Argentinians. And yet when few of them would make references to their families' origins, the first point of identification remains Argentina, not Europe.

In what follows, I turn my focus to the experiences of Argentinian immigrants in the Canadian context by looking into their notions of adaptation and integration in the new social context as these are closely related to their identity formation experiences through the processes of identification and differentiation that Stuart Hall, Frantz Fanon and Homi Bhabha refer to.

In Chapter 1, I referred to Bhabha's analysis of Fanon's three conditions that underlie an understanding of the 'process of identification' ([1994] 2000). Central to Fanon's process of identification are the notions that individuals exist in relation to others and that the place of identification is also a space of splitting where those points of differentiation give us an identity. In looking at the case of Argentinian immigrants to Canada, we can appreciate how these processes unfold through identification with the 'host society' and a differentiation from points of similarity and familiarity, that is, a departure from Argentinian-ness, Latin-American-ness and other immigrants. 


\section{Identification with Canadian Lifestyle and Values}

While the majority of research participants say that they either strongly or somewhat identify with Canada, only three of them identify as Canadian. The distinction is important. One would assume that if someone identifies strongly with a context, he or she would also develop a sense of belonging. However my research shows that for Argentinian immigrants, there is a difference between seeing yourself 'as one of the group' and seeing yourself as living and 'functioning well' within the group by accepting and embracing their values, rules, norms and lifestyle. A clear example of this is Camila, who has been living in Canada for over ten years and identifies with Canadian values and lifestyle but continues self-identifying as Argentinian, never as Canadian:

Pamela: When people ask you where are you from, what do you tell them? Camila: from Argentina

Pamela: have you always self-described that way?

Camila: Yes, yes, it's always been like that. I'm not the kind of person who says Argentinian but Canadian citizen, or... no, I'm Argentinian and if people start inquiring about my status I say I have my citizenship since 2005 but it's not something I identify with.

Pamela: did it ever happen to you that you said "I'm Canadian"?

Camila: no, never... no, never.

When I first started thinking about this research, I envisioned that if not most, at least many people would rehearse a nostalgic narrative in which they would romanticize the homeland and be critical of the new social setting. However I found that research participants speak positively of their immigration experience and consider themselves well integrated into Canadian society. This notion that Argentinians are well integrated into Canadian society is further strengthened by 'official' discourses. For instance, at an event sponsored by the Argentinian Embassy in Ottawa, this is what one of the officials said in a speech addressing Argentinians living in Ottawa who were present at the event: 
Embassy Official: The Argentinian community is comprised of professionals (lawyers, doctors, academics, scientists, psychologists, artists, etc.) who have had an excellent integration into Canadian culture and society. (Field notes, December 6, 2012)

In asking research participants why they identify with Canada, most said that they identify with the normative values of the country. For instance, one quoted the Canadian Citizenship Guide and said she identifies with the values promoted on that document. Others mentioned that their values and personalities fit better in Canadian society where 'predictability', 'order', 'punctuality', ‘professionalism', 'stability', ‘freedom of speech', 'promotion of tolerance', 'zero tolerance to violence', etc. are values promoted by the government. For these participants this is a sign of 'the proper functioning of institutions' and evidence that 'the Government works towards the wellbeing of people'. These ideas reflect the importance they give to feeling that they live in a society where order, safety, and predictability prevail. For many of them, a sense of identification with Canada grew stronger with the observation that these values are either absent from or deteriorating in their country of origin, especially as these elements remain important to their well-being, and are part of their identity. For instance, a research participant mentioned that he no longer identifies with certain aspects of Argentinian culture (e.g. the lack of respect towards seniors, the lack of manners and order, etc.) and that he feels it is 'natural' for him to live in Canada where he feels his way of behaving is the norm rather than the exception (e.g. being punctual, being professional and respectful, respecting norms and regulations, etc.). In a sense, these participants appreciate the Canadian lifestyle and identify with what they see as the values of Canadian society, and they do so while rejecting the lifestyle and values of their country of origin.

While participants emphasize a strong sense of identification with the Canadian lifestyle, few Argentinians consider themselves Canadians. For many participants this is 
because their sense of belonging remains at the level of emotional attachment, which they maintain with their place of birth. Their emotional attachment to the homeland overrides participants' rejection of those things from their homeland they don't identify with. While many Argentinian immigrants feel very positively towards the Canadian context, they rarely feel a complete sense of belonging. In response to a question about selfidentification, this is what Sandra said:

Sandra: Ahh I say from Argentina, I say from Mendoza, because this is where I've lived most of my life and it's where I have all my family and I have my feelings there [...] but what happens to me is that being a Canadian citizen gives me a lot of satisfaction because I really like the country, how it works, I love it [...] but I haven't gotten to the place where if someone asks me I say 'I am Canadian' especially because of the accent [...] because when I speak they know that I am not Canadian, that I am an immigrant.

While only three participants self-identify as Canadian, two of them even from a very early stage, and one of them before acquiring Canadian citizenship, the majority stress they don't self-identify as Canadian. Several of them refer to not being born here as the reason why they don't think they are Canadians in spite of holding Canadian citizenship (an example of this narrative comes from Camila and Sandra as illustrated in the previous quotations). Furthermore, these participants stress that the mere fact of being asked "Where are you from?" is a clear indication, and a reminder, of difference. Yet for other participants, self-identification is tied to context. Estela provides an example of this kind of contextual self-identification:

Estela: It depends on where I am. I don't always have the same answer, it's not that I'm lying, it depends on the context.

While different research participants offer different responses to the question of self-identification, it is clear that while positional and fluid, self-identification remains primarily attached to the place of birth rather than the place of residence. Furthermore, a 
defining element of participants' identity is the notion of belonging and the affective and emotional connection that these immigrants continue to have towards the homeland.

With a few exceptions, it is interesting that participants 'fail' to recognize their European ancestry (whenever this applies, which is the majority of cases) and their skin color as elements that play a role in their positive integration experience.

We should not ignore the fact that the majority of those interviewed made the decision to move to Canada seeking not only their economic wellbeing but also because of increasing dis-identification with the social, political and cultural context of their homeland. These aspects presumably make them more eager to accept the migratory change and purposely seek integration. Having an open mind towards Canada's values and lifestyle clearly plays a role in how immigrants are perceived and in some cases welcomed, however we should not jump to the conclusion that acceptance and integration are merely a matter of a good predisposition. Rather we need to consider their structural dimensions, that is, how these dynamics fit within existing stereotypes that render certain groups more 'acceptable' than others. In talking to research participants, it is clear that many of them fail to see that their experiences are tied to how they fit within existing stereotypes. In addition, while they recognize the influence of their conditions of entry to Canada (that is, as skilled workers, professionals with a fairly high level of education and language proficiency) and their 'positive immigration experience', it is not all that evident to the majority of participants that all of these aspects (white ethnicity, level of skills and 'positive' integration) are interconnected within a system of racial hierarchies that is deeply entrenched in Canadian society. 
In the next chapter I will further discuss the various dynamics of inclusion and exclusion and how the Argentinian experience 'fits' within these. At this point, it is worth noting that when participants are asked where they consider they 'fit in' within the various groups in Canadian society, they rarely reply by making reference to their racialized positioning within majority or minority groups. In fact, they tend to identify with the large white majority (mostly anglophone but at times francophone), failing to see themselves as a white minority group within the white majority. It is clear that these responses are tied to their historically constructed identity. The discussion in Chapter 1 pointed to how the historical and discursive processes of identity formation in Argentina have constructed Argentinian identity as a 'white' race of European descent. Participants mention how they 'blend in' due to their appearance and a few of them make reference to this as an advantage. The great majority of them understand the notion of exclusion and discrimination exclusively in racial terms, which is why so many of them sustain that they are not discriminated against. To them, this is seen as further validation of their testimonies of positive integration.

Along with reflections on their positioning within Canada's groups, participants offered their opinions about multiculturalism. These are, in general terms, mixed. Six participants hold a positive view; three participants hold a mixed view, two hold a negative view, and finally three participants hold contradictory views (one of these participants leaning towards a negative view and two leaning towards the positive side). The six participants holding a positive view of multiculturalism emphasize that multiculturalism fosters a culturally richer society where they have the opportunity to come in contact with many cultures and diverse people. These opinions are, in my view, 
linked to the group's identification with the white dominant group as this tends to be a 'majority' view. As the majority of this group identifies with the dominant racial and ethnic Canadian majority, they also echo the dominant position. Three of those six participants, however, remark that although they like multiculturalism, they do recognize some of its flaws. For instance, they mention that it is difficult to 'put limits to culture' as certain cultural practices seem more acceptable than others to them. For instance, their understanding is that it is okay for multiculturalism to provide a platform to showcase a diversity of cultures as long as 'these people' are not resisting integrating by not being willing to learn the language, for example, or conforming to society's norms in other ways. Again, these narratives provide an example of how, as this group identifies with the white dominant group and positions themselves as being or being with the "owner", the "manager of the nation" (Hage 1998), they also echo the dominant liberal or conservative position.

Three research participants held mixed views emphasizing there is 'still a lot to be done' and stressing that they see multiculturalism as problematic in so far it weakens a sense of national identity. These participants struggled with their own opinion of multiculturalism as they recognize that this is problematic for themselves and their place in Canadian society. However, they point to the fact that in a society 'where everything seems to go', there is much confusion about boundaries and norms and that, in a sense, they hope for a more homogeneous society (an example of this kind of narrative comes from Juliana). When comparing Canada's management of ethnic diversity to that of Argentina, Latin America or the United States, some participants emphasize that with all 
its shortcomings, multiculturalism in Canada 'does a great job'. An example of this narrative comes from Estela:

Estela: I think they do a formidable job, uhm... I like it as an idea, which doesn't mean that there isn't... uhm, that I don't find that taken to certain... I mean, with this I'm not saying that there isn't conflict and that the severity of conflicts is high, and that maybe there are limits to integration, I think that there probably are limits to people's capacity for integration, I'm not an expert on that but there are certain differences which are difficult to bridge, but anyways I think they do an excellent job.

Two research participants, however, hold a very negative view of multiculturalism, pointing that "it may be a great idea but it doesn't work" (Camila) and that "it may work as an idea, as a discourse but I don't feel it, I don't perceive it as real, I think that there is a dominant culture" (Daniel). Finally, three participants hold contradictory views. For moments they emphasize that they 'like' multiculturalism but then reflect on how they also see it as "hypocritical" (Veronica) as a policy that "hides what really goes on' (Juan Manuel and Veronica). They acknowledge that the policy has a number of positive aspects (e.g. that it deals with minority groups better than in other societies), however they think that multiculturalism many times acts as a curtain that covers what really goes on. An example of this kind of narrative comes from Maximiliano, who first said he likes multiculturalism but later in the interview concluded:

Maximiliano: it really bothers me this whole thing about multiculturalism, I think it's very... very... ehm... how could I say, I think it's a technique to maintain the political evolution of this country well under control by an elite, by Montreal's Anglophone elite and an Anglo and Francophone elite from Toronto to Ottawa, that complex elite compound is the one that dominates this [...] for you it's ok but for others not, that's what multiculturalism hides.

In these cases, participants are able to capture the notion that while their own experience as 'Others' is not depoliticized by multiculturalism, there are others who are 
more disadvantaged by a policy that celebrates diversity within the parameters of yearly cultural festivities.

The previous analysis suggests that there is a link between 'whiteness' and narratives of positive immigration experience. Furthermore, these two elements are tied to notions of successful integration to Canadian society. I am not necessarily suggesting that white ethnic minority groups automatically have higher chances of identification with Canadian lifestyles and values, rather, I argue that the 'unmarked white centre' (Mackay 2002) of Canada's multicultural society and the conditions of entry of Argentinian immigrants to Canada actively incorporate this group (an ethnically white minority group) as an ally of the nation. In doing so, these immigrants position themselves as being with the 'owner' of the nation and rehearsing the dominant position. In this regard 'unmarked whiteness' and white privilege favor the immigration experience of this group, strengthening their sense of identification with Canada. These points of identification are linked to existing stereotypes constructed within fixed racial hierarchies.

\section{Difference and Splitting from Argentinian-ness, Latin-American-ness and 'Others'}

As previously mentioned, the place of identification is also a space of 'splitting' where our differentiation from others is what gives us an identity (Bhabha [1994] 2000, 99-101). In trying to understand the emergence of a new Argentinian identity in the context of immigration to Canada, we need to consider how Argentinian immigrants have split from elements of the 'former' Argentinian identity and differentiated themselves 
from 'Others' in order to embrace the development of new identities, one which now incorporates elements of the new social context.

The experience of Argentinian immigrants to Canada cannot be referred to as one where the preservation of a group identity through efforts to form associations and/or organized communities has taken place, at least not in the geographical context of the current research. I suggest that the case of recent Argentinian immigrants to the National Capital Region is one where new forms of identities emerge, and that they exhibit the fluid and developmental features of diasporic identities. These 'new' identities are characterized by a strong identification with the newly encountered social world while selective elements of the previous identities, which are meaningful to the individual actor, are preserved. At the same time, I argue that 'new' identities are formed through 'splits' from three key elements. The first is a distancing from similarity and familiarity, where elements of the Argentinian identity and lifestyle are left behind in order to embrace new ones encountered. The second distancing occurs from another element of familiarity, that is, a differentiation from the Latin American culture with which Argentinians undoubtly share a number of similarities (such as language, religious and family values, among others). A third 'splitting' occurs from other immigrants, with whom Argentinian immigrants, purposely at times and unconsciously at others, differentiate from and fail to see a shared experience.

\section{Distancing and Splitting from Other Argentinian Immigrants}

One would assume that, while some people may have personal reasons to avoid members of the inner group, the majority would look for opportunities to reconnect with 
those like them when abroad seeking the comfort of familiarity. However, my research shows that while many of the interviewees may have developed, over the course of their years in Canada, small circles of friendships with other Argentinian immigrants and other Latin Americans, it does not appear that sharing a place of origin forms the basis for relationship building and association. Furthermore, in the particular case of Argentinians, these immigrants do not belong to any formal community associations. When asked about their friendships, their habits and ways in which they preserve their Argentinian roots and costumes, either publicly or within the privacy of their homes, some participants explain that there are various reasons why they decide to distance themselves from associating with other Argentinian immigrants and instead embrace new relationships. An example of this narrative comes from Veronica:

Veronica: When moving here, we purposely decided to stay away from the Argentinian community because we didn't want to have anything to do with the Argentinian or the Latin American community. We came here to meet [people] and [get to] know [the country], we came to integrate, not to isolate ourselves.

Veronica's case is interesting. She came to Canada with another member of her family. When she moved to Canada she had to start a new life and was determined to have a successful immigration experience, to get to know the people, learn the language, explore the country and the culture. Since then, Veronica has formed her own family and although she says her experience wasn't easy, she considers that one of the key aspects of her successful integration was to make an effort to meet new people and get to know the new environment rather than to 'hide' among what was familiar to her. This, according to her, along with a strong desire to leave behind her life in Argentina, is what allowed her to make Canada her new home. 
In order to better understand the motivations behind many Argentinian immigrants' determination to have a positive immigration experience, we need to make references to the conditions under which so many of them left the country. While the country's earlier experience of military dictatorship (in the 70s) is still very much alive in the memory of Argentinians, this is not usually brought up in the interviews as a basis for negative perspective of the current situation in their home country. The years surrounding the economic crisis that hit Argentina in the year 2001 are characterized by an atmosphere of severe distrust in the political class and in the State as an institution. The political and economic instability of the country was accompanied by a profound social and cultural transformation that is often framed by Argentinians (both immigrants abroad and residents) as a 'decline of the Argentinian nation' in the most encompassing sense of the term. As many Argentinians saw their country 'fall apart' many of them left the homeland seeking a better place to leave, seeking safety and stability for themselves and for their children. For example, Lautaro says that he left Argentina because 'he was looking for a place where he could dream'. Others point to how values were changing and they no longer felt they fit in such an environment. Some are more explicit and express their strong rejection towards what has become of Argentinian culture. While most research participants explain that their connection to the homeland remains mainly on the basis of emotional ties, which they maintain with their families and close friends, the majority of them speak of a deepening sense of non-belonging. As their homeland went through decades of transformation, many of them feel they no longer fit in what their country has become. 
Other research participants explain that on arriving to Canada they made an effort to distance themselves from other Argentinians and/or Latin Americans in order to increase their chances of learning the language and avoid 'forming a ghetto'. According to these participants, when immigrants form these close groups where they only interact with immigrants like themselves and only speak their native language, the chances of integration are reduced.

Even when many Argentinian immigrants pursue small, informal cycles of friendships with other Argentinian immigrants, many of them purposely avoid any kind of formal group association. While for other diasporic groups it seems 'normal' (and one could perhaps argue necessary) to organize more formally to celebrate and embrace their cultural origins, Argentinian immigrants to the National Capital Region do not seem to have succeeded in establishing a united and active Argentinian community organization.

Research participants have opinions to share about why they think Argentinian immigrants do not seem interested or able to organize themselves more formally. In general terms, the observation is that people have 'little' interest in finding other Argentinians because of various reasons. Among the reasons for example participants mention that rather than having an interest in developing relationships on the basis of nationality, some are more interested in establishing friendships on the basis of affinity. In other words, they identify with those with whom they share the same values, interests, and similar level of social capital: 'someone they felt they can talk to' they say, with whom they can carry an interesting conversation. These preferences are also strengthened by the fact that these participants tend to have a high level of proficiency in English and/or French due to their professional status and this is a major factor in their ability to 
interact with non-Latin Americans. Others mention that they simply don't feel the desire or interest in finding other Argentinians while others explain that since they left the country because they no longer identified with it, they didn't come to Canada trying to find what was purposely left behind. Others express the desire to belong to a group of Argentinians but simply haven't come across people they feel comfortable with or whom they would choose as friends back home so they don't feel they have to establish a relationship here simply because they share a nationality.

Two-thirds of participants, however, make references to some group characteristics, which they don't want to associate with. As examples they mention the "competitive nature of Argentinians", the lack of solidarity toward members of the inner group, the persistent criticism and gossip that characterizes group associations, among others. For example, Martin has an interesting view on this. He moved to Canada in 2007 and has since formed a robust group of Argentinian friends. He is also well integrated into Canadian society. In Canada he pursued graduate studies, has a 'Canadian' job, and has formed an extensive network of people, which includes Anglo and French Canadians, Argentinians, Latin Americans and other immigrants. He also established strong emotional ties with people from different backgrounds. When asked about those he has relationships with, he says that he enjoys his friendships with other Argentinians but that this does not mean that he wants to isolate himself on the basis of being Argentinian. On the contrary, he likes to relate to different kinds of people. He also explains that one of the reasons why he is not interested in forming part of an organized Argentinian community and association is because he heard that there tends to be a lot of conflict and discrepancies: 
Martin: When I heard about that (he's referring to the conflicts) I said, I don't want to have anything to do with soap operas, with psychodramas so... I've always been more about the one on one relationship or having friendships with other couples, I feel this way I have more control over the situation you know? The relationship is much stronger, if not I find I end up talking about superficial things, mundane things, which I'm not even interested in...

[Then he continued]

I don't know why in these meetings of Argentinians there's always the anti-Canada one, that group dynamic is interesting... there is always someone, you know... the leader, anyways, there's always the anti-Canada one.

[Then he continued]

I'm not very fond of those Argentinians who want to re-establish Argentina here.

Many research participants stress that they prefer to associate with 'people similar to them' rather than with other Argentinians, other Latin Americans and/or other immigrants with whom they don't find points of similarity. They explain that for them the country of origin is not as relevant as for instance education level or overall 'cultural' level. For instance, they mention that they feel more comfortable and identify more with people they feel they can have interesting conversations with, with people who share similar interests to them, people who are open to cultural differences, etc. They do not frame these points of similarity in terms of class although there are clear links between class status, education levels, and overall cultural level as this is related to access to opportunities.

While research participants do not identify these points of distancing as a sign of dis-unity but rather as a more coincidental occurrence, often the description of how they feel towards other Argentinian immigrants expresses the notion that lack of solidarity and dis-unity are traits of Argentinian-ness. It seems that these traits carry on and continue their course in a new geographical location. This notion is further supported by a blurb 
found on a web page, which promotes cooperation and solidarity among Argentinians in Canada, by identifying certain assumed traits:

Argentinian professionals are very well trained and capable professionals spread out on the Globe. We have the tendency to be independent and silent between us, consequence of our cultural background and prejudices. Let's celebrate our professional and business capabilities and successes with others. This group is a first step to connect each other. No matter what your profession is, whether your are an engineer, lawyer, doctor, artist, actress, actor, journalist, accountant, owner of a business, etc. if you have a position of empowerment, and wish to help colleagues or compatriots to develop relationships and professional visibility, this is the site for you to use". (From the website "Profesionales Argentinos en Canada. Date retrieved December 3, 2012. http://www.linkedin.com/groups/Profesionales-Argentinos-en-Canada-

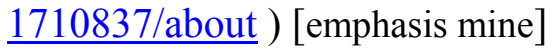

As shown by the previous quotation, the 'tendency to be independent' which is often portrayed as a 'consequence of our cultural background and prejudices' appears as a recognized and assumed characteristics of Argentinians and, arguably, as one of the reasons why Argentinians 'tend to be silent between [them]'.

\section{Splitting from Latin Americans and 'Others'}

With a few exceptions, the majority of research participants failed to self-identify as Latin Americans. Furthermore, when asked about their relationship with other immigrants and with Latin Americans, several explain that in an effort to adapt and integrate, many of them decide to break from that which is familiar to them including those who speak the same language. My research shows that the relationship between Argentinians and Latin Americans, or between individuals belonging to these two categories, is one where there tends to be a lack of mutual identification. This seems to foster a sense of non-belonging to each other's group identity. When asked how he selfidentifies, one research participant said that he is "from Argentina, I never say Latin 
American or South American, even though we are". It seems that among Argentinian immigrants, there is the notion that 'we don't see ourselves as Latin Americans'.

While Argentinians are Latin Americans not only on the basis of geography, but also due to cultural proximity and similarity, this lack of mutual recognition and identification can be traced to nation building discourses which aimed to distance Argentina from Latin America, as discussed in Chapter 1. While it might be expected that, in a new and foreign environment, Argentinian immigrants would feel closer (at least on the basis of a shared language) to those who are similar to them, this is not what the majority of research participants expressed during interviews.

Even when the countries share a number of common characteristics, there are also tensions, which reflect the differences between them. In the case of Argentinians and Latin Americans, these tensions have strengthened the boundaries of difference. For instance, while some Argentinian immigrants do express a sense of belonging to the Latin American collective, they also emphasize that they are not recognized as members of this group. An example of this kind of narrative is provided by Daniel who, when living for several years in a Latin American country emphasized that these kinds of exchanges occur quite often:

Daniel: I remember a few times having told a taxi driver for example, I'm not a gringo, I'm Latin American just like you, and he told me, no, you are not like me.

I suggest that these exchanges are a product of a relationship that has been historically poorly managed clearly having repercussions in the way Argentinians and other Latin Americans relate to one another. Juliana, refers to 'the things that are not said' but which can be perceived when referring to this relationship:

Juliana: And then, with the whole latino thing, I don't know, as I was telling you before, I don't consider myself latina because for me the culture is so different and generally I 
don't feel like I really fit in because, for example, if I were to become a member of the latin community, I don't really fit in and people make you make you aware of it you know? Even when they don't say it, there is something that tells you that you don't belong...

Pamela: What is it that makes you think or feel that you don't fit in?

Juliana: Well, in part for being Argentinian, I think... I don't know is just different ... well and then there is the whole thing that people usually, as a first impression, they don't like us, or... you know, all that, and thirdly, because again, it's a mix so weird that you end up not being one thing and not being the other so you are somewhere in between ... so that's why I would be more interested if there was a group, an Argentinian community here because it would be more my situation you know? Like, you left Argentina, you have that part of the culture but you also understand this one, that would be nice, but anyways, there isn't such thing...

My research also shows that, in addition to a lack of identification with other Latin Americans, participants' identification with other minority groups such as immigrants from other regions is also weak. Again, in general terms, the lack of identification with these various 'Others' seems to be strengthened by their efforts to belong to the majority and the desire for adaptation and integration. For some of them, the lack of identification comes from not seeing themselves as immigrants in 'racial terms', that is, due to the fact of being a 'white ethnic' group. At other times participants emphasize that since this country is 'full of immigrants' and somewhat well equipped to welcome and integrate them, the condition of 'immigrant' is not something that they feel they are constantly reminded about.

While most research participants speak of occasions when they feel 'strange' or 'foreign', they explain that this is related to encountering new experiences and trying to make sense of the new social context. For example, many of the entries in Guillermo's blog, are an attempt to make sense of the new social world, its rules, its norms, its 'do's' 
and 'don'ts ${ }^{25}$. In trying to understand this lack of identification, it appears that many Argentinian immigrants reject the negative association that themselves or others make towards the notion of being an immigrant. Some of them mention that in reviewing journals written in the year when they immigrated to Canada, they used to write things such as "I hate being an immigrant" and that now, ten years or so later they are still aware that they are immigrants "but the word is no longer a burden for [them]". When asked about such preliminary notions, people mentioned that part of the reason they disliked the term was because of negative expectations and associations (such as being 'fresh off the boat'), which were things they did not identify with.

Notwithstanding, it is interesting to see how the identification with the notion of being an immigrant is very fluid for Argentinian immigrants. While many of them stress that they don't self-identify as 'immigrants' or they don't 'overthink' their status as such, they clearly refer to themselves extensively as 'immigrants' during the interviews. In my view, the recognition, or lack thereof, of being an immigrant is very much tied to context. It seems that when the context for the discussion refers to the negative connotations of the term 'immigrant', participants more or less resist the association with the exception of those who see themselves as target of some of these negative connotations of being an immigrant (e.g. being excluded from certain things). This is clearly linked to the resentment towards the racialized stereotyping of immigrants which conflicts with research participants" understanding of their "racial" status. However, when the notion of being an immigrant is raised in a context where the term doesn't come with its negative

\footnotetext{
${ }^{25}$ For more on the blog, visit http://loszieglerencanada.com/. Particularly interesting entries can be found under the categories: "How is Canada", "The Winter in Canada", "Studying in Canada", "Health in Canada", "Working in Canada", "Read First", "Living in Canada" and "Uses and Customs in Canada"
} 
associations (e.g. in 'cultural celebrations' when bringing in the 'ethnic' dish to the office pot-luck is a reason for celebration), Argentinian immigrants do not express such rejection towards this label.

Others mention that knowing that they are immigrants makes them feel obliged to act in a certain way but that as time goes by and they better understand their place in society and what are the expectations of them, they adjust and start feeling more positively about it. My research shows that while the majority remains conscious of the fact that they are immigrants, they also differentiate from the notion of being an immigrant. Martin for example says:

Martin: I don't deny my condition of immigrant but neither do I go around waving the immigrant flag, I mean, I don't want to say I'm not proud of it because it would be as saying I'm ashamed of it.

While Argentinian immigrants are aware they belong to various categories, namely being Argentinians immigrants, being Latin Americans, being members of the larger immigrant group, it seems that in an effort to re-build their lives here in Canada, they interpret this as a need to split from many of the things that are familiar to them in order to make room for new things. This desire to belong and integrate is also strengthened by emotional practices, as discussed below.

\subsection{On the Fluidity of Identity and the Emotional Connection}

Maruška Svašek proposes that "emotional processes shape human mobility and vice versa" $(2010,865)$. She argues that mobility (migration) and emotions are mutually constitutive for it is the emotional responses to our environment and the social structure which often give rise to decisions to leave our home country in search of a new one. She stresses that we need to better understand "how can we conceptualize emotions and to 
what extent are emotions of immigrants influenced by structural constrains" (Svašek 2010, 865).

I agree with Svašek's theoretical positioning, which identifies affects and emotions as central features of international migration, and understands emotions as aspects of a dynamic processes where "[t]he self $[\ldots]$ is neither regarded as a closed container of passions, nor as an entity that simply reacts to forces from outside, but rather as a multiple, relational being-in-the-world that is captured by his or her surroundings, engaging with past, present and future situations" $(2010,868)$. These ideas show up very strongly in this research. Furthermore, participants' emotional accounts of the immigration experience suggest that their identity formation processes are interconnected and mutually constitutive. In this final section, I want to discuss how Argentinian immigrants' processes of identity formation are interconnected to their emotional responses by looking at the various stages of their migration and integration experiences.

When Argentinian immigrants made their decision to leave their homeland, more often than not, this decision was based on a number of 'practical' concerns, as well as a result of their emotional reaction to their personal circumstances and the social context. Their emotional responses were linked to structural constraints among others that shaped their lives. In some cases, participants made the decision to leave Argentina for other reasons (e.g. because of emotional attachment to family members who made the decision to migrate, this is the case of those immigrating as members of the family class). However, in the majority of cases it was the economic, political, social and cultural circumstances that Argentina was going through that made people consider other options (e.g. severe and increasing unemployment; banking crisis, rising levels of corruption, 
institutions 'falling apart', etc.). Finally, at other times, it was a combination of personal circumstances, which coupled with an increasingly deteriorating context, motivated participants to leave rather than to remain in circumstances of turmoil and crisis.

As Argentina entered the economic crisis of 2001, many research participants felt 'forced' to look for options to leave. However, most identified a combination of circumstances that grew over time, lasting up to a decade prior to their actual departure rather than referring only to the economic crisis. For Lautaro, for example, the reasons that made him search for another place were not based on a desire to attain a better economic position but rather because he was "looking for a healthier life". Lautaro is an example of a professional Argentinian who was overall doing well when he decided to leave Argentina. He had a good job, a good family, and enjoyed a fairly good economic position but Lautaro says that the reason why he decided to leave Argentina dates back to many years ago when he temporarily lived abroad and started realizing that he "was pretty disappointed with Argentina". He explains that the reasons for his disappointment were found in how much he had changed while living abroad and how the experience had brought him to a point of realization that the country he thought he belonged to was a "mere construction and imagination that had little to do with reality". He spoke of how when being abroad "[he] found himself and [his] relationship with the world" and how a return to Argentina represented a "cultural shock and of identity". While Lautaro's circumstances are very personal and unique, there seems to be a persistent element in the narratives of those who made the decision to leave Argentina and this is the increasing feeling that they 'didn't fit' and 'didn't identify' with the context they were living in. 
For some of them, the search for a new place started as an adventure, without knowing whether they would stay in Canada, go back to Argentina, or search for yet another place. For others, the commitment to make Canada their new home is so strong that they do whatever is necessary to "make it work", and to "not look back". In the case of this last group their dis-identification with their own country has grown so strong that it has given rise to emotions of rejection, shame, embarrassment, and at times, anger over seeing how their homeland has become a place where they no longer feel they belong. Martin says that "what happened in Argentina (he is referring to the political and economic crisis of 2001) made [him] a bit angry" and that if here in Canada someone is to confuse him with European, he would be "a bit happy" (Martin has a European last name). This is one of many examples of how the hostility of their own environment drove them to find a new place.

For Estela, her decision to leave Argentina was strengthened by the crisis taking place in Argentina. However, in her case, the decision to "look for life outside" was based on a combination of personal and social circumstances. She explains that the last years prior to her departure, due to personal and private circumstances she felt she was "ok on the outside but on the inside, she felt she was ripping apart":

Estela: I really needed to make a fundamental change in my life, there was like an internal scream, because everything that was going on around me was pointing to what was going on inside me.

For many participants the decision to look for another home grew out of a strong sense of non-belonging, a lack of identification with the values, the context and the situation of the country. In many cases, it was this sense of isolation that made them not only look for a new place to live but also, to establish the strong connection and 
identification that many of them developed when coming to Canada. Many of them find in Canada a stable, secure home, as well as a lifestyle and values they feel 'fit' their needs and their identity. While most participants recall that, especially at the beginning, the migration experience was challenging, for most of them it also means an opportunity to start anew, something that many see as positive.

In one of his blog entries, Guillermo reflects on the notion that the immigration experience can be understood as "an opportunity to start a new life, to leave behind some things in order to begin new ones":

I was thinking about the dozens of people who have found in Canada the opportunity to re-invent themselves, to be who they couldn't be or to become that which they had left behind [because of lack of opportunities]. Or those who came to find something new, which they hadn't even imagine. I think of us who, through the immigration experience, have had the opportunity to get to know ourselves exactly as we really are: to get to know ourselves again with our strengths and weaknesses and to re-discover ourselves as persons. (From the blog Los Ziegler en Canada. Entry: Resucitar a travez de la inmigración, la promesa de una nueva vida on April 8 2012. Date retrieved January 8 , $2012 \mathrm{http}: / /$ loszieglerencanada.com/2012/04/08/resucitar-inmigracion/)

While this is the experience of the majority of research participants, it is important to also voice the experience of those for whom the experience is different. For these, in the face of a sense of partial identification and a strong sense of non-belonging and isolation, the emotional connection has not unfolded positively but rather in an ambivalent and at times negative form. More often than not, this is the experience of those participants arriving under the family category. These participants feel that their migration to Canada was not the result of a personal decision but rather of a set of circumstances beyond their control. What is problematic for this group is that, for diverse reasons, going back is no longer an option and they find themselves living their lives in a place where they feel they do not belong and where their sense of identification and 
familiarity is weak. Some of them speak of a sense of loss of identity because they feel the relational and positional elements that constituted their former identity are absent in the new location. They feel they have little relation to their immediate surroundings. While they have been able to 'rebuild' their lives in Canada, in the sense that they found employment, often pursued further education and developed various kinds of relationships, they also feel a profound sense of lack of deeper meaning in their lives, and the notion that they merely 'function' in society. Perhaps coincidentally, these four participants are the only ones in the research who speak nostalgically about their homeland and hence are much more critical of the Canadian context. Furthermore, they see their immigration experience as quite traumatic and as the main impediment to rebuilding fulfilling lives in Canada.

Speaking of 'complete integration' or 'total isolation' is not appropriate for either group. Rather, the experience of research participants is one where either integration or dis-identification is the stronger experience although the other remains present. When identification and integration take place, there is usually a positive emotional response to the new context, one that can be seen as growing out of a strong desire to leave the past behind and move forward. For those who do not identify with their new country, there is rather an ambivalent or even negative response to the sense of non-belonging, which translates into less positive emotions. These emotions negatively influence future encounters with the social structure and 'others', further strengthening those anticipated negative emotions. 


\subsection{Conclusion}

In this chapter, I argue that the identity formation experiences of Argentinian immigrants to the National Capital Region have two main interconnected processes, namely identification and differentiation. My research shows that, while there are some exceptional cases, Argentinian immigrants have embraced their experiences in Canada on the basis of a strong sense of identification with Canadian values and lifestyles. This sense of identification is one of the main reasons why research participants emphasize that they consider their immigration experience to be generally positive, referring to their adaptation and integration. However, in order for participants to develop this sense of integration, it is necessary for them to embrace the new social world even when this means that they will distance themselves from past elements of similarity and familiarity. While the reasons many in this group identify with Canadian society may be found in affinity, 'racial similarity' with the dominant group and the conditions of entry, which have 'facilitated' their integration; the reasons for 'splitting' from elements of the 'old identity' are found in a number of factors.

In this chapter I argue that the reason why the majority of research participants distance themselves from other 'Others' are strategic, historical, habitual and emotional. They are strategic in the sense that these immigrants are in the process of negotiating their place in Canadian society and their experience suggests that the most efficient way to attain this goal is through integration rather than isolation. It is historical in the sense that the legacy of colonial and post-colonial rationales that built the Argentinian nation as 'homogeneously white European' (Garguin 2007) positions Argentina as closer to 'white' societies such as Canada, rather than as closer to Latin American geography, 
culture and identity. It is habitual in the sense that Argentinian immigrants to Canada 'bring habitus in' (Bourdieu 1991) to their new country continuing a prioritization of individual wellbeing over group solidarity. Finally, it is emotional for ambivalent feelings and tensions towards the homeland reinforce the development of new practices interconnected to their desire to begin anew and integrate even if that means that they need to break from what is familiar. While I stress that for some research participants the experience is different from the main conclusions drawn here, my research suggests that the reasons for these exceptions are linked to the participant's personal history and the limitations they encountered in choosing Canada as their new home. In the next chapter, I look at the 'location' of Argentinian immigrants in Canadian society and I trace links between the processes of identification and differentiation and the group's experiences of integration and marginalization. I suggest that the partial 'blend in' and also their partial exclusion in fact strengthen these patterns of identification and differentiation. Furthermore, they are mutually constitutive of their notions of who they are in Canada, which, through personal strategies of reacting, feeling and reflecting, shape their identity formation experiences and the emergence of 'new' identities of second wave Argentinian immigrants. 


\title{
Chapter 4
}

\section{On the Verge of Belonging: the Partial Inclusion of 'Others' into}

\author{
Canadian Society
}

P: "alguna vez te sentís excluido en esta sociedad? De alguna manera?"

D: "todos los días ... eh... sí... pero uhm... no sé, creo que yo tengo ideas pero yo no puedo decir que la razón por la cuál yo me he sentido excluido es porque soy inmigrante, no sé... puede ser, puede no ser... eh... pero sí... buscar trabajo es un desafio y siempre he estado haciendo trabajos... trabajos más, probablemente más simples de los que podría estar haciendo, no, no, estoy bien con eso pero es una realidad, eh... después mucha gente esta programada para no entenderme porque yo tengo un acento y... mucha gente tiene voluntad pero hay mucha gente que... es como... [risas] eh... eso es interesante porque yo sé que con acento y todo me... me sé expresar y lo puedo resolver, pero... bueno, eh. Y... si no sé, yo creo que siempre, siempre, yo podré vivir acá no sé 20 años, 30 años y nunca, nunca voy a ser parte de, en parte porque no estoy interesado y en parte porque nunca podría llegar a mezclarme en el sentido de alguien me confundiría, 'uh ese tipo es canadiense o no? no va a pasar eso! Si me ven, si me escuchan, si me... van a notar que no, que algo esta un poquito 'off' [...]. Un tiempo a esta parte en vez de pensar en irme pienso en cómo funcionar mejor y cómo adaptarme y hay cosas en las que no me quiero adaptar, pero pienso que puedo estar cómodo sin adaptarme a todo o sin aceptar todo." Daniel

\section{$P$ : "do you ever feel excluded in this society? In any way?"}

D: "everyday... ehm... yes, but, uhm... I don't know, I think I have some ideas but I cannot say that the reason why I have felt excluded is because I'm an immigrant, I don't know... could be, could be not... ehm... but yes... looking for a job is a challenge and I've always had to do jobs... jobs more, simpler than the ones that I could be doing, no, no... I'm ok with that but it's a reality, ehm... then, many people are programmed to not understand me because I have an accent and... a lot of people have a good predisposition but there's a lot of people who, it's like... [laughs, further thinking] ehm... that's interesting because I know that with an accent and everything I... I can express myself and I can solve things, but... anyways, ehm. And... I don't know, I think I'll always, I could live here I don't know 20 years, 30 years and I'm never going to be part of... in part because I'm not interested and also because I could never blend in to the point that someone would confuse me, 'Is that guy Canadian or not?' That will never happen! Whoever sees me, whoever hears me, if they... they'll realize that no, that there is something a bit off. [...] At some point instead of thinking of leaving I started to think about how can I better function and how can better adapt myself. And there are aspects in which I don't want to adapt but I think that I can be comfortable here without completely adapting or without accepting everything."

Daniel

In the previous chapter I advance two main arguments. The first one is that the processes of identity formation of Argentinian immigrants to Canada's National Capital 
Region around the year 2000 is characterized by the emergence of 'new identities' and that this occurs through processes of both identification and differentiation vis-à-vis some groups in the host society, and other 'Others'. I emphasize that these patterns of identification and differentiation are connected to historical and discursive processes taking place in the Argentinian context (late $19^{\text {th }}$ and early $20^{\text {th }}$ centuries), which have constructed a homogeneous, white, Euro-Argentinian identity (Garguin 2007). At the same time this historical and discursive identity construction is connected to the selfproclaimed positive immigration experience of these immigrants, which fits well within Canada's multicultural framework for the management of diversity. My second argument is that in the case of Argentinian immigrants, the development of new identities is also interconnected to personal practices such as self-reflection upon emotional responses towards both the left-behind homeland and the new social setting. In this chapter I focus on the location of Argentinian immigrants in Canadian society. My aim is to gain a better understanding of how this group negotiates its location and what are the strategies employed for claiming rights for recognition and equality in Canadian society. I argue that although Argentinian immigrants to Canada are actively incorporated as allies of the nation and its white dominant groups, they remain 'Others' nonetheless. Furthermore, I emphasize that these experiences of integration and also marginalization influence these immigrants' notions of who they are in Canada and that ultimately, the self-awareness of their location within Canadian society shape their identity formation experiences.

In the past thirty years, we have seen the rise of identity politics in Canada. Historically, minority groups have claimed their rights to accommodation and recognition through various forms of political organization and mobilization on the basis of various 
identity claims (Eisenberg and Kymlicka 2011). My research shows that accommodation and integration of Argentinian immigrants to Canada does not necessarily follow the same dynamics as some other minority groups such as: racial groups, indigenous groups, and religious groups who have fought for the recognition of their rights and identity (Eisenberg and Kymlicka 2011). Argentinian immigrants have not historically organized themselves politically to claim the recognition of an 'Argentinian identity'. This is partially due to what I have presented in the previous chapter, that is, the challenges that Argentinian immigrants face in this region in terms of organizing themselves more formally. In addition, it has been shown that Argentinian immigrants do not ally themselves with other 'Others' (e.g. Latin Americans) for more inclusion. On the contrary, my research suggests that Argentinian immigrants continue forming a nonexplicit 'alliance' with the white Anglo-Canadian majority on the basis of identification, while their connection to Argentinian and Latin American immigrants remains at the level of individualized informal friendship cycles based on certain affinities such as language and family values. It is on the basis of this 'alliance' that Argentinian immigrants claim to be successfully integrated into Canadian society.

However, it is important to note that there are some exceptions to this 'positive' narrative of successful integration. Some Argentinian immigrants are more critical of their location in Canadian society, on the basis of experiences of exclusion, and discrimination. Looking closely at the narratives of those who claim to be integrated and included, one finds narratives that are fraught with internal contradictions. This group claiming successful integration attributes their rather positive experience to their 'blending in', their skills, and also their affinity with Canadian normative values and 
lifestyles. Nonetheless, the internal contradictions revealed in participants' narratives and the lack of 'uniformity' in them signals the complexity of their experience, and of their location in Canadian society. I argue that although Argentinian immigrants may in fact be 'allies' and more 'desirable immigrants' than others, they remain 'Others' nonetheless.

In this chapter, I look closely at Argentinian immigrants' narratives in order to better understand their experiences and their location in Canadian society. I argue that while Argentinian immigrants may in fact enjoy certain benefits in comparison to other 'Others', they still remain at the level of partial, conditional inclusion into Canadian society. While it can be argued that Argentinians in Canada are a group of immigrants who experience 'far less' discrimination and exclusion than other ethnic groups, they still remain targets of subtle forms of discrimination. These subtle forms of discrimination provide evidence of prevalent notions of 'otherness', and the various forms of resistance towards all 'Others', even those who are often seen as allies, or friends, those who do not threaten the dominance of the white Anglo-Saxon majority group.

This chapter is organized in the following manner: I begin by looking at the 'location' of Argentinian immigrants in Canadian society in general and I suggest that while Argentinian immigrants are actively recognized and incorporated as 'allies of the nation', their inclusion is still only partial due to profound limitations to the full integration of all 'Others'. Secondly, I address participants' narratives with regards to their notions of integration. The discussion is focused on how whiteness and the conditions of entry of this group are linked to these narratives and notions. Thirdly, through examining participants' narratives regarding accents, language barriers and recognition of credentials, I suggest that this group encounters 'subtle forms of 
discrimination' which set limits to their full integration. In Chapter 3, I emphasize that the strong sense of identification these immigrants have with Canada has its own set of particular 'reasons', and that it is further strengthened by processes of differentiation that occur simultaneously. I argue that "the meeting point" where 'former identities' meet these new processes of identification and differentiation allow for the development of 'new' identities of Argentinian immigrants of the second wave. Here, I further emphasize that the emergence of these 'new' identities is not a simple, linear or 'unproblematic' process. Rather, it is complex process in which these immigrants encounter conditions that favour their integration resulting in positive experiences of inclusion, as well as structural barriers, which result in negative experiences of marginalization. I argue that the internalization of these experiences, which occurs through various personal practices, such as reacting, feeling and reflecting, shape their self-understanding of who they are in Canadian society, their identity formation experiences, and the emergence of 'new' identities.

\subsection{The Location of Argentinian Immigrants in Canadian Society: on Being Included, but only Conditionally}

According to Citizenship and Immigration Canada, immigrants are considered well integrated when they reach a point of similar income, labour force participation and language acquisition as the Canadian born population (Frideres 2008, 86). It is with this objective in mind that immigration and integration policies are formulated to achieve these objectives. James Frideres explains that integration involves two dimensions: a personal integration and a structural integration $(2008,80)$. From the narratives presented 
in previous chapters, it seems that Argentinian immigrants have achieved both these dimensions of integration. However, jumping to such conclusion would be simplistic.

A close examination of participants' narratives suggests that they pair the notion of 'will' with that of 'positive immigration'. Approximately two thirds of interviewees understand integration as a matter of 'attitude' and 'personal will'. According to many of them, integration is (almost exclusively) an individual responsibility, downplaying or ignoring its structural dimension. This view is also strengthened by the data gathered through observations and content analysis of blogs. For instance, twenty-one out of the twenty-five key articles selected from the blog Los Ziegler in Canadá make specific references to the individual's responsibility and agency in having a positive immigration experience. Eleven of those twenty-five key entries refer specifically to the responsibility of 'learning the language and the culture' as key aspects to better positioning oneself in Canadian society ${ }^{26}$. The underlying message in all these entries is that in order to "cause a good impression in Canada and be accepted" (Los Ziegler in Canadá, 5 November 2012) one must focus on learning the language and the culture in order to find good employment and positively integrate.

A similar narrative was encountered while conducting fieldwork. During an informal social gathering where several Argentinians were conversing about the validation of their credentials and the issue of disappointment over not being able to work in a profession one was trained it, those present agreed that 'informing oneself' and doing

\footnotetext{
26 Particularly interesting entries are: "How to cause a good impression in Canada and be accepted" Date of entry 5 November 2012; "How to travel to Canada to learn English, work and learn its culture" Date of entry 8 November 2012; "Announcement of FWS' new requirements" Date of entry 19 December 2012; "Federal Skill Trade Program" Date of entry 2 January 2013.
} 
'everything in one's power' is a personal responsibility and that one should not 'blame'

others for one's disappointments and failures:

Four of us were having a classic discussion about Argentinians being this and that. The conversations turned into a discussion about people's expectations. Lucas ${ }^{27}$ said something about how people want to come here because they blame the Argentinian state for not providing well-being for them, and then started reflecting on how Argentinians are always blaming something or someone for their circumstances. Juan and Matias seemed to agree. They continued reflecting. Matias said "Argentinians are always ok to criticize but when it comes to proposing ideas to improve things, everyone is silent [...] no one contributes nothing". The stories kept coming.

The conversation carried and towards the end, Juan reflected: when you come to Canada "you are like a baby, you have to learn everything from scratch, you have to learn all the rules again". We all reflected. He added "they are very patient here with immigrants, because we don't know anything, everything is new". And then we started talking about how there is a cost benefit balance to the experience ... (Field notes, September 2012).

It doesn't mean that research participants and those engaging in discussions carried out in blogs and during observations are not critical of their positioning in Canadian society. However, it seems that the 'benefits' outweigh the costs, and that the outcome of the experience is in one's hands. Nonetheless, some research participants suggest that it is unrealistic to expect that immigrants should have full equality. Lack of equality does not seem as problematic for research participants as one would expect. On the contrary, they seem conscious of 'their place in society'. This is particularly relevant given that, as presented in the previous chapter, research participants do not 'label' themselves as immigrants, yet this awareness that as immigrants one should not necessarily expect equality appears contradictory to their lack of explicit identification as immigrants. The following quotation illustrates the notion of 'conditional location' within Canadian society:

Camila: when you are a guest, or as... an immigrant in a country, I mean... you don't have the same rights, I don't mean the rights as in rights to equality as the law marks but I mean natural rights, the ones that rise instinctively.

${ }^{27}$ The three participants' names (Juan, Matías and Lucas) are pseudonyms. 
Camila has an interesting understanding of her location in Canadian society. On the one hand she acknowledges that by virtue of being a citizen of this country she enjoys the same 'legal rights' as everyone else; on the other hand she remains conscious that through 'natural rights, the ones that rise instinctively' her full inclusion is 'conditional' as subtle differences become boundary markers. To Camila and the majority of participants, it is only natural to not have full substantial equality.

I would argue that the experience of this group may come across as 'positive' and less complex than that of other racialized minority groups because Argentinian immigrants rarely speak of being the target of direct forms of discrimination or as having a sense of being excluded. However, it appears that these same narratives are fraught with internal contradictions in that participants would make a statement and then 'contradict' it later on during the same interview. This suggests that the complexity of these immigrants' experiences needs to be looked at beyond what appears on the surface. While Argentinian immigrants may represent a group of successfully integrated immigrants, especially when compared to other immigrant groups who have been targets of more explicit forms of discrimination and exclusion as for example the case of Sikhs living in Canada (see Dhamoon 2009, 19), and other racialized non-white groups such as Blacks, South Asians, and Indigenous peoples (see Gunew 2004, 47 for her discussion of Roxanne Ng's work 1993) one should not quickly jump to conclusions and assume that these more 'desirable immigrants' are not also subjects of exclusion. The case of Argentinian immigrants to Canada allows us to see how even 'more desirable' immigrants still remain at the margins of society, without necessarily enjoying full rights and inclusion. The conditions of full integration transcend, in my view, the self- 
understanding of Argentinian immigrants as fully incorporated and recognized in Canadian society. In what follows, I discuss the patterns and extent of inclusion and exclusion of this group to support the above argument.

\subsection{Whiteness, Skills, and Degrees of Inclusion}

The interviews reveal that the majority of research participants think coming to Canada as skilled workers has 'benefited' them especially in the sense that they don't encounter 'the language barrier' as much as some other immigrants. This is tied to the conditions of entry under which these immigrants arrived in Canada discussed in Chapter 2 where I discuss research participants' profiles and patterns of Argentinian immigration to Canada.

For instance, one of the research participants, Sandra, stresses how when immigrating through the Quebec skilled worker program, her previous knowledge of English and French language (which she acquired during the year prior to moving to Gatineau because knowledge of french a requirement to immigrate through this program) certainly impacted her immigration experience in a positive way. Another factor that participants mention is having had a good education back home, which they link to having 'better opportunities than other immigrants in Canada have'. The combination of language skills and a university degree suggests to participants that they will enjoy upward mobility in Canadian society. For instance, when Gonzalo was asked about his immigration experience in general terms, his sense of identification and more specifically about what he considers has influenced his 'positive integration', he said:

Gonzalo: I identify more with... with Canadian people [...] with the majority. Yes, I don't, I don't identify with minorities, like with Muslim people, that kind of culture... see, there I use the concept of an immigrant, there I understand what it is to be an immigrant, 
maybe that's why I don't feel an immigrant. Because I see [for example the people who work at] the cleaning company in my building, everyone talks about their brothers and sisters... having very little resources, not having the opportunity to progress in the country... and how they will end up working in that type of activity, so there I see the difference...

Pamela: Where do you see the difference that makes you identify with the majority rather than with minorities?

Gonzalo: in the possibilities of what you can become here, the possibility to study or to progress and contribute to the country...

Pamela: Do you think that this is somewhat linked to the conditions under which you arrived in Canada?

Gonzalo: yes, definitely

Pamela: Which of those are the ones you would highlight the most?

Gonzalo: well... the possibility to study in Argentina. Yes having free access to University is one of the good things that our country has.

Gonzalo emphasizes that he considers his possibilities to 'progress' in Canadian society are linked to coming with a university degree from back home, a requirement when immigrating through the Quebec skilled worker program.

Various participants shared accounts of how when going for job interviews, or in various social interactions, they are mistaken for Europeans and even Americans. While participants do not always acknowledge this directly, they see this definitely as a point of advantage for them as they acknowledge that 'other immigrants have it rougher than [us]' (e.g. Sandra and Analía). For instance, in sharing her first impressions when moving to Canada, Sandra said:

Sandra: in my case in particular, I didn't feel that discrimination. This is from a subjective point. Uhm... I don't know if that is because actually everytime I went to apply for jobs they would ask me if... maybe because of the color of the skin... I mean... because... in my particular case... or they would say to me 'oh, I thought you were from the States, oh I thought you came from Europe, oh you come from Germany, or you come from... '. Because they would never relate it to the fact that I come from Latin America. I don't know if it's because of that, or if there is a factor that signals me that no, that it doesn't make me feel very different, I mean, except when you start talking which is when obviously they say 'ah, where are you from? I thought you were from... '. [...] And now 
that I think about it, after meeting people from Latin America or other countries that maybe because of the colour of the skin, or because of the language, or because of the way of dressing I though 'oh yes, these people have indeed felt very strongly being immigrants'... but in my case I didn't feel it.

Except for the previous quotation, where Sandra clearly makes the connection between the color of her skin and being 'almost mistaken for Canadian', or having an advantage over other immigrants, the great majority of participants do not necessarily understand the connection between their overall positive immigration experience and the 'unmarked whiteness' that Eva Mackay refers to (2002). 'Racial elements' were barely accounted for during interviews and nearly absent in blog discussions. However, what is interesting about Sandra's response is that even when she makes reference to the color of her skin as potentially a reason why in her particular case she didn't feel that discrimination she follows by stating that '[she] doesn't know if it's because of that'. The fact that participants do not explicitly make the connection between 'being well integrated' and 'being white' speaks to their own positioning as white subjects in Canadian society. White privilege passes almost unnoticed to many of them.

\subsection{Accents, Credentials, and Degrees of Exclusion}

I have just referred to how unconscious white privilege can be interpreted as the reason why this group sees itself as more integrated and why these immigrants fail to identify this as one of the key factors contributing to their 'acceptance' and integration. However, almost without exception research participants do refer to language abilities and accents as things that 'give them away'. As expressed by Sandra in the previous quotation, it seems as if Argentinian immigrants 'would pass for Canadians' until they begin to speak. Some research participants do not see the issue of language and accents as 
problematic however they make (quite extensive) reference to how these are markers of difference. Others such as Martín for example, explain with certain grievance, how the accent makes him feel at times a foreigner:

Pamela: How did you feel when you arrived here?

Martin: ehm... well I think it varied according to the moment, there were moments when ... for example, when, when I started here, my... my English of course 9 or 10 years ago was not the same [as] now and I had a strong accent and there were moments when I felt bad when people would ask me 'what?' or 'I didn't understand' and they would ask me if I said this word and I had said some other thing, and some times... even now, right? Ehm... and, and that's hard because when people don't understand you or when you don't understand that's something difficult and you feel you don't belong, uhm...

As this quotation shows, research participants feel that their accents contribute to people's perception of them as 'outsiders' or they simply feel 'frustrated with themselves' (Martín) for not being able to completely blend in. Five research participants admit openly that their accent not only represents a signifier of difference but also results in them being not as qualified as those who can speak without an accent. For example, in sharing her experiences at work, Analía refers extensively to how she notices that opportunities and privileged positions are always reserved for 'long term white Canadians who speak the language (native speakers)' and how the opportunities for immigrants who may have the same level of education and skills are not considered for high ranking positions:

Analia: yes, I think that there is a systemic discrimination with regards to the positions held in organizations, I see it at work, that all the management part, ehm... in general those positions are occupied by Canadian people [...] and yes there is a tendency to promote people [...] I mean... Canadian, white, originally from here, who have the language and so on... and I see that immigrant people, even if you don't have visible differences, physically, it's like, it is very marked the difference between being administrative staff and management. Still, there are very few people, immigrants who are in management position and very few Canadians who are in 'admin'. But it's curious, that the majority [of immigrants] have no access to those positions, right? [...] and if they make it to management they are usually assigned to community projects rather than HR or Health, those are like the heavy positions... 
What is notorious about Analía's and Sandra's narratives is that even when some participants make reference to the racial dimension of privilege and inclusion (in the example of Analía how 'privileged positions are reserved for whites') they still do not make a explicit connection to their own experience as a white ethnic immigrant group. The second interesting thing about the conversation with Analía is that even when she remarks how 'privileged positions are kept for long term white Canadians', she immediately invalidates her own opinion and experience by making comments such as "not everything is for everyone", "it is natural for humans to resist difference" and stress how this experience "is something personal and exceptional and not something that applies to the entire society". She had previously said that she experienced discrimination on more than one occasion (at school and at work) on the basis of language proficiency (mostly due to her accent) and based on the "structure itself", which is "programed to benefit those Canadian born". However when asked about how she felt about these instances of discrimination she said that it brings her disappointment but insists that her experience had been overall "easy" and positive. For instance in talking about the situation at work, she said:

Analia: well, I was pretty disappointed because, the person this came from, technically is... this person is so involved with newcomers, with immigrants in general, s/he designs programs for new immigrants, develops programs for new immigrants so to find out that unconsciously [the person] has such biases goes to show how strong it is and how strongly it persists at a subconscious level, but I think, I insist, I think [this person] hasn't even realized what [s/he] is doing and... witnessing this episode was very interesting because if this is a case that goes unnoticed in the case of a person who is so exposed then, that gives you an idea of how things work out at levels where the process is much more internal... 
Along the same lines, Alicia, who claims that "she never feels excluded" but that "language is an issue" explains that this is because when paired with a native speaker, immigrants are in a disadvantaged position:

Alicia: excluded, no... not, excluded no... is more a matter of abilities, ehm... I thing that for a native person, for someone from here, born here, who speaks the language perfectly, who speaks English or French [...] competing with them for a work position is difficult, so it's like for me I have extra work to do. My extra work is to try to do what I know how to do and try to be in my best shape with the languages... other than that I think that the current situation, concerning finding a job, uhm... it's more related to the economic situation, to the economic crisis and the financial crisis and the issue with the US than situations of discrimination.

For Alicia the key is to acquire extra skills (abilities) in order to compensate for the fact of having an accent. The examples presented above illustrate well what Ghassan Hage (1998) refers to as 'nationalist practices of exclusion' where, despite best efforts made by immigrants, the 'owner of the nation' is the one who ultimately regulates inclusion. This is the moment when, as Hage argues, "the democratic logic of accumulation ${ }^{28}$ reaches its limits" $(1998,61)$ for in spite the best efforts made by 'allies of the nation' a line is drawn to exclude them.

In blog entries, "the problem with the language" (Los Ziegler in Canadá, 6 September 2006) is framed in terms of language proficiency as being a key element towards successful immigration and adaptation, particularly linked to work opportunities, which are open to those who speak the language fluently. The following quotation illustrates this notion:

\footnotetext{
${ }^{28}$ Ghassan Hage refers to "how people can accumulate certain forms of Whiteness" $(1998,60)$ through 'efforts' to improve their language abilities and skills. He argues "[ $t]$ his dynamic of accumulation reaches its limitations, however when it comes face to face with those whose richness in national capital does not come from a struggle to accumulate and 'be like' White Australians, but who appear 'naturally' White Australians" (61). While Hage's analysis is focused on the 'white Australian nation' his arguments link strongly to the Canadian experience.
} 
I am sure that during the last few months many of you have made a great effort to improve your English in order to speak fluently. All of you know that by gathering time from who knows where to learn English you will have better chances to access a good work position in Canada [...]. At this time, when new migratory programs require proof of language level, having a good level of English is key. (From the blog Los Ziegler en Canadá. Entry: Webinar: "Cómo puedes viajar a Canadá a aprender inglés, trabajar y aprender su cultura" on 8 November 2012. Date retrieved 8 January 2013 http://loszieglerencanada.com/search/webinar)

The type of reactions that participants have towards having an accent varies. Seven research participants see it merely as a marker of difference but not problematic for them (e.g. the cases of Sandra and Alicia). Six participants have mixed feelings about it (e.g. the case of Martín) and only one research participant did not raise the issue of language at all. For five research participants the accent and language capabilities are explicitly seen as one of the main factors preventing them from attaining equal opportunities in the workforce (e.g. the case of Analía). However, this group often implies that this is not necessarily a limitation of Canadian society but rather of 'human encounters' where 'it is natural' to resist those who are different from us. For three research participants, having an accent is not so much the 'problem' for them as it is people's reaction to their accents. As presented previously, one of the research participants, Daniel, explains "because of [his] accent some people are programmed to not understand [him]". Two of these three participants mention that it frustrates them that people ask them to repeat what they are saying several times even when they know they are understood or suspect it is their interlocutor's resistance what prevents them from being understood. One research participant was directly told that she could not fulfill certain tasks in her job 'because of her accent'. While this can be regarded as an extreme example, the fact that nearly all research participants brought up the issue of accents as signifiers of difference is significant. In some cases it is internalized and seen as a 
personal limitation while in other cases it is understood as a clear boundary marker or even as sign of exclusion.

Regardless of how the experience of a perceived accent is internalized by each research participant, it is clear that many feel frustrated about how others respond to it. They explain that when people are constantly making reference to the accent, even when they are noted in a complimentary manner (e.g. "oh you are so cute", "your accent is so exotic") the experience can be frustrating because of the persistent reference to being different. While this attention to 'difference' is 'insignificant' for some people, for others the experience is painful. Ultimately, as Ghassan Hage stresses "it is in the accumulation of such 'insignificant' moments that the national aristocracy distinguishes itself from other nationals in everyday life" $(1998,64)$. In spite of how participants internalized the experience, these are crucial moments of boundary drawing.

In her discussion of 'Who counts as European?', Sneja Gunew looks at multiculturalism in Australia and Canada arguing that in "accounts of citizenship and the nation are the structurally aligned 'others"' $(2004,46)$. Gunew stresses that we need to look closely into notions of European-ness in order to understand how different racialized groups have become (or not) 'Europeans'. She argues that "European and Western in fact often slide directly into English or British and no distinctions are made amongst these categories" (Gunew 2004, 48). In the Canadian case, the literature points to how in Canada, various Continental European groups (particularly Southern and Eastern Europeans) have 'become white' (notably the Ukrainians and Italians, among others, see Gunew 2004; Zucchero 2005). Gunew emphasizes that in Canada, those European groups who "were not perceived to be part of the English/French European axis" $(2004,47)$ 
would be regarded as ethnic/racial minorities. She points to how the defining characteristic in being perceived as European (both in Australia and in Canada) is not only a matter of skin color but also of English language proficiency, in other words, whether one has a NESB (non-English-speaking-background) (Gunew 2004, 34). This point is particularly significant in understanding some of the barriers encountered by Argentinian immigrants to Canada. Although I have pointed to how this group blends in quite successfully, there is a significant factor that could, arguably account for their partial exclusion. Despite a historical self-construction of a 'Euro Argentinian identity' (Garguin 2007), these immigrants are not European immigrants in Canada, furthermore, even if they could 'pass' for Europeans, which kind of Europeans would they be? Gunew's argument (also Hague's 1998) about how only certain Europeans (read English) account for Europeans in Australia, and arguably in Canada, helps us further understand the location of Argentinian immigrants as 'Others', even when there are different kinds of them. I have already referred to Kandyioti's (2008) study of Argentinians in Europe (particularly in France) and to how despite their own self-perception as Europeans rather than Latin Americans, Argentinians are not seen as such by Europeans. I would argue that in Canada there are, although not the same, similar dynamics in place. Despite their own imaginary and best efforts, Argentinian immigrants are not seen in Canada as belonging to the 'European English/French' axis. 


\section{How Andrés Got a Job! But Only After Becoming André}

Closely related to the aspect of accents is that of foreign names. The following scenario illustrates this well. Adriana's husband ${ }^{29}$ had a successful professional career back in Argentina, however when he moved to Canada he had been unemployed for several years. Adriana says that her husband had been receiving advice from a social worker who helped him with resumé drafting and job-searching techniques. Adriana mentioned that the social worker told her husband that she had "checked his entire resumé and everything was perfect, the problem is [she said] that there is no work". As the husband left the social worker's office, Adriana says that the social worker followed her husband and once they were outside her work premises told him to change his name on his resumé "from Andrés to André ${ }^{30}$ but do not tell anyone that I told you". Adriana's husband went home and did as the social worker suggested. Adriana says that a week after Andrés changed his name on his resumé (to the French version of his Spanish name) he found employment. However, Adriana concluded that she "doesn't know if her husband found employment right away because he changed his name on his resumé". While Adriana shared this anecdote without suggesting that this could imply any form of resistance to the inclusion of those who appear foreign, the story clearly illustrates some of the barriers that even professional, well qualified immigrants face (after all he went for the interview and got the job!).

\footnotetext{
${ }^{29}$ In order to protect the identity of this research participant, I will refer to her and her husband in general terms and through the use of new pseudonyms. While some minor omissions and alterations of the story have been made, key elements have been preserved in order to make the point.

${ }^{30}$ The names 'Andrés' and André are pseudonyms, however, as in the case of the participant's husband his 'Spanish' name was 'frenchized' as per the social worker's suggestion.
} 


\section{'Everything that I Brought with Me Did Not Count', but That's OK}

When talking about transitioning from their former professions to the job market here in Canada, it appeared that many participants are performing jobs or working in positions that do not align with the requirements of skills requested in order to immigrate to Canada. The literature informs us that usually immigrants struggle to find jobs that match their skill level especially during the first few years after immigrating, and particularly during the first year (Girard et al. 2008). Furthermore, although social capital plays an important role in determining the type of employment immigrants will find in those initial years after immigration, the literature emphasizes that immigrants will likely work for lower wages that the Canadian born population (Grant 1999; Reitz 2001; Li 2003; Banerjee 2009; Xue 2009; Frank 2010; Bonikowska and Hou 2010; Xing 2010). However, it is noteworthy that those immigrants who came through the Quebec program and who were selected on the basis of preferred professions even several years since their immigration, continue working in occupations that do not match their education and skill level. Participants in this research note that this is part of the immigration experience and to what several of them refer to as the process of 're-inventing themselves'.

My research shows that this self-repositioning in the new context is not seen as exclusionary or discriminatory. This is not to say that participants enjoy these challenges, on the contrary most of them emphasize that the first few years were indeed very difficult, yet they don't see these as instances beyond the normal challenges of immigration. Sandra for example, was a fairly well established professional in Argentina. Although she maintains a strong connection to the homeland, she embraces her new life here in Canada. In speaking about her experience as an immigrant, it was interesting to 
find out that, in spite of having given up a successful career in Argentina she is content working in a position outside her professional field and below her level of training. In her view this is part of the immigration experience in a country that highly values 'Canadian things' as she noted:

Sandra: There are some differences which are normal because, well because of the system, in the sense that maybe it's impossible, right? Let's suppose, at a job, if you want to compete, well not compete but, uhm... if you compare people who are Canadian or maybe not Canadian but who were raised here... well, it's very difficult to level yourself with someone who has lived in this system and that maybe with 25 years of experience, or who... maybe they have a level of education with a masters, or with a PhD, or even more, because well, the system is so different, but that's something that has to do more with the system... with saying 'well, where do you come from, what's your education? And the educational system in Canada yes, it's like here they only value what is Canadian... so whatever you bring with you from outside, in terms of experience, in terms of your university degree, in terms of anything, well, it doesn't count unless it's Canadian experience, or a Canadian University degree, or a Canadian previous job. That yes, I have noticed that very strongly.

Sandra is referring to the 'deep sense of national pride' that she observes here in Canada. She explains that when looking for a job, or even when looking into getting involved in recreational activities, it is only when she acquired some Canadian experience that it would count. She offers reflections on how this is interesting to her coming from Argentina, which is a country that highly values foreign things, that is, foreign credentials and foreign work experience, more so than the Argentinian experience. She expanded on that:

Sandra: Everything that I brought with me didn't count [...] what helped me to add up on my resumé was my experience here, it's like your life begins from zero, from the moment you come here, whatever you study here, etc.

Regardless of this statement, Sandra insists that she has never felt discriminated against or excluded (in terms of work opportunities, in social settings, etc.) because for her, it is the fact that she doesn't have a certain background or specific education, or the 
simple fact of coming from another country, which renders her not fit for certain jobs. She concludes by adding:

Sandra: No, not at all (referring to ever feeling discriminated or excluded), I mean, yes I've noticed what I mentioned to you before, that when coming here and whatever you bring with you doesn't count for much but not because you come from another country or you belong to another race, no no no...

In the case of Sandra, Analía, Alicia, and the majority of research participants, there is a tendency to diminish the presence of discrimination. However, when there is an acknowledgement of exclusion and discrimination, the issue is treated as an individual problem' and participants see themselves as 'responsible for solving their own problem' through acquiring more skills, education, perfecting their language skills, etc. This aspect links to what was previously mentioned at the beginning of the chapter regarding participants' notion that the 'positive immigration experience' is an outcome of will, attitude and personal responsibility. Participants fail to see discrimination as a structural problem that affects them not only on an individual level but rather as personal experience that reflects the larger issue faced by other racialized and non-racialized minority groups.

There were other narratives equally fraught with internal contradictions. While some participants would share openly that they see no evidence of exclusion or discrimination, the fact that many of them were quite far from performing jobs that match their level of skill signals that there are incongruences in these 'positive' experiences.

At times, the interview process itself allowed participants to realize that they had been subjected to different forms of exclusion and discrimination, especially in the workplace, however they had not thought of the experience in those terms. A good example of this is Gonzalo who, when reflecting on the issue of exclusion and 
discrimination, first responded that the only time he felt discriminated against was when he went to take his driving test. He insists that, other than that, he never felt discriminated against, "not even the times when I returned to Canada. I felt like I was returning to my second home". However during his reflection, he said:

Gonzalo: I haven 't witnessed any cases, I haven't heard much, oh... wait, you are right... when I worked for the 'xxxx company'31 [...] the manager, who was Quebecois, and all the supervisors, who were also Quebecois discriminated against the employees, who in their majority were Somali [...] but no, not against me, well, I was a bit discriminated by a supervisor.

Gonzalo went on to tell the story about his experience working for this company operating in Ottawa and how his supervisor "who was a Canadian without education, who in his life has not been out of this country, a person who doesn't even have a passport, which means that his cultural level is quite limited, as it happens with all those who work in this type of company" discriminated against him. He recalls being promoted to supervisor but then had to return to his previous position. While talking about this experience, he realized that this had been a case of discrimination. Even though he enjoyed working in that place, he concluded that in these kinds of companies discrimination takes place because supervisors are 'socially resentful for having to deal with immigrants'. Furthermore because immigrants represent a threat to this group of Canadians as both compete for these jobs. Towards the end of the conversation he concluded:

Gonzalo: it was weird, it was a nice experience but ended up a bit discriminatory.

\footnotetext{
${ }^{31}$ In order to protect the identity of this research participant, the name and specific details about the company he worked for are avoided, however, it should be noted that the company operated in Ottawa.
} 
It appears that except when participants had a direct experience of discrimination, they fail to understand certain situations as forms of exclusions, but as one of the research participants, Juliana, mentioned "I think it's everywhere, it's only a matter of opening your eyes". Many of them stress that while they have never been discriminated against, they are aware that there is discrimination against immigrants in general but especially against those who are visible minorities. Many of them emphasize that white Canadians make racist comments around them and they realize that clearly they are not being seen as immigrants because if they were, people would not make such comments in their presence. This, to them, is a clear indicator that while not targeting them, racism and discrimination is part of everyday life.

Reflecting on what type of comments or episodes of discrimination they had witnessed, participants say that in general terms these are comments making fun of people's accents (e.g. 'how the brownies speak' followed by imitations). A research participant, Juliana, who worked at a community service centre ${ }^{32}$ located in a low-income neighborhood in Ottawa says that receptionists tend to judge immigrants going to the centre by "giving them looks" and making comments about them implying that these immigrants are 'un-clean'. She also mentions that sometimes even when no words are spoken "you can tell by the way they look at them how they think of them". While Juliana did not recall other specific examples, she emphasized that comments about immigrants imply that they are 'dirty', 'unsocial', 'wild', 'lazy', etc. However, she and other participants insist that the fact that some people would even make these comments in their presence is a sign that they are not perceived as the same as other immigrants.

\footnotetext{
${ }^{32}$ The participant's place of work has been altered in order to protect her identity, however, it should be noted that both Canadians and immigrants work and receive services from this centre.
} 
Clearly these immigrants are being 'incorporated' and signaled to identify as white subjects (Hage 1998). As this occurs, their patterns of self-identification as part of the white dominant majority is validated and strengthened, which in turn shapes the formation of 'new' identities.

The conversations around the topic of discrimination and exclusion suggest that participants, while not having been a direct target of discrimination, are not unaware of the issue. This dynamic suggests that this group is being incorporated into the nation as a white subject, as an ally to the white dominant majority. This experience 'feeds' Argentinian immigrants' self-understanding of being included and integrated. As their presence does not pose a threat to Canada's unified identity, these immigrants see themselves as actively incorporated as 'allies' of the 'white nation' (Hage 1998). I would argue that such self-understanding is an indicator that their presence as 'Others' is not threatening to the nation-building project rather than evidence of their full integration. In addition, my understanding of this 'blending in' dynamic strengthens the 'lack of need' to develop solidarity bonds between members of this group and those similar to them (e.g. Latin American immigrants) because their degree of integration and recognition within Canadian society is, in the view of many, sufficient as it is. As I mentioned at the beginning of this chapter, this is a complex process in which these immigrants encounter structural conditions that favour and/or 'obstruct' their integration experience, which could be described as a lower degree of exclusion, but also a rather partial or conditional degree of inclusion. As Argentinian immigrants in Canada engage in various personal practices of reacting and reflecting upon these experiences, their self-understanding of their location in Canadian society shapes their identity formation experiences and their 
notions of who they are, resulting in the emergence of 'new' identities where those processes of identification and differentiation are very much connected to their experiences of incorporation and marginalization.

\subsection{Conclusion}

This chapter looks at the 'location' of Argentinian immigrants in Canadian society with the purpose of better understanding how this group is incorporated into the nation. I suggest that while Argentinian immigrants are actively recognized and incorporated as 'allies of the nation', their inclusion remains partial or on a 'conditional' basis due to prevailing notions of 'otherness' and the still profound limitations to full integration of 'Others' into Canadian society. Secondly, the chapter examines participants' notions of 'successful integration' in order to better understand how 'whiteness' and the conditions of entry are linked to their experiences. Thirdly, the chapter focuses on a discussion of narratives regarding accents, language barriers and recognition of credentials where I argue that in spite of this group's narratives of 'positive immigration' these immigrants still encounter 'subtle forms of discrimination', which set the limits to their full integration.

By looking at examples of 'partial inclusion' and 'partial exclusion', I propose that although Argentinian immigrants might enjoy certain benefits in comparison to other 'Others', they still remain at a level of 'conditional inclusion' into Canadian society. Argentinians in Canada provide an example of groups of immigrants who experience far less discrimination and exclusion than other ethnic groups. However, the subtle forms of discrimination that the group does encounter actually reveal the prevalence of notions of 
'otherness' and the resistance in Canadian society to full recognition, integration and equality of all kinds of 'Others', even those actively incorporated as allies of the 'white nation'. These experiences of incorporation and marginalization shape these immigrants' identity formation experiences. As these immigrants do not tend to be direct targets of overt forms of discrimination, they are signaled to identify as white subjects and with the majority. However, the subtle forms of discrimination that they experience further emphasize the need to continue differentiating and splitting from those who are seen as 'Others' through a rupture of group affiliation and solidarity among themselves, as well as through the continuous pursuit of better qualifications and skills. 


\section{Chapter 5}

\section{"I am Interested in Understanding the Place Where I Live... and From There, I Can Feel I Belong": Conclusions}

The thesis explores the experience of second wave Argentinian immigrants, who arrived in Canada's National Capital Region between 1999 and 2007. Participants in this research are professional immigrants who arrived under the skilled worker program (both Quebec and Federal programs) and those who came under the family class category joining main applicants under the skilled worker program ${ }^{33}$. All those who came as family members were at least of high school age when arriving in Canada.

The methodological approach to this investigation is a mixed method qualitative research. The triangulated techniques employed included: qualitative semi-structured face-to-face interviews, non-obtrusive participant observation, and content analysis of blogs featuring discussions about the immigration experience of Argentinians. The main source of data came from a total of fourteen interviews conducted in the Ottawa-Gatineau area with both males and females between the ages of 27 and 45 who maintain a connection to Canada's National Capital Region either through residence, work or studies. Research participants were originally from four provinces of Argentina: Buenos Aires, Cordoba, La Pampa, and Mendoza bringing to this research a good representation of the regional and cultural diversity of their country of origin.

\footnotetext{
${ }^{33}$ With the exception of one research participant who arrived under the family category but to join his Canadian partner.
} 
The thesis has five chapters. Chapter 1 offers introductory remarks and lays out the research questions and theoretical framework for the thesis. Chapter 2 is concerned with the methodology employed for the present investigation. Chapter 3 addresses the question of identity formation processes of the Argentinian diaspora through a discussion of identification and splitting. Chapter 4 looks closely into participants' narratives about experiences of inclusion, and of exclusion in order to better understand the positioning of Argentinian immigrants in Canadian society and its link to the emergence of 'new' identities.

\subsection{The Formation of 'New' Identities and the Location of Argentinian Immigrants in Canadian Society}

The research question that guides this investigation seeks to gain a better understanding of the identity formation processes of Argentinian immigrants to Canada's National Capital Region. Based on the notion that identities are fluid, relational, strategic, positional, and always developing, this thesis asks: how do Argentinian immigrants to Canada experience identity formation at the "meeting point" of social conditions of migration in Argentina and Canada and individual practices? A main concern is to better understand how structural elements and constraints such as Argentinian white nation discourse, Canadian immigration policy, and the reality of white domination despite official multicultural policy, together with personal practices of reacting, reflecting, and feeling, have shaped these immigrants' identity formation experiences. 
I have advanced two main arguments in the thesis. First, that the identity formation experiences of Argentinian immigrants to Canada are linked to two main relational processes, namely identification and differentiation. Second, that these two processes are linked to the group's location as an 'Other' who 'blends in', albeit partially. The case of Argentinian immigrants to Canada allows us to study a group whose inclusion into Canadian society is conditional. I emphasize that these experiences of integration and marginalization are interconnected to these immigrants' patterns of identification and differentiation, as well as their notions of who they are in Canada. Ultimately, these processes shape their identity formation experiences and give rise to the emergence of 'new' identities through various personal practices. I shall summarize these arguments in turn.

I have suggested that the processes of identification and differentiation are shaped by two sets of postcolonial identity categories: the Argentinian/European versus the rest division, which originated from Argentina, and in Canada the English (even British) versus the rest division. The 'new' identities that Argentinian immigrants have formed is characterized by a fairly strong sense of identification with the white Anglo Canadian dominant group even when selective elements of their previous identity are preserved.

My research shows that the process of identification has been made possible by three main interconnected aspects. The first one is that both countries share a history of colonization, more specifically as settler societies, similar 'whitening' processes and discourses have been central to nation-building in both. While there are some significant differences between the Canadian and the Argentinian experience, these similarities contribute to the strong sense of identification Argentinian immigrants have towards 
Canadian society. Second, and interconnected to the previously mentioned aspect, is the 'blending in' of Argentinian immigrants in Canadian society. This has undoubtedly provided certain advantages to the group, especially when compared to other immigrant groups. Due to their physical appearance, most Argentinians enjoy more acceptance and inclusion in various spheres of life. I argue that being 'white' in Canadian society is most definitely advantageous for Argentinian immigrants, as they have been less exposed to certain forms of exclusion and discrimination than other racialized non-white minorities. Furthermore, the 'blending in' that the majority of research participants have referred to also strengthens the sense of identification Argentinian immigrants feel with Canadians and with Canada. Thirdly, I argue that the strong identification that Argentinian immigrants feel towards the white Anglo majority is strengthened by the conditions of entry under which this group has arrived in Canada. Because these immigrants came equipped with certain skills (work experience, high education level, language abilities, 'adaptability' characteristics, etc.) that place them in more favorable brackets of society, their experience and integration has been in general terms positive. I refer at length in this thesis to the fact that while these arguments are drawn from the dominant narrative of participants in this research, they should not be regarded as a unified narrative of all Argentinian immigrants to Canada. In Chapters 3 and 4 I provided examples of some exceptions to this dominant narrative.

Although Argentinian immigrants speak of a strong sense of identification with Canadian society, they also refer to processes of differentiation, which occur more or less simultaneously. Participants' narratives suggest that, as Argentinian immigrants seek integration into Canadian society, they tend to split from minority groups such as other 
Argentinian immigrants, Latin Americans, and other immigrants. This is not to say that Argentinian immigrants do not have individual relationships or form small circles of friendships with these 'Others'. However, it appears that, contrary to the experience of some other minority groups in Canada (e.g. those who organize themselves more formally in order to advance their claims for inclusion and recognition), the case of Argentinian immigrants offers an example of different group dynamics. In the case of Argentinian immigrants, a strong sense of identification with the Canadian majority is further strengthened by positive emotional responses developed towards the host society while more ambivalent emotions characterize their connection to the homeland and to those who represent their homeland in the new social context. I argue that due to this complex set of emotions that Argentinian immigrants have towards the homeland, they have developed a mixed sense of belonging where identification with Canadian normative values and lifestyle prevail over that with key referential others, namely Argentinian immigrants, Latin Americans and immigrants in general. It should be noted, however, that the connection that these immigrants maintain with 'Others' (especially with Argentinians and other Latin Americans) are on the basis of a shared language and familial values. I see these dynamics (identification and splitting) as making a distinctive experience of integration and of identity formation where these immigrants have incorporated characteristics of the new society. I propose that these practices of identification and splitting are closely related to structural conditions of the unmarked white centre of multiculturalism in Canada and the criteria for entry of this group, which actively incorporate these immigrants as allies of the nation. In addition, these dynamics are connected to the need to be strategic in placing oneself in the social world, the need to 
belong, the desire for integration, and the emotional responses towards the homeland and the new society. At the same time, these immigrants have retained central elements of the 'old' identity; for instance, participants emphasize how language, names and relationships are central to who they are. Coincidentally these are the elements that they share with 'Others like them' but not necessarily with the host society.

My second main argument builds on the previous argument. I suggest that the case of Argentinian immigrants to Canada provides a specific example of conditional inclusion and partial exclusion. By looking at different forms in which Argentinians are included into Canadian society, we can better understand how these experiences of incorporation strengthen their processes of identification with the host society. I emphasize the role of white ethnicity and skills as the main 'contributors' towards these immigrants' inclusion. At the same time, I argue that although these immigrants may enjoy a fairly advanced level of inclusion, they still remain 'Others' in Canadian society. While Argentinian immigrants may be seen as allies and considered more 'desirable' immigrants than others, my research shows that this group, (just as certain white ethnic groups such as those from European, non-English-speaking-background discussed by Gunew 2004), confronts a rather 'partial' inclusion. Although participants to this research were rarely targets of direct forms of discrimination, they emphasize that they are aware of the presence of discriminatory practices towards several racialized non-white immigrant groups. The fact that Argentinian immigrants refer to having witnessed countless racial comments made by white Canadians, suggests that they are not seen as immigrants but rather, they are signaled to identify as white subjects. 
Argentinian immigrants' own experience is one where they are rather exposed to subtle forms of exclusion and discrimination. The narratives of how language abilities, accents, and limited recognition of foreign credentials have been markers of difference were brought up repeatedly. These factors are barriers that prevent Argentinian immigrants from attaining a full degree of participation and equality in all aspects of life. Furthermore, they point explicitly to 'the limits of tolerance of difference' (Hage 1998; Mackay 2002) at the heart of Canadian multiculturalism and to the hostility towards 'Others' in Canadian society where in addition to existing racial hierarchies, there is a resistance to recognize and incorporate all kinds of 'Others' as fully equal. I have argued that the strong identification and self-understanding (as being fully included) that Argentinian immigrants express, is connected to their location within the racial hierarchy. However, even when Argentinian immigrants stress that exclusion and discrimination is not directly targeted to them, their narratives are fraught with internal contradictions that provide examples of what I argue can be seen as limited forms of inclusion. While this is not the experience of all Argentinian immigrants to Canada, this is a fairly well supported finding based on these narratives.

The experiences of incorporation and marginalization of Argentinian immigrants to Canada are connected to what I have referred to as the unmarked white centre of multiculturalism, which denotes prevalent notions of 'otherness'. Although this group is being incorporated into the nation as a white subject, as an ally to the white dominant majority, the subtle forms of discrimination faced by the group point to the limitations of multiculturalism as a fair, all-inclusive policy and practice. The rise of identity politics in Canada over the past thirty years attests to the complexities and inequalities imbedded in 
official multiculturalism. Even though this group of relatively privileged immigrants experiences far less discrimination when compared to other immigrants (e.g. racialized non-white minorities) they still encounter resistance to their full recognition. This example, when immigrant groups who align themselves (and are incorporated) as allies of the nation are only partially included, provides evidence of the limitations of multiculturalism as fully recognizing, integrating and granting equality to all, as well as of persistent notions of 'Others' as inferior, and of the racialized hierarchical arrangement of 'otherness'.

As I have suggested, the identity formation experiences of Argentinian immigrants to Canada are linked to the two main relational processes of identification and differentiation, which are interconnected to their location as 'desirable, yet conditionally included Others'. As these immigrants 'blend in' albeit partially, their practices of identification as white subjects and with the dominant majority are validated and strengthened. Their experiences of marginalization and exclusion, however, suggest to these immigrants that differentiating themselves from various 'Others' can perhaps be a road towards more integration. Ultimately, these processes of identification and differentiation (which are grounded on their individual experiences and encounters with various social structures) aid to construct their notions of who they are in Canadian society. This complex process 'meets' various personal practices where these immigrants, feel, react and reflect upon their experience. These experiences, encounters and practices shape the identity formation of Argentinian immigrants to Canada giving rise to the emergence of 'new' identities. 
In this thesis, I have aimed to contribute to the fields of Latin American diaspora studies in Canada, which is a fairly recent body of work whose relevance is increasing due to the rapid changes in the political and economic landscapes of the Americas. As the distances shrink, the challenges increase. I have also aimed to contribute to the field of 'white ethnicity' studies by conducting research on the specific case of Argentinian immigrants living in dominantly white societies yet at its margins. My objectives in this regard have been to gain a better understanding of the racialized hierarchization of 'otherness' so that these notions can be contested. Furthermore, to better understand how these various dynamics shape the identity formation processes of racialized white minority groups such as Argentinian immigrants. My aspiration is to continue working and contributing to this field of studies, which still needs much development.

Thirdly, and more generally, this investigation aimed to make a contribution to the field of identity studies by exploring new 'meeting points' for the development of identities. As each identity is unique, it is meaningful to continue expanding our knowledge. Given that identities are fluid and in continual development, new knowledge remains our objective.

\subsection{Final Thoughts on Moving Forward}

This research has provided many opportunities for academic self-development as well as personal growth. I am grateful for having had the opportunity to challenge my views and explore a topic so close to my own identity.

This investigation has also opened new lines of scholarly inquiry that would be worth pursuing in future research. One suggestion is that the dynamics of practices of 
identification and differentiation be further explored in order to incorporate the narratives of those groups with whom Argentinian immigrants differentiate from. Further exploration of the relationship between Argentinian immigrants and other Latin American immigrants to Canada who share similar characteristics with them would be necessary meaningful. As Luisa Veronis (2006) reminds us the growth of this heterogeneous group raises new questions regarding notions of community, identity and the politics of difference. The scope of this research has limited me from moving beyond the case of Argentinian immigrants but the findings up to this point suggest that these dynamics should be further investigated as they are sociologically significant. While I have argued that the main point of identification for Argentinian immigrants has been with the Canadian white dominant majority, I have also mentioned that participants suggested that points of connection with other minority groups such as Latin Americans and other immigrants remain mainly on a personal rather than collective level. While the thesis has explored mostly social and structural aspects, further exploration of the personal and emotional dimensions would be relevant to the investigation of immigrants' identities. In addition, it would be meaningful to gain a better understanding of how other Latin Americans and also immigrants in non-professional categories identify and differentiate, and how their experiences find commonalities and differences with that of Argentinian Latin Americans. A study of this kind would be significant in helping us better understand some of internal dynamics and inequalities within this group. This would, perhaps, shed light into a broader knowledge of the "meeting points" of power dynamics (which render some groups more included than others) and the development of diasporic identities. 
Secondly, this thesis has advanced arguments about the positionality of Argentinian immigrants within Canadian society. However, these have been drawn from the narratives of Argentinian immigrants only. These are meaningful conclusions that could be strengthened (or challenged) by incorporating the narratives of other sectors of society on the topic of white ethnicity. This would be a large project but one worth pursuing for it would allow us to better understand these complex dynamics of inclusion and exclusion of which we still don't know as much as necessary. As researchers we need to continue investigating and contesting the categorizing of 'Other' so that we can attempt to break the illusion that full equality has been achieved in Canadian society. This would be sociologically significant as only this way we can hope that current hierarchical systems will ever be challenged. In contesting, expanding and sharing our knowledge of the categorization of 'otherness' we could perhaps move towards achieving the 'promises' of multiculturalism.

As I write these final lines I also reflect on my own experience of having become someone new. Four years ago when I met that girl in that line up, I understood very little about why I said who I was. This research, the experiences of those who participated in it, and the invaluable guidance of my mentors, have allowed me to learn about the processes of identity formation beyond what I imagined possible. With profound gratitude, my hope is that these pages may be shared among us with a sense of curiosity and openness about what we have to say about ourselves. 


\section{Appendices}

\section{Appendix A General Interview Questionnaire for Research Participants}

\section{A.1 Sub-Appendix: Interview Questionnaire for Research Participants. English Version}

\section{Opening interview questions}

1. Tell me a little bit about your home/life in Argentina and when you immigrated to Canada.

2. What where some of the reasons why you (and your family) decided to move to Canada?

3. What made you decide to come to Canada instead of going to another country, for instance, the US or Australia?

4. Do you remember how you thought about being an immigrant soon after immigration to Canada? And how do you think about being an immigrant in Canada now in 2012?

\section{$\underline{\text { Identity and self-identification }}$}

5. When people ask you where you come from, what do you say? How do you describe yourself?

a. Do you remember how you used to define yourself in Arg.?

6. When was the first time, if so, that you described yourself as a Canadian?

7. My personal experience was that at different times or in different situations, I identified myself as 'Argentinian', and then at other times I used to say I was a "Latin American", and yet at other times I started saying I was 'Canadian' without making reference to my other nationality, or the other groups in which I participated:

a. Have you had a similar experience?

b. Tell me more about those situations.

c. Who do you find you identify with the most? (if necessary the researcher will propose if that is with other Argentinians, with Canadians, with other Latin Americans) 


\section{Claims to rights and group affiliations}

8. Do you have regular contact with other Latin Americans or other immigrants? What kinds of contact?

9. Do you participate or belong to a community group? (or have you in the past?)

a. If so, does this group organize around certain issues? What are these issues?

10. In your opinion, what do you think are the reasons why Argentinian immigrants have a tendency to not organize themselves formally as a community?

11. Do you think Argentinian immigrants have "better chances of integration" than other immigrants?

a. If so, why?

12. What is your opinion about Canada's multiculturalism?

13. In your view, does Canada's multiculturalism make it a more tolerant society?

14. Where do you feel you fit in among different groups in Canada? Do you describe yourself (or see yourself) as a visible minority or do you feel you are white like the majority groups: English or French Canadians?

15. Do you ever feel excluded in this society?

If the answer to this is yes, then:

a. How so? Give an example of a situation when you experienced exclusion or felt like a foreigner?

b. How do you deal with this?

c. What do you think are the reasons why you feel excluded? or What is it that makes you feel that way?

d. Do you think that the coming to Canada as a skilled worker/professional/dependant has an effect on your experience of integration into Canadian society? (Laura's comment: ask as a follow up question, if relevant)

\section{Memory and connection to the homeland}

16. Do you think about Argentina often?

17. What usually comes to mind when you think about Argentina? 
18. How do you maintain the culture at home? (e.g. what costumes have carried out?)

\section{$\underline{\text { Closing general questions }}$}

19. Knowing what you know today, would you immigrate to Canada again?

20. If so, what would you change about your experience?

21. Participants will be asked if there is anything else that they would like to add to the discussion.

\section{A.2 Sub-Appendix: Interview Questionnaire for Research Participants. Spanish Version}

\section{$\underline{\text { Cuestionario general para entrevista con participantes }}$}

Preguntas generales:

1. Contáme un poco de tu vida/hogar en Argentina y cuando inmigraste a Canadá?

a. Si inmigró por la provincial de Quebec, preguntar sobre ese programa.

2. Cuáles fueron las razones por las cuales decidiste (o decidieron) inmigrar a Canadá?

3. Por qué Canadá y no otro país, por ejemplo Estados Unidos o Australia?

4. Te acordás qué pensabas de ser inmigrante cuando recién te mudaste a Canadá y como pensás de ser inmigrante ahora en 2012?

\section{Identidad y auto-identificación}

5. Cuando la gente te pregunta de donde sos... que les decís? Como te describes a vos mismo/a?

a. Te acordás como te definías en Argentina?

6. Cuando fue la primera vez, si es que ocurrió, que te describiste a vos mismo/a como Canadiense?

7. Mi experiencia personal ha sido que en diferentes tiempos o en diferentes situaciones me identifique a mi misma como Argentina, y luego en otras 
épocas solía decir que era Latina y en otros tiempos o circunstancias decía que era Canadiense sin siquiera hacer referencia a mi otra nacionalidad $u$ origen...

a. Haz tenido una experiencia similar?

b. Contáme un poco mas de estas circunstancias

c. Con qué grupo te sentís mas identificado/a? (de ser necesario proponer si es con Argentinos, Latinos, Canadienses u otros inmigrantes

\section{Reclamación de derechos y afiliaciones grupales}

8. Tenés contacto regular con otros Latinoamericanos o con inmigrantes?

a. Qué tipo de contacto?

9. Participas o perteneces a algún grupo comunitario? - o en el pasado

a. De ser así, este grupo se organiza alrededor de ciertos temas? Cuáles son esos temas?

10. Cuáles crees que son las razones por las cuáles los Argentinos tienen menor tendencia a formar un grupo o una comunidad?

11. Crees que los Argentinos tienen "mas facilidad que otros inmigrantes a integrarse?

a. De ser así, porque?

12. Qué opinas del multiculturalismo?

13. Desde tu punto de vista, crees que la política multiculturalista Canadiense hace de esta una sociedad mas tolerante?

14. De todos los grupos que existen en Canadá, donde sentís que encajas mejor o con cuál te identificas mejor?

a. Te describes a vos mismo/a o te ves como parte de la minoría (visible) o te identificas con los grupos mayoritarios (blancos) ingleses o franco-Canadiense?

15. Alguna vez te sientes excluído/a en esta sociedad?

Si la respuesta es si...

a. Como exactamente? Dame un ejemplo de una experiencia o una situación en la que te hayas sentido extranjero/a

b. Como afrontas estas situaciones?

c. Cuáles crees son las razones por las que te has sentido excluido/a? o que es lo que ha pasado que te ha hecho sentir así? 
d. Crees que el haber venido a Canadá como parte de la categoría inmigratoria que llegaste (profesional, clase familiar, clase trabajador calificado) ha afectado de alguna manera tu experiencia de integración a la sociedad Canadiense?

\section{Memorias y conexión con la tierra natal}

16. Pensás en Argentina seguido?

17. Qué es lo que te viene a la mente cuando pensás en Argentina?

18. Qué costumbres Argentinas haz continuado en tu casa o en tu vida?

Preguntas de cierre

19. Sabiendo lo que sabes hoy, inmigrarías a Canadá otra vez?

20. De ser así, que cambiarías de tu experiencia?

21. Hay algo más que quieras agregar? 


\section{Appendix B Interview Questionnaire for Blogger}

\section{B.1 Sub-Appendix: Interview Questionnaire for Blogger. English Version}

\section{Opening interview questions}

1. Tell me a little bit about your home/life in Argentina and when you immigrated to Canada.

2. What where some of the reasons why you (and your family) decided to move to Canada?

3. What made you decide to come to Canada instead of going to another country, for instance, the US or Australia?

4. Do you remember how you thought about being an immigrant soon after immigration to Canada? And how do you think about being an immigrant in Canada now in 2012?

\section{$\underline{\text { Identity and self-identification }}$}

5. When people ask you where you come from, what do you say? How do you describe yourself?

a. Do you remember how you used to define yourself in Arg.?

6. When was the first time, if so, that you described yourself as a Canadian?

7. My personal experience was that at different times or in different situations, I identified myself as 'Argentinian', and then at other times I used to say I was a "Latin American", and yet at other times I started saying I was 'Canadian' without making reference to my other nationality, or the other groups in which I participated:

a. Have you had a similar experience?

b. Tell me more about those situations.

c. Who do you find you identify with the most? (if necessary the researcher will propose if that is with other Argentinians, with Canadians, with other Latin Americans)

\section{Claims to rights and group affiliations}

8. Do you have regular contact with other Latin Americans or other immigrants? What kinds of contact? 
9. Do you participate or belong to a community group? (or have you in the past?)

a. If so, does this group organize around certain issues? What are these issues?

10. In your opinion, what do you think are the reasons why Argentinian immigrants have a tendency to not organize themselves formally as a community?

11. Do you think Argentinian immigrants have "better chances of integration" than other immigrants?

a. If so, why?

12. What is your opinion about Canada's multiculturalism?

13. In your view, does Canada's multiculturalism make it a more tolerant society?

14. Where do you feel you fit in among different groups in Canada? Do you describe yourself (or see yourself) as a visible minority or do you feel you are white like the majority groups: English or French Canadians?

15. Do you ever feel excluded in this society?

If the answer to this is yes, then:

a. How so? Give an example of a situation when you experienced exclusion or felt like a foreigner?

b. How do you deal with this?

c. What do you think are the reasons why you feel excluded? or What is it that makes you feel that way?

d. Do you think that the coming to Canada as a skilled worker/professional/dependant has an effect on your experience of integration into Canadian society? (Laura's comment: ask as a follow up question, if relevant)

\section{Questions for Guillermo}

16. We've talked a bit about this but tell me, Why did you decided to start a blog about the migration experience of Argentinians to Canada?

a. Who is your blog for, Who do you write for?

17. In one of your blog reflections, (cite title) you write about how one of your readers (Ernesto) refers to Canada as the 'backyard to the US' and you write 
"I rather live in this backyard (which by the way has flowers) than in the one I used to be a decade ago", tell me:

a. What was "offensive" about Ernesto's e-mail?

b. Is Canada now your "home?

c. If so, how do you deal with, or negotiate if you will, the fact that you identify so strongly with being an Argentinian (I mean, you provide services through your blog to Argentinians, you are working on getting your immigration officer credentials and are starting a small business on this, you reflect daily and have become a writer on these issues, you maintain a strong social circle of Argentinian friends) and the fact that you feel very strongly as Canada being your home and the best home and future you can provide to your family?

18. In another reflection (cite title "ser rehenes de nuestras contradicciones") you write about your, 'disappointment' if I may call it, with this notion that opportunism, cheating the system, taking advantage of others whenever possible, seem to be characteristics that run in the "Argentinian DNA". The responses to your reflection on this were massive and overall I find people tend to agree with you. I thought this notion of the Argentinian DNA very interesting because you also write about (and your commentators follow) how when you decided to leave Argentina these things where precisely the ones you were 'running away from'. Tell me:

a. How then, do you see Argentinian identity?

b. Do you see it as fixed, sort of something we cannot escape or do you think that the immigration experience may change some of those "genes" in the Argentinian DNA?

19. How do you thing the Argentinian experience in Canada might differ from that from other Latin Americans or other immigrant groups?

\section{Memory and connection to the homeland}

20. Do you think about Argentina often?

21. What usually comes to mind when you think about Argentina?

22. How do you maintain the culture at home? (e.g. what costumes have carried out?)

\section{$\underline{\text { Closing general questions }}$}

23. Knowing what you know today, would you immigrate to Canada again?

24. If so, what would you change about your experience? 
25. Is there anything else that you would like to add?

\section{B.2 Sub-Appendix: Interview questionnaire for blogger. Spanish version $\underline{\text { Cuestionario para entrevista con Guillermo Ziegler }}$}

Preguntas generales:

1. Contáme un poco de tu vida/hogar en Argentina y cuando inmigraste a Canadá?

a. Si inmigró por la provincial de Quebec, preguntar sobre ese programa.

2. Cuáles fueron las razones por las cuales decidiste (o decidieron) inmigrar a Canadá?

3. Por qué Canadá y no otro país, por ejemplo Estados Unidos o Australia?

4. Te acordás qué pensabas de ser inmigrante cuando recién te mudaste a Canadá y como pensás de ser inmigrante ahora en 2012 ?

\section{Identidad y auto-identificación}

5. Cuando la gente te pregunta de donde sos... que les decís? Como te describes a vos mismo/a?

a. Te acordás como te definías en Argentina?

6. Cuando fue la primera vez, si es que ocurrió, que te describiste a vos mismo/a como Canadiense?

7. Mi experiencia personal ha sido que en diferentes tiempos o en diferentes situaciones me identifique a mi misma como Argentina, y luego en otras épocas solía decir que era Latina y en otros tiempos o circunstancias decía que era Canadiense sin siquiera hacer referencia a mi otra nacionalidad $u$ origen...

a. Haz tenido una experiencia similar?

b. Contáme un poco mas de estas circunstancias

c. Con qué grupo te sentís mas identificado/a? (de ser necesario proponer si es con Argentinos, Latinos, Canadienses u otros inmigrantes

\section{Reclamación de derechos y afiliaciones grupales}

8. Tenés contacto regular con otros Latinoamericanos o con inmigrantes?

a. Qué tipo de contacto? 
9. Participas o perteneces a algún grupo comunitario? - o en el pasado

a. De ser así, este grupo se organiza alrededor de ciertos temas? Cuáles son esos temas?

10. Cuáles crees que son las razones por las cuáles los Argentinos tienen menor tendencia a formar un grupo o una comunidad?

11. Crees que los Argentinos tienen "mas facilidad que otros inmigrantes a integrarse?

a. De ser así, porque?

12. Qué opinas del multiculturalismo?

13. Desde tu punto de vista, crees que la política multiculturalista Canadiense hace de esta una sociedad mas tolerante?

14. De todos los grupos que existen en Canadá, donde sentís que encajas mejor o con cuál te identificas mejor?

a. Te describes a vos mismo/a o te ves como parte de la minoría (visible) o te identificas con los grupos mayoritarios (blancos) ingleses o franco-Canadiense?

15. Alguna vez te sientes excluido/a en esta sociedad?

Si la respuesta es si...

a. Como exactamente? Dame un ejemplo de una experiencia o una situación en la que te hayas sentido extranjero/a

b. Como afrontas estas situaciones?

c. Cuáles crees son las razones por las que te has sentido excluido/a? o que es lo que ha pasado que te ha hecho sentir así?

Crees que el haber venido a Canadá como parte de la categoría inmigratoria que llegaste (profesional, clase familiar, clase trabajador calificado) ha afectado de alguna manera tu experiencia de integración a la sociedad Canadiense?

\section{Sobre el blog:}

16. Hemos hablado un poco de esto pero contáme, por qué decidiste empezar un blog sobre tu experiencia migratoria a Canadá?

a. Para quien es el blog? Para quien escribís?

17. En una de tus reflexiones en el blog (mi patio trasero tiene flores) tu lector se refiere a Canada como "el patio trasero de los Estados Unidos" y tu escribes "prefiero vivir en este patio trasero (y haces referencia al hecho de que tiene flores) que en el que estaba hace una decada atras...contame: 
a. Qué fue lo que te result "ofensivo" si puedo usar esa palabra, del email de Ernesto?

b. Vos considerás a Canada "tu hogar" ahora?

c. De ser asi, como lidias, o negocias si podemos decirlo asi el hecho de que vos sos "bien Argentino" y sin embargo veo que tambien estas muy a favor de Canada y digamos que te gusta este pais o por lomenos crees que este pais ofrece buenas oportunidades para vos y tu familia.

18. En otra reflexión (ser rehenes de nuestras contradicciones) hablas un poco de tu "decepcion" si puedo llamarlo asi, con este tema del oportunismo, de esta cosa de querer estafar al sistema o de buscar como sacar ventaja y decis algo muy interesante, decis que parece que esto "esta en el ADN Argentino". Me llamo mucho la atencion esto... contame

a. Cómo ves entonces a la identidad Argentina?

b. La ves como algo fijo (AND es para toda la vida), una suerte de cosa fija o preestablecida que no podemos escapar, o crees que la experiencia migratoria puede cambiarnos?

19. Como crees que la experiencia migratoria Canadiense de los Argentinos pueda ser diferente de aquella de otros grupos latinoamericanos?

\section{Memorias y conexión con la tierra natal}

20. Pensás en Argentina seguido?

21. Qué es lo que te viene a la mente cuando pensás en Argentina?

22. Qué costumbres Argentinas haz continuado en tu casa o en tu vida?

$\underline{\text { Preguntas de cierre }}$

23. Sabiendo lo que sabes hoy, inmigrarías a Canadá otra vez?

24. De ser así, que cambiarías de tu experiencia?

25. Hay algo más que quieras agregar? 


\section{List of Tables}

\section{Chapter 1}

Table 1: Latin Americans in Canada's Major Cities as of 2001

\begin{tabular}{|l|l|}
\hline $\begin{array}{l}\text { Latin/Central/South American, n.i.e. - } \\
\text { Total responses }\end{array}$ & $\mathbf{2 0 0 1}$ Census \\
\hline Toronto & 14,895 \\
\hline Montreal & 1,955 \\
\hline Vancouver & 3,635 \\
\hline Ottawa-Gatineau total & 1,755 \\
\hline Ottawa Gatineau - Ontario part & 1,755 \\
\hline Ottawa Gatineau - Quebec part & 205 \\
& \\
\hline
\end{tabular}

Note: Data from 2001 Census, based on a $20 \%$ sample data

Source: From Statistics Canada "Total Population by Ethnic Origin (single and multiple responses) - 20\% Sample Data"

http://www12.statcan.gc.ca/english/census01/products/standard/profiles/Rp-

eng.cfm?TABID $=1 \& \mathrm{LANG}=\mathrm{E} \& \mathrm{APATH}=3 \& \mathrm{DETAIL}=1 \& \mathrm{DIM}=0 \& \mathrm{FL}=\mathrm{A} \& \mathrm{FREE}=0 \& \mathrm{GC}=0 \& \mathrm{G}$

$\mathrm{K}=0 \& \mathrm{GRP}=1 \& \mathrm{PID}=72851 \& \mathrm{PRID}=0 \& \mathrm{PTYPE}=55430,53293,55440,55496,71090 \& \mathrm{~S}=0 \& \mathrm{SHOW}$

$\underline{\mathrm{ALL}}=0 \& \mathrm{SUB}=0 \& \mathrm{Temporal}=2001 \& \mathrm{THEME}=57 \& \mathrm{VID}=0 \& \mathrm{VNAMEE}=\& \mathrm{VNAMEF}$

Note: Based on LATIN/CENTRAL/SOUTH AMERICAN, N.I.E. - TOTAL RESPONSES

'n.i.e.' means 'not included elsewhere'.

Includes responses such as Latin American, Central American, South American, Latino, etc.

Excludes the following groups which were collected as separate responses in 2001: Argentinian, Belizean, Bolivian, Brazilian, Central/South American Indian, Chilean, Colombian, Costa Rican, Ecuadorian, Guatemalan, Hispanic, Honduran, Maya, Mexican, Nicaraguan, Panamanian, Paraguayan, Peruvian, Salvadorean, Uruguayan and Venezuelan. 


\section{Chapter 1}

Table 2: Latin Americans in Canada's Major Cities as of 2006

\begin{tabular}{|l|l|}
\hline $\begin{array}{l}\text { Latin American immigrants in a } \\
\text { Canadian major City }\end{array}$ & $\begin{array}{l}\mathbf{2 0 0 6} \\
\text { Census }\end{array}$ \\
\hline Toronto & 99,290 \\
\hline Montreal & 75,400 \\
\hline Vancouver & 22,695 \\
\hline Calgary & 13,415 \\
\hline Edmonton & 9,210 \\
\hline Ottawa-Gatineau total & 10,630 \\
\hline Ottawa Gatineau - Ontario part & 8,090 \\
\hline Ottawa Gatineau - Quebec part & 2,540 \\
\hline
\end{tabular}

Note: Data from 2006 Census, based on a $20 \%$ sample data of the total number of Latin Americans.

Source: From Statistic Canada "Visible Minority Groups, 2006 Counts, for Canada and Census Metropolitan Areas and Census Agglomerations - 20\% Sample Data" Available at http://www12.statcan.gc.ca/census-recensement/2006/dp-pd/hlt/97562/pages/page.cfm?Lang $=\mathrm{E} \& \mathrm{Geo}=\mathrm{CMA} \&$ Code $=01 \&$ Table $=1 \&$ Data $=$ Count $\&$ StartRec $=126 \& S$ ort $=2 \&$ Display $=$ Page $\& C$ SDFilter $=5000 \quad$ Date retrieved March 21, 2013. 


\section{Chapter 2}

Table 3: First Wave of Argentinian Immigration to Canada 1970s

\begin{tabular}{|l|l|}
\hline Year & $\begin{array}{l}\text { Yearly rate of Argentinian immigrants } \\
\text { to Canada }\end{array}$ \\
\hline 1970 & 200 \\
\hline 1973 & 948 \\
\hline 1974 & 1088 \\
\hline 1975 & 674 \\
\hline
\end{tabular}

Source: Available at http://www.thecanadianencyclopedia.com/articles/latin-americans; Date retrieved March 9, 2013 


\section{Chapter 2}

Table 4: Central and South American Immigration to Canada: 1968 to 1995

\begin{tabular}{|l|l|l|}
\hline Period of immigration & $\begin{array}{l}\text { Percentage of total } \\
\text { Canadian immigration }\end{array}$ & $\begin{array}{l}\text { Total number of } \\
\text { immigrants }\end{array}$ \\
\hline 1968 and 1972 & $3.4 \%$ & 24,863 \\
\hline 1973 and 1977 & $7.4 \%$ & 63,598 \\
\hline $1978-1982$ & $6.1 \%$ & 36,262 \\
\hline $1983-1987$ & $11 \%$ & 56,442 \\
\hline $1988-1992$ & $8.7 \%$ & 91,061 \\
\hline $1993-1995$ & $2.8 \%$ & 19,433 \\
\hline $1968-1995$ & $7 \%$ & 311,345 \\
\hline
\end{tabular}

Source: From page "Changing Immigration Patterns and the Emergence of Visible Minorities on the Department of Justice website. Table 2: Immigrant Arrivals by Countries of Last Permanent Residence, 1967-1991. Date retrieved March 5, 2013 Available http://www.justice.gc.ca/eng/pi/rs/rep-rap/2002/rp02 8-dr02_8/t2.html\#sec1 


\section{Chapter 2}

Table 5: Second Wave of Argentinian Immigration to Canada 2000s

\begin{tabular}{|l|l|}
\hline Year & $\begin{array}{l}\text { Yearly rate of Argentinian immigrants } \\
\text { to Canada }\end{array}$ \\
\hline 2000 & 401 \\
\hline 2002 & 815 \\
\hline 2003 & 1,669 \\
\hline 2004 & 1,548 \\
\hline 2005 & 1,086 \\
\hline 2006 & 759 \\
\hline 2007 & 565 \\
\hline
\end{tabular}

Source: Statistics Canada, Report on the Demographic Situation in Canada 2005 and 2006 available http://www.statcan.gc.ca/pub/91-209-x/91-209-x2004000-eng.pdf 


\section{Chapter 2}

Table 6: Latin American Immigration to Canada in 2007 by Main Countries of Origin

\begin{tabular}{|l|l|}
\hline Country of origin & $\begin{array}{l}\text { Total landed immigrants to Canada in } \\
\text { the year } \mathbf{2 0 0 7}\end{array}$ \\
\hline Mexico & 3,226 \\
\hline Colombia & 5,382 \\
\hline Peru & 1,502 \\
\hline Argentina & 565 \\
\hline
\end{tabular}

Source: Table A-4.1 Landed immigrants in Canada by country of birth, 1981 to 2007 on the Report on the Demographic Situation in Canada 2005 and 2006, p. 60. Available on http://www.statcan.gc.ca/pub/91-209-x/91-209-x2004000-eng.pdf 


\section{Bibliography}

Abu-Laban, Yasmeen and Gabriel, Christina. 2002. Selling Diversity: Immigration, Multiculturalism, Employment Equity, and Globalization. Peterborough, Ont.: Broadview Press.

Adsett, Margaret. 2011. "The Notion of Multiculturalism in Canada and France: A Question of Different Understandings of Liberty, Equality and Community" In Managing Ethnic Diversity: Meanings and Practices from an International Perspective, edited by Reza Hasmath, 47-64. Toronto: University of Toronto.

Ahmed, Sara. 2004. The Cultural Politics of Emotion. New York: Routedgle.

Altheide, David. 1996. "Ethnographic Content Analysis" In Qualitative Media Analysis, 13-22. United States: Sage Publications Inc.

Armony, Victor. 2011. "The Challenge of Naming the Other in Latin America". In Identity Politics in the Public Realm: Bringing Institutions Back In, edited by Avigail Eisenberg and Will Kymlicka, 164-189. Vancouver: UBC Press.

Banerjee, Rupa. 2009. "Income Growth of New Immigrants in Canada: Evidence from the Survey of Labour and Income Dynamics". Relations industrielles/Industrial Relations 64 (3): 466-488.

Bhabha, Homi. [1994] 2000. "Interrogating Identity: Franz Fanon and the Postcolonial Prerogative". In Identity: a Reader, edited by Paul Du Gay, Jessica Evans, and Peter Redman, 94-101. United Kingdom: Open University.

Bissondath, Neil. [1994] 2002. Selling Illusions: The Cult of Multiculturalism in Canada. Toronto: Penguin.

Bonikowska, Aneta and Hou, Feng. 2010. "Reversal of Fortunes or Continued Success? Cohort Differences in Education and Earnings of Childhood Immigrants". International Migration Review 44 (2): 320-353.

Bourdieu, Pierre. 1991. "First Lecture. Social Space and Symbolic Space: Introduction to a Japanese Reading of Distinction". Poetics Today. 12(4): 627-638

Brannick, Teresa and Coglhan, David. 2007. "In Defence of Being 'Native': A Case for Insider Academic Research". Organizational Research Methods 10 (1): 59-74.

Brazier, Jana Evans and Mannur, Anita. 2003. "Nation, Migration, Globalization: Points of Contention in Diaspora Studies". In Theorizing Diaspora: A Reader, 
editors Jana Evans Braziel and Anita Mannur, 1-22. United Kingdom: Blackwell Publishing Ltd.

Chen, Xiaobei. 2013. "Not Ethnic Enough: The Cultural Identity Imperative in International Adoptions from China to Canada". Unpublished Manuscript. Carleton University.

Citizenship and Immigration Canada. 2012. "Apply to Immigrate to Canada". Dates retrieved July 7, 10, 11, 2012; December 12, 2012 and January 23, 24, 2013. http://www.cic.gc.ca/english/immigrate/apply.asp

Corbin Dwyer, Sonya and Buckle, Jennifer. 2009. "The Space Between: On Being an Insider-Outsider in Qualitative Research". International Journal of Qualitative Methods 8 (1): 54-63.

Davidson, Tonya. 2011. "Nostalgia and Postmemories of a Lost Place: Actualizing "My Virtual Homeland" In Ecologies of Affect: Placing Nostalgia, Desire and Hope, edited by Tonya Davidson, 43-63. Waterloo, Ontario, Canada: Wilfrid Laurier University Press.

Denzin, Normal and Lincoln, Yvona. [1994] 2000. "Introduction: The Discipline and Practice of Qualitative Research" In Strategies of Qualitative Inquiry, edited by Norman Denzin and Yvonna Lincoln, 1-44. United States: Sage Publications.

Department of Justice. 2013. "Changing Immigration Patterns and the Emergence of Visible Minorities". Department of Justice website. Table 2: Immigrant Arrivals by Countries of Last Permanent Residence, 1967-1991. Date retrieved March 5, 2013. Available http://www.justice.gc.ca/eng/pi/rs/rep-rap/2002/rp02 8dr02 8/t2.html\#sec1

Dhamoon, Rita. 2009. Identity/Difference Politics: How Difference is Produced and Why It Matters. Vancouver: UBC Press.

Diameti, Mario. 2001. "Preface" to Irse: Cómo y por qué los argentinos se están yendo del país by Diego Melamed, 9-11. Buenos Aires: Editorial Sudamericana.

Dick, Caroline. 2011. "Group Rights and the Politics of Identity”. In The Perils of Identity: Group Rights and the Politics of Intragroup Difference, 19-35. Vancouver: UBC Press.

Durand, Jorge and Massey, Douglas. 2010. "New World Orders: Continuities and Changes in Latin American Migration" ANNALS AAPSS 630: 20-52.

Eisenberg, Avigail and Kymlicka, Will. 2011. "Bringing Institutions Back In: How Public Institutions Assess Identity". In Identity Politics in the Public Realm: 
Bringing Institutions Back In, edited by Avigail Eisenberg and Will Kymlicka, 130. Vancouver: UBC Press.

Espin, Oliva. 1987. "Psychological Impact of Migration on Latinas." Psychology of Women Quarterly 11: 489-503.

Fanon, Franz. [1952] 1967. Black Skin, White Masks. New York: Grove Press, Inc. (Originally published in Paris, France as Peau Noire, Masques Blancs, by Editions de Seuil).

Findlay, Linda. 2003. “The Reflexive Journey: Mapping Multiple Routes". In Reflexivity: A Practical Guide for Researchers in Health and Social Sciences, edited by Linda Findlay and Brendan Gough, 3-20. UK, USA, Australia Blackwell Publishing.

Flyvbjerg, Bent. 2001. Making Social Sciences Matter: Why Social Inquiry Fails and How Can it Succeed. Cambridge University Press.

Frank, Kristyn. 2010. "The Economic Integration of Recent Immigrants to Canada: A Longitudinal Analysis of Dimensions of Employment Success". Dissertation Abstracts International, A: The Humanities and Social Sciences 71 (1): 346.

Frankenberg, Ruth. 1993. "White on White: The Interviewees and the Method" in White Women Race Matters, 23-42. Minneapolis: University of Minnesota Press.

Frideres, James. 2008. "Creating an Inclusive Society: Promoting Social Integration in Canada". In Immigration and Integration in Canada in the Twenty-first Century, edited by John Biles, Meyer Burstein, and James Frideres, 77-10. Kingston: McGill-Queens University Press.

Gallagher, Charles. 2000. "White Like Me? Methods, Meaning and Manipulation in the Field of White Studies" In Racing Research Researching Race: Methodological Dilemmas in Critical Race Studies, edited by France Windance Twine and Jonathan W. Warren, 67-92. United States: New York University Press.

Garguin, Enrique. 2007. “ 'Los Argentinos Descendemos de los Barcos’: The Racial Articulation of Middle Class Identity in Argentina (1920-1960)" Latin American and Caribbean Ethnic Studies 2 (2): 161-184.

Gilroy, Paul. 2003. "The Black Atlantic as a Counterculture of Modernity”. In Theorizing Diaspora: A Reader, editors Jana Evans Braziel and Anita Mannur, 49-82. United Kingdom: Blackwell Publishing Ltd.

Ginienievicz, Jorge. 2008. "Citizenship Learning and Political Participation: The Case of Latin American-Canadians" London Review of Education, 6 (1): 71-85.

Ginienievicz, Jorge. 2010. "Identity Politics and Political Representation of Immigrants: 
The Perceptions of Latin Americans in Toronto". Journal of Immigrant \& Refugee Studies 8: 261-283

Girard, Magali; Smith, Michael; and Renaud, Jean. 2008. "Economic Integration of New Immigrants: Adequation Between the Employment Prior to Arrival in Quebec and Since Jobs Immigration". Canadian Journal of Sociology/Cahiers canadiens de sociologie. 33 (4): 791-814.

Glaser, Barney and Strauss, Anselm. 1967. The Discovery of Grounded Theory: Strategies for Qualitative Research. Chicago: Aldine Publishing Company.

Goldring, Luin. 2006. Latin American Transnationalism in Canada: Does it Exist, What Forms Does it Take, and Where is it Going? In Transnational Identities and Practices in Canada, edited by Vic Satzewich and Lyod Wong, 180-201. Vancouver, Canada: University of British Columbia Press.

Grant, Mary Lela. 1999. "Immigration in Canada: Context, Assimilation and Labour Market Impacts". Dissertation Abstracts International 61(01A): 296.

Grimson, Alejandro. [2004] 2005. "La Experiencia Argentina y sus Fantasmas" (The Argentinian Experience and its Ghosts). In La Cultura en las Crisis Latinoamericanas (Culture in Latin American Crisis). Consejo Latinoamericano de Ciencias Sociales, edited by Alejandro Grimson, 187-203. Buenos Aires, Argentina: CLACSO.

Grimson, Alejandro and Kessler, Gabriel. 2005. On Argentina and the Southern Cone: Neoliberalism and National Imaginations. Routhedge: New York.

Grimson, Alejandro. 2005. "New Xenophobias. New Ethnic Politics". In On Argentina and the Southern Cone: Neoliberalism and National Imaginations, edited by Alejandro Grimson and Gabriel Kessler, 117-144. New York: Routhedge.

Gunew, Sneja. 2004. "Colonial Hauntings: The Colonial Seed of Multiculturalism". In Haunted Nations: The Colonial Dimensions of Multiculturalism, 31-48 London; New York: Routhedge.

Guzman, Florencia. 2006 "Africanos en la Argentina: Una reflexión desprevenida" ("Africans in Argentina: An Unexpected Reflection"). Andes [online]. (17): 197238. ISSN 1668-8090.

Hage, Ghassan. 1998. White Nation: Fantasies of White Supremacy in a Multicultural Society. Annandale, NSW: Pluto Press; West Wickham, Kent, U.K.: Comerford and Miller.

Hall, Stuart. [1991] 1997. "Old and New Identities, Old and New Ethnicities". In Culture, Globalization and the World-System: Contemporary Conditions for the 
Representation of Identity, edited by Anthony King, 41-68. Minneapolis: University of Minnesota Press.

Hall, Stuart. [1993] 2003. "Cultural identity and Diaspora" In Theorizing Diaspora: A Reader, editors Jana Evans Braziel and Anita Mannur, 233-246 United Kingdom: Blackwell Publishing Ltd.

Hall, Stuart. [1996] 2000. "Who Needs Identity?" In Identity: a Reader, edited by Paul Du Gay, Jessica Evans, and Peter Redman, 15-30. SAGE Publications Ltd. United Kingdom: Open University.

Kandiyoti, Dalia. 2008. "The New Emigrations and Argentine Identities: Alicia Dujovne Ortiz's Al que se va”. In Bulletin of Spanish Studies LXXXV(5): 621-636.

Landolt, Patricia; Goldrin, Luin; and Bernhard, Judith. 2011. "Agenda Setting and Immigrant Politics: The Case of Latin Americans in Toronto". American Behavioral Scientist 55 (9): 1235-1266.

Le Goff, Philippe. 2004. "Immigration to Canada: What Policy, for What Purposes". Library of Parliament. Canada.

Li, Peter. 2003. "Initial Earnings and Catch-Up Capacity of Immigrants." Canadian Public Policy 29 (3): 319-337.

Mackey, Eva. 2002. "The 'Bottom Line': 'Canada First' and the Limits of Liberalism". In The House of Difference: Cultural Politics and National Identity in Canada, 141-167. Toronto: University of Toronto Press.

Madison, Soyini. 2008. "Critical Ethnography and Street Performance: Reflections of Home, Race, Murder, and Justice". In Strategies of Qualitative Inquiry, edited by Norman Denzin and Yvonna Lincoln, 243-256. United States: Sage Publications.

Mauthner Natasha and Doucet, Andrea. 2003. "Reflexive Accounts and Accounts of Reflexivity in Qualitative Data Analysis". Sociology 37 (3): 413-431.

Mata, Fernando. 1985. The Four Immigrant Waves from Latin America to Canada: Historical, Demographic and Social Profiles. Unpublished manuscript, Toronto: York University.

Melamed, Diego. 2001. Irse: Cómo y por qué los argentinos se están yendo del pais. (Leave: How and Why are Argentinians leaving the country) Buenos Aires: Editorial Sudamericana.

Nayak, Anoop. 2007. “Critical Whiteness Studies”. Sociology Compass 1 (2): 737-755.

Picotti, Dina. 1998. "Introduction" In La Presencia Africana en Nuestra Identidad 
(African Presence in our Identity), pp. 13-16. Buenos Aires: Serie Antropológica. Ediciones del Sol.

Reiss, Suzanna. 2011. "Immigration, Race and the Crisis of National Identity in Canada". In Managing Ethnic Diversity: Meanings and Practices from an International Perspective, edited by Reza Hasmath, 65-84. Toronto: University of Toronto.

Reitz, Jeffrey 2001. "Immigrant Skill Utilization in the Canadian Labour Market: Implications of Human Capital Research.” Journal of International Migration and Integration 2 (3): 347-378.

Rummens, Joanna Anneke. 2003. "Conceptualizing Identity and Diversity: Overlaps, Intersections, and Processes". Canadian Ethnic Studies/Etudes Ethniques au Canada 35 (3): 10-25.

Said, Edward. 1978. Orientalism. New York: Vintage Books.

Siltanen, Janet; Willis Alette and Willow Scobie. 2008. "Separately Together: Working Reflexively as a Team". International Journal of Social Research Methodology 11 (1): 45-61.

Silva, Kumarini. 2009. "Oh, Give Me a Home: Diasporic Longings of Home and Belonging”. Social Identities 15 (5): 693-706.

Statistics Canada. 2001. "The Latin American Community in Canada" Date

Retrieved: February 28, 2013 http://www.statcan.gc.ca/pub/89-621-x/89-621$\underline{\mathrm{x} 2007008 \text {-eng.htm\#2 }}$

Statistics Canada. 2001. "Total Population by Ethnic Origin (single and multiple responses - 20\% Sample Data". Date retrieved March 21, 2003 http://www5.statcan.gc.ca/subject-sujet/result-resultat.action?pid=30000\&id=$\underline{30000 \& \text { lang }=\text { eng\&type }=\text { CENSUSTBL\&pageNum }=1 \& \text { more }=0}$

Statistic Canada. 2006. "Visible Minority Groups, 2006 Counts, for Canada and Census Metropolitan Areas and Census Agglomerations - 20\% Sample Data". Date retrieved March 21, $2003 \quad$ http://www12.statcan.gc.ca/censusrecensement $/ 2006 / \mathrm{dppd} / \mathrm{hlt} / 97562 /$ pages $/$ page.cfm? $\mathrm{Lang}=\mathrm{E} \& \mathrm{Geo}=\mathrm{CMA} \& \mathrm{Code}=$ $01 \&$ Table $=1 \&$ Data $=$ Count $\&$ StartRec $=126 \&$ Sort $=2 \&$ Display $=$ Page $\&$ CSDFilter $=5$ $\underline{000}$

Statistics Canada. 2008. "Report on the Demographic Situation in Canada 2005 and 2006". Date retrieved January 30, 2013. http://www.statcan.gc.ca/pub/91-209-x/91-209-x2004000-eng.pdf

Strauss, Anselm and Corbin Juliet. 1990. Basics of Qualitative Research: Grounded Theory Procedures and Techniques. Sage Publications Inc. 
Svašek, Maruška. 2010. "On the Move: Emotions and Human Mobility" Journal of Ethnic and Migration Studies 36 (6): 865-880.

Thobani, Sunera. 2007. Exalted Subjects: Studies in the Making of Race and Nation in Canada. Toronto: University of Toronto Press.

Veronis, Luisa. 2006. "Rethinking Transnationalism: Latin American Immigrants' 'Imagined Community' in Toronto". In Rethinking Transnationalism: Citizenship and Immigrant Participation in Neoliberal Toronto, 11-27. Dissertation. Toronto: University of Toronto.

Veronis, Luisa. 2007. "Strategic Spatial Essentialism: Latin American's Real and Imagined Geographies of Belonging in Toronto". Social \& Cultural Geography, 8 (3): 445-473.

Veronis, Luisa and McAlone, Brie. 2010. Latin American Migration and the Border: A Preliminary Report. Study conducted through Project Ottawa, 1-25. Unpublished Manuscript. University of Ottawa.

Xing, Yue. 2010. Implicit Contracts and Immigrant Wages in Canada. Dissertation. Carleton University.

Xue, Li. 2009. "Social Capital and Labour Market Outcomes of Recent Immigrants to Canada: Employment Entry, Wages and Duration of Access to the First Job in Intended Occupation" Dissertation Abstracts International, A: The Humanities and Social Sciences 70 (4): 1376.

Zucchero, Jim. 2006. Migration, Historical Memory, and Ethnic Identity in ItalianCanadian Writing (1945-2002). Dissertation Abstracts International, A: The Humanities and Social Sciences. 